FE-2363-1

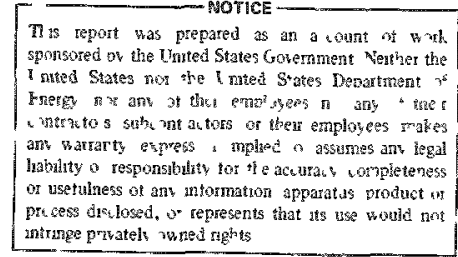

\title{
MHD-ETF DESIGN CRITERIA
}

\author{
F.D. Retallick \\ PROJECT MANAGER
}

WESTINGHOUSE ELECTRIC CORPORATION

Advanced Energy Systems Division

P.O. Box 10864

Pittsburgh. Pennslyvania 15236

Date Published - APRIL 1978

\section{PREPARED FOR THE UNITED STATES DEPARTMENT OF ENERGY}

Under Contract No. EF-T/-C-01-2363

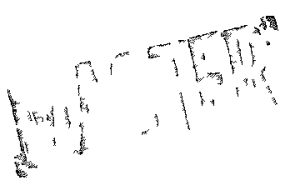




\section{DISCLAIMER}

This report was prepared as an account of work sponsored by an agency of the United States Government. Neither the United States Government nor any agency Thereof, nor any of their employees, makes any warranty, express or implied, or assumes any legal liability or responsibility for the accuracy, completeness, or usefulness of any information, apparatus, product, or process disclosed, or represents that its use would not infringe privately owned rights. Reference herein to any specific commercial product, process, or service by trade name, trademark, manufacturer, or otherwise does not necessarily constitute or imply its endorsement, recommendation, or favoring by the United States Government or any agency thereof. The views and opinions of authors expressed herein do not necessarily state or reflect those of the United States Government or any agency thereof. 


\section{DISCLAIMER}

Portions of this document may be illegible in electronic image products. Images are produced from the best available original document. 


\section{ABSTRACT}

A proposed criteria document for the MHD Engineering Test Facility has been prepared. This document is prepared in a manner similar to other criteria documents that nave been unilized on major engineering development programs of pilot scale powerplants.

The criteria emphasizes the use of a systems approach and consists of eight sections covering, Scope, Design Objectives, Plant Siting, Plant Engineering, Testing, Plant Operations, Plant Costing, and Scheduling. 
1.0 SCOPE

$\underline{\text { Page }}$

$1.0 \quad$ SCOPE

2.0 MHD-ETF DESIGN OBJECTIVES

3.0 PLANT SITING CRITERIA

4.0 PLANT ENGINEERING CRITERIA

5.0 TESTING CRITERIA

6.0 PLANT OPERATIONS CRITERIA

125

7.0 PLANT COSTING CRITERIA

8.0 SCHEDULING CRITERIA

137

9.0 APPENDICES 


\section{TABLE OF CONTENTS}

$\begin{array}{lll}1.0 & \text { SCOPE } & \frac{\text { Page }}{2.0} \text { MHD-ETF DESIGN OBJECTIVES }\end{array}$

3.0 PLANT SITING CRITERIA

3.1 SITE GEOLOGY 4

3.1.1 Groundwater 4

3.1 .2 Seismology 4

3.2 SITE TOPOGRAPHY 4

3.3 SITE CLIMATOLOGY AND METEOROLOGY

3.4 RESOURCE AVAILABILITY 6

3.4.1 Water 6

3.4.2 Eiectricity 6

3.4.3 Transportation 6

3.4 .4 Coal 7

3.4.5 Natural Gas and/or Oil 7

3.4 .6 Labor 7

3.4 .7 Socieconomics 7

3.5 SUPPORT SERVICE REQUIREMENTS 8

3.5.1 Security 8

3.5 .2 Medical 8 


\section{TABLE OF CONTENTS}

3.5.3 Sire Personnel

3.5.4 Fire Protection 8

3.5.5 Communications 8

3.6 ENVIRONMENTAL REGULATIONS 9

3.6.1 Montana Laws 9

3.6.1.1 Montana Major Facility Siting Bill 9

3.6.1.2 Water Quality Standards 13

3.6.1.3 Air Quality Standards 16

3.6.1.4 Solid Waste Laws 18

3.6.2 Federal Laws 19

3.7 LOCAL AND FEDERAL LAWS AND CODES 19

3.7.1 Health and Safety 19

3.7.2 Acquisition of Woter Rights 19

3.7.3 Water Treatment Standards 20

3.7.4 Fire Protection Standards 20

3.7.5 Sewage Treatment Standards 20

3.7.6 Electrical Codes 20

$\begin{array}{lll}3.7 .7 & \text { Height Restrictions } & 20\end{array}$

3.7.8 Explosion Hazards 20

3.7.9 Acquisition of Right of Way for Power Line Corridor 20 


\section{TABLE OF CONTENTS}

4.0 PLANT ENGINEERING CRITERIA

4.1 PLANT FUNCTIONAL DESCRIPTION 21

4.2 CONFIGURATION SELECTION 21

4.3 OPERATING REQUIREMENTS AND DESIGN PARAMETERS 24

4.3.1 Steady State Operation 24

4.3.2 Startup and Shutdown 25

4.3.2.1 Startup from Ambient 25

4.3.2.2 Startup from Hot Standby 25

4.3.2.3 Shutdown to Ambient 25

4.3.3 Power Loading and Unloading 26

4.3.4 Allowable Electrical Power Output Parameter 26 Variation

4.3.5 Definition of Events 26

4.3.5.1 Normal Events 26

4.3.5.2 Offmosign Evenis 27

4.3.5.3 Shutdown Events 27

4.3.5.4 Uncontrolled Events 27

4.3.6 Classification of Events 27

4.3.6.1 Normal Events 27

4.3.6.2 Off-Design Events 28 
TABLE OF CONTENTS

Page

4.3.6.3 Shutdown Events 28

4.3.6.4 Uncontrolled Events 28

4.3.7 Design Parameters 29

4.4 FUNCTIONAL AND PROCESS DESIGN 29

4.4.1 Coal Handling 32

4.4.1.1 System Description $\quad 32$

4.4.1.2 Functional Requirements 33

4.4.1.3 Design Basis 33

4.4.1.4 Safery and Operating Safeguards 34

4.4.1.5 Maintenance 34

4.4.1.6 Instrumentation and Controls 35

4.4.2 Coal Processing 35

4.4.2.1 System Description $\quad 35$

4.4.2.2 Functional Requirements 36

4.4.2.3 Design Basis 36

4.4.2.4 Safety and Operating Safeguards $\quad 37$

4.4.2.5 Maintenance 38

4.4.2.6 Instrumentation and Controls 38

4.4.3 Air and Oxidant Supply 38

4.4.3.1 System Deseription 38

4.4.3.2 Functional Requirements 39 
TABLE OF CONTENTS

4.4.3.3 Design Basis

4.4.3.4 Safety and Operating Safeguards

4.4.3.5 Maintenance

4.4.3.6 Instrumentation and Controls

4.4.4 Seed Storage and Feed

4.4.4.1 System Description

4.4.4.2 Functional Requirements

4.4.4.3 Design Basis

4.4.4.4 Safely and Operating Safeguards

4.4.4.5 Maintenance

4.4.4.6 Instrumentation and Controls

4.4.5 MHD Hot Gas Power Train

4.4.5.1 System Description

4.4.5.2 Funcrional Requirements

4.4.5.3 Design Basis

4.4.5.4 Safety and Operating Safeguards

4.4.5.5 Maintenance

4.4.5.6 Instrumentation and Controls

4.4.6 Superconducting Magnet

4.4.6.1 System Description 


\section{TABLE OF CONTENTS}

4.4.6.3 Design Basis

4.4.6.4 Safely and Operating Safeguards

4.4.6.5 Maintenance

53

4.4.6.6 Instrumentation and Controls

4.4.7 MHD Power Conditioning (Inverters) 54

4.4.7.1 System Description 54

4.4.7.2 Functional Requirements 54

4.4.7.3 Design Basis 55

4.4.7.4 Safety and Operational Safeguards 56

4.4.7.5 Maintenance 56

4.4.7.6 Instrumentation and Controls 56

4.4.8 Air Preheat System 57

4.4.8.3 System Description $\quad 57$

4.4.8.2 Functional Requirements 58

4.4.8.3 Design Basis 59

4.4.8.4 Safety and Operating Safeguards $\quad 60$

4.4.8.5 Maintenance 60

4.4.8.6 Instrumentation and Controls 60

4.4.9 Clean Fuel Storage!'Supply and Burner 61

4.4.9.1 System Description 61

4.4.9.2 Functional Requirements 61 


\section{TABLE OF CONTENTS}

4.4.9.3 Design Basis 62

4.4.9.4 Safery and Operating Safeguards 63

4.4.9.5 Maintenance 63

4.4.9.6 Instrumentation and Controls 63

4.4.10 Waste Heat Recovery 64

4.4.10.1 System Description 64

4.4.10.2 Functional Requirements 65

4.4.10.3 Design Basis 65

4.4.10.4 Safery and Operating Safeguards 68

4.4.10.5 Maintenance 68

4.4.10.6 Instrumentation and Control $\quad 68$

4.4.11 Solids Recovery and Seed Reprocessing Systems 69

4.4.11.1 Systems Description 69

4.4.11.2 Functional Requirements 72

4.4.11.3 Design Basis 73

4.4.11.4 Safery and Operating Safeguards 74

4.4.11.5 Maintenance 74

4.4.11.6 Instrumentation and Controls 74

4.4.12 Heat Rejection 75

4.4.12.l System Description 75

4.4.12.2 Functional Requirements 75 


\section{TABLE OF CONTENTS}

4.4.12.3 Design Basis

4.4.12.4 Safety and Operational Safeguards

77

4.4.12.5 Maintenance

77

4.4.12.6 Instrumentation and Controls

4.4.13 Stack and Exhaust Gas Systems 78

4.4.13.1 System Description 78

4.4.13.2 Functional Requirements 78

4.4.13.3 Design Basis 79

4.4.13.4 Safery and Operational Safeguards

80

4.4.13.5 Maintenance

80

4.4.13.6 Instrumentation and Controls

80

4.4.14 Waste Handling 80

4.4.14.1 System Description

4.4.14.2 Functional Requirements

80

4.4.14.3 Design Basis

4.4.14.4 Safety and Operational Safeguards

4.4.14.5 Maintenance Criteria

4.4.14.6 Instrumentation and Controls

4.5 EQUIPMENT AND SYSTEMS DESIGN

4.5.1 Equipment Specifications

4.5.2 Codes and Standards 


\section{TABLE OF CONTENTS}

\begin{tabular}{|c|c|c|c|}
\hline 4.5 .3 & \multicolumn{2}{|l|}{ Drowings } & 83 \\
\hline 4.5 .4 & \multicolumn{2}{|c|}{ Design Analysis } & 83 \\
\hline 4.5 .5 & \multicolumn{2}{|c|}{ Design Margins } & 84 \\
\hline 4.5 .6 & \multicolumn{2}{|c|}{ Reliability } & 84 \\
\hline 4.5 .7 & \multicolumn{2}{|c|}{ Design Reviews and Audits } & 84 \\
\hline 4.5 .8 & \multicolumn{2}{|c|}{ Quality Assurance } & 84 \\
\hline \multicolumn{3}{|c|}{ PLANT CONTROL AND INSTRUMENTATION } & 86 \\
\hline \multirow[t]{7}{*}{4.6 .1} & \multicolumn{2}{|l|}{ Control } & 86 \\
\hline & 4.6 .8 .1 & Design Basis & 86 \\
\hline & 4.6 .1 .2 & Plant Control Philosophy & 86 \\
\hline & 4.6 .1 .3 & Mechonization & 88 \\
\hline & 4.6 .1 .4 & Control of System Transients & 88 \\
\hline & 4.6 .1 .5 & Steady Stote Operation & 89 \\
\hline & 4.6 .1 .6 & Equipment and Emission Protection & 90 \\
\hline \multirow[t]{7}{*}{4.6 .2} & \multicolumn{2}{|c|}{ Instrumentation and Data System } & 91 \\
\hline & 4.6 .2 .1 & System Definition & 92 \\
\hline & 4.6 .2 .2 & Objectives & 93 \\
\hline & 4.6 .2 .3 & Constrainits & 94 \\
\hline & 4.6 .2 .4 & Probes and Primary Sensors & 94 \\
\hline & 4.6 .2 .5 & Doto Acquisition System & 95 \\
\hline & 4.6 .2 .6 & Dara Formating and Dissemination & 96 \\
\hline
\end{tabular}




\section{TABLE OF CONTENTS}

4.7 PLANT ARRANGEMENT AND CIVIL DESIGN 97

4.7.1 Equipment Lists 98

4.7.1.1 MHD Cycle 98

4.7.1.2 Heat Recovery System 99

4.7.1.3 Steam Bottoming Plant 99

4.7.1.4 Support Systems $\quad 100$

4.7.1.5 Accessory Electric Equipment $\quad 100$

4.7.1.6 Miscellaneous Power Plant Equipment $\quad 101$ (Balance of Plant)

4.7.1.7 Transmi ssion Plant 101

4.7.2 Overall Plant Descriptive Drawings 102

$\begin{array}{ll}\text { 4.7.3 Electrical Design Criteria } & 103\end{array}$

4.7.3.1 Codes and Standards 103

4.7.3.2 Utility Power for Startup and Operation 103

4.7.3.3 Power Conversion 105

4.7.3.4 MHD-ETF Switchyard 106

4.7.3.5 Standby Diesel Generator 106

$\begin{array}{ll}\text { 4.7.3.6 Uninterruptible Power Supply } & 107\end{array}$

4.7.3.7 Secondary Unit Substation 108

4.7.3.8 Cables, Cable Trays and Conduits 109

4.7.3.9 Fire Protection 110 
TABLE OF CONTENTS

Page

$\begin{array}{ll}4.7 .3 .10 & \text { General Criteria } \quad 110\end{array}$

4.7.3.11 Safety 111

4.7.3.12 Maintenance $\quad 112$

4.7.4 Civil/Structural Design Criteria 113

4.7.4.1 Codes and Standards 113

4.7.4.2 Structural Design and Analysis Procedures 113

4.7.4.3 Loads and Loading Combinations 114

4.7.4.4 Reinforced Concrete Design 117

4.7.4.5 Structural Steel Design 117

4.7.4.6 Foundation Design 117

4.7.4.7 Civil Design 117

4.7.4.7.1 Roads $\quad 117$

4.7.4.7.2 Railroads $\quad 118$

4.7.4.7.3 Sonitary Sewer $\quad 118$

4.7.4.7.4 Drainage 118

4.7.4.7.5 Fence 119

4.7.4.7.6 Fire Protection $\quad 119$

$\begin{array}{lll}5.0 & \text { TESTING CRITERIA } & 120\end{array}$

$\begin{array}{lll}5.1 & 120\end{array}$

$\begin{array}{lll}5.2 & \text { TEST OBJECTIVES } & 120\end{array}$

$\begin{array}{lll}5.3 & \text { TEST TYPES } & 121\end{array}$

5.3.1 Materials or Supportive Information Tests 121

5.3.2 Subscale Component and Subsystem Tests $\quad 122$ 


\section{TABLE OF CONTENTS}

5.3.3 Full Scale Component and Subsystem Tests

Page

5.3.4 MHD-ETF Preliminary Testing

5.4 CATEGORIZATION OF TESTS 122

5.4.1 Development Tests 123

5.4.2 Qualification Tests 123

5.4.3 Pre-Requisite Tests $\quad 123$

5.5 TEST PLANNING AND DOCUMENTATION 123

$\begin{array}{ll}6.0 & \text { PLANT OPERATIONS CRITERIA } \\ & 125\end{array}$

6.1 MAINTAINABILITY 125

6.1.1 Maintenance Repair Cycles $\quad 125$

6.1.2 Service and Access Design Criteria $\quad 125$

6.1.3 Maintenance Facilities 126

6.1.4 Routine Maintenance $\quad 126$

$\begin{array}{lll}6.2 & \text { SAFETY } & 126\end{array}$

6.2.1 Safety Design 126

$\begin{array}{ll}6.2 .2 \text { Fence Barriers } & 127\end{array}$

6.2.3 Safety Program 127

$\begin{array}{lll}6.3 & \text { OPERATING STAFF } & 128\end{array}$ 


\section{TABLE OF CONTENTS}

Page

7.0 PLANT COSTING CRITERIA

7.1 CAPITAL COSTS APPROACH

129

7.1.1 Breakdown of Depreciating Assets Accounts

7.1.2 Basis for Indirect Cost Accounts

134

7.2 OPERATING AND MAINTENANCE COSTS

8.0 SCHEDULING CRITERIA

137

8.1 EQUIPMENT

8.1.1 Demand Dates

137

8.1.2 Schedule Elements

8.1.3 Schedular Detail

137

8.1.4 Schedule Minimization

8.1.4.1 Long Lead Material Release

8.1.4.2 Risk Release

139

8.1.4.3 Alternate Supply

8.2 CONSTRUCTION

8.2.1 Program Required Dares $\quad 140$

8.2.2 Construction Methods 140

8.2.2.1 Construction Sequence 141

8.2.2.2 Site Preparation and Construction

141

Temporary Facilities 


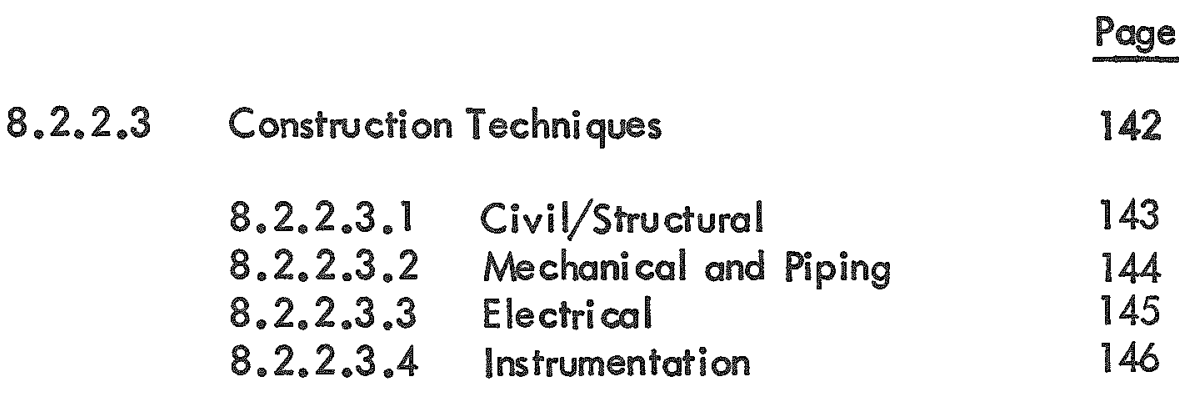

9.0 APPENDICES

148

APPENDIXA - DESCRIPTION OF HYPOTHETICAL SITE FOR AN

149 MHD ENGINEERING TEST FACILITY

\section{LIST OF FIGURES}

No.

Title

Page

2-1 Major Open Cycle Magnetohydrodynamic System Development Phases

4-1 General Arrangement of an MHD/Steam Plant

4-2 Seed Ash Processing (Overall) Flow Diagram 70

4-3 MHD-ETF Electrical Power System - Simplified One-Line

104 Diagram

\section{LIST OF TABLES}

No.

Title

$\underline{\text { Page }}$

4-1 Coal and Ash Analysis

7-1 Summary of Direct Costs for ETF Operation and Maintenance

7-2 Working Capital Requirements for ETF Operation and Maintenance

136

8-1 Equipment Application Rating Criteria 


\subsection{SCOPE}

This document establishes criteria to be urilized for the design of a pilot-scale open cycle, coal-fired MHD/steam plant. Criteria for this Engineering Test Facility (ETF) are presented relative to plant siting, plant engineering and operations, MHD-ETF testing, costing and scheduling.

Since this document has been prepared as a basis for initiating conceptual design, the criteria in some areas allow for alternate possibilities and drow heavily on previous experience and judgements and the MHD-ETF conceptual design guidelines. The document also consolidates various criteria that have been generated in formulating the MHO-ETF program and its interrelationship with other aspects of the National MHD Program.

It is expected that a document such as defined here will mature with the MHD-ETF definition until finally it becomes a controlled document for use in the actual design of MHD-ETF. 


\subsection{MHD-ETF DESIGN OBJECTIVES}

The National MHD Program is based on three overlapping and complementary phases, as depicted in Figure 2-1. Phase 1 is based on data derived from prior activities and extends to the engineering, development and testing of major components and subsystems in the Component Development and Integration Facility (CDIF), an upgraded Arnold Engineering Development Center (AEDC) facility and other existing or planned facilities. During this first phase, the conceptual design of MHD-ETF is accomplished and a commercial baseline plant design is defined.

Phase II concentrates on the design, construction and operation of MHD-ETF, a pilot-scale demonstration plant of 150-300 MWt. Design and construction of MHD-ETF depends on a parallel development program utilizing the facilities developed in Phase 1.

Phase III will demonstrate power plant performance and reliability for a commercial scale unit of several hundred electrical megawatts. This plant is designated the Commercial Demonstration Plant (CDP).

Within the framework of the total National MHD Program, the specific MHD-ETF objectives are:

- To test a combined coal-fired open cycle MHD/steam system in an integrated power plant configuration.

- To demonstrate the capability to utilize smaller scale component development coupled with analysis as a means of designing an integrated plant.

- To provide component, subsystem and system data to verify the technology and analytical methods necessary to the design of larger size plants for general commercial use.

- To serve as a means for evaluating and resolving critical problem areas and interactions not amenable to solution in the component test programs. 


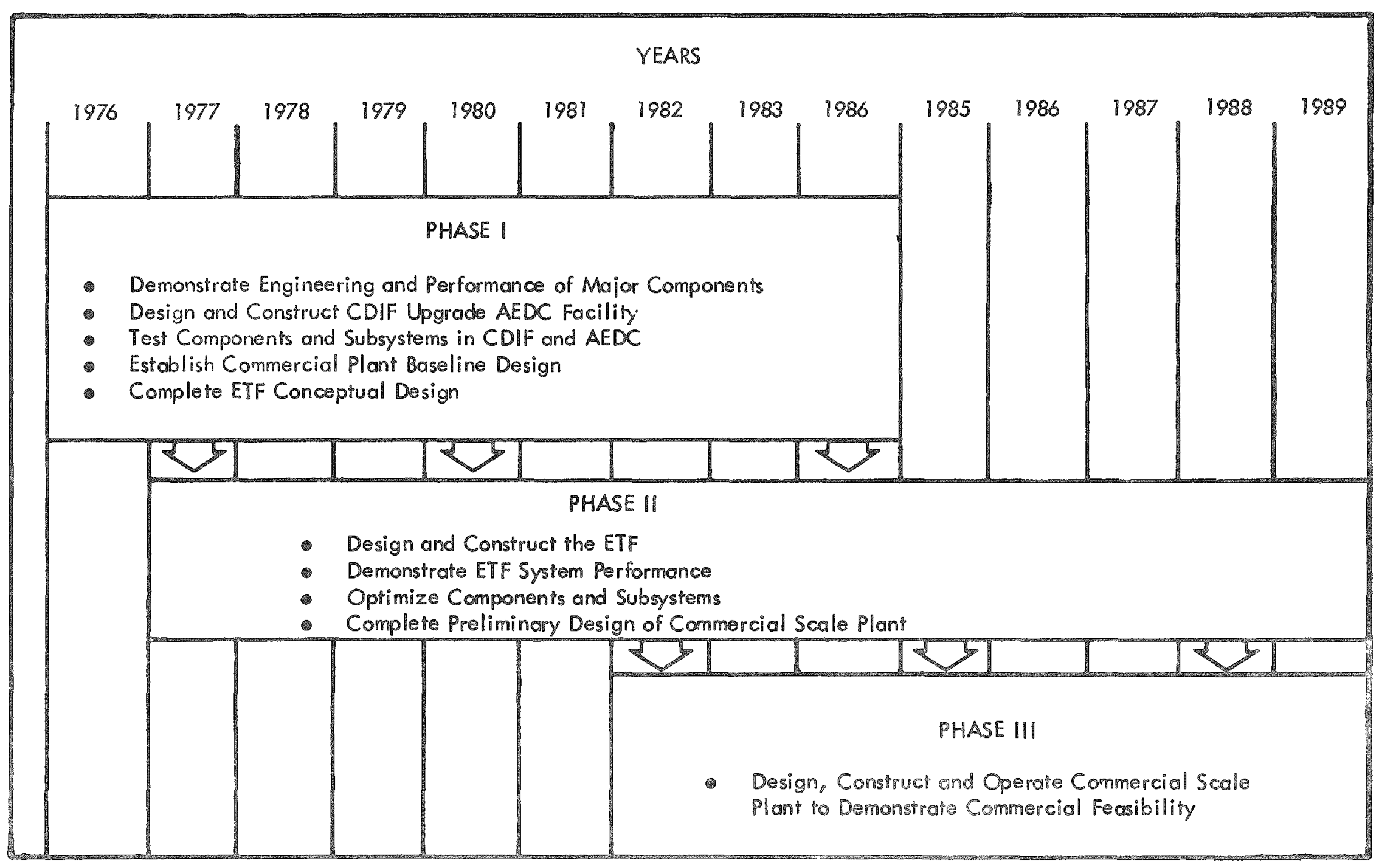

Figure 2-1. Major Opan Cycle Magnetohydrodynomic System Development Phases 


\subsection{PLANT SITING CRITERIA}

The site for the MHD-ETF has been previously identified as being located in western Montana, and for purposes of initial conceptual design, a hypothetical site description, presented as Appendix A in Section 9.0 to this document, has been provided. The following criteria have been written for the selection of a specific site for the MHD-ETF in this same geographical region.

\subsection{SITE GEOLOGY}

The alluvial fill or other surface soil material at the site should have uniform gradation from fines to larger materials. The surface and upper stratums of soil should be stable and structurally capable of supporting the foundation loads imposed by the MHD-ETF power plant and related ancillary facilities. The bedrock which the surface fill rests on should have mild to moderate relief. The soils should preferably have a low to moderate percolation rate so that lining of cooling water and ash disposal ponds is not required. The surface soil stratums should be capable of being excavated without the employment of explosives or costly removal techniques.

\subsubsection{Groundwater}

Groundwater levels should be at sufficient depth such that dewatering during construction of foundations is not a major or costly problem.

\section{1 .2 Seismology}

The site would preferably be located in a zone II area rather than a zone III seismic risk area.

The soil stratums should be free of known geological faults which would increase seismic risk to the facilities.

\subsection{SITE TOPOGRAPHY}

The topography of the region is characterized by mountain ranges (8000-10000 ft) separated by relatively wide flat valleys. The valley which the site is located in should be characterized 
by gently rolling or flat surface areas. The site should have light to moderate levels of vegetation and should be at a moderafe altitude which would not provide problems for construction and operation of the facilities. The specific site should be locared in a relatively flat area to minimize grading for access roads, railroads and site facilities.

The site should have sufficient relief to provide for construction of cooling water and ash settling ponds.

A landfill site will be required for disposal of ash and sludge from the power plant. Site selection will consider availability of potential landfill areas in the vicinity of the ETF. The disposal area utilized will be designed in accordance with state of Montana environmental quality regulations. The effecis of the potential leaching of contaminated water from the ash and sludge disposal area into underground water basins will be evaluared as well as the effecis of surface runoff into the local drainage system.

Surface drainage features of the site should not present major problems and require expensive construction such as stream diversion to prevent flooding. Site topography will be a major consideration for site selection.

\subsection{SITE CLIMATOLOGY AND METEOROLOGY}

A candidate site should hove an efficient dispersion climatology to reduce the potential environmental impact of stack gas emissions and cooling tower vapors.

Rugged terrain near the site would intensify the formation of cold air pockets in deep valleys thus producing more low-level inversions resulting in reduced atmospheric dispersion. Rolling terrain in the site vicinity would cause more air turbulence near the surface thus increasing atmospheric dispersion. 


\subsection{RESOURCE AVAILABILITY}

\subsubsection{Water}

Water availability will be a major consideration in site selection. Water rights will be required from the local streams, groundwater basin or from local water supply in sufficient quantity for plant process requirements, fire protection and potable water supply. Areas are to be preferred that have water of a reasonably clean quality.

\subsubsection{Electricity}

The principal supplier of electrical power in westem Montana is the Montana Power Company (MPC). Transmission lines owned by the MPC are rated at 230, 161, 100,69 and 50 kV. The Bonneville Power Administration supplies power to 500 and $230 \mathrm{kV}$ transmission lines in northwestern Montana.

Electrical power for construction and operation should be available from the Montana power system. The Montana power system will also have to be utilized for testing the commercial capabilities of the MHD power supply. Sites which minimize land acquisition costs and construction costs for transmission lines will be favorably considered.

\subsubsection{Transportation}

Western Montana is served by three major railroads. The proximity of the site to the mainline of one of these railroads will be a favorable consideration for site selection. This would minimize costs of spur track construction for coal delivery and provide for equipment delivery.

Western Montana is served by Interstate Highway Routes 15 and 90, Federal Highway Routes 10, 91 and Alte mate Route 10, and State Routes 41 and 287. The proximity of the site to this highways system will expedite the delivery of MHD system components and construction material while minimizing the construction costs of access roads. The movement of construction personnel, operating personnel and visitors to the plant area will also be expedited. 
Because of the demonstration aspects of the facility and the need for freque nit trips by development personnel as well as visitors, fovor shall be given to sites that are convenient to local air transportation.

\subsubsection{Coal}

The MHD-ETF will operate on low sulphur Montana Rosebud sub-bituminous coal. The high sulphur Illinois "6 coal is an alternate fuel. The coal will be transported by rail and a consideration for site selection will be transportation costs from the coal field.

\subsubsection{Natural Gas and/or Oil}

The utilization of natural gas and/or oil in various plant processes requires that the site be located where such resources can be obtained without undue difficulty. Subsiantial quantities of oil for preheater operation may be needed.

\subsubsection{Labor}

The local labor supply should be able to provide a substantial portion of the construction labor force of skilled and experienced craftsmen required to construct the facility.

The local force should also be capable of supplying the semi-skilled, skilled, and technical personnel required for operation of the ETF.

\subsubsection{Socieconomics}

The socieconomic impact of the ETF on the people and the support services of the nearby communities should be minimal. The site proximity to communities with adequate labor supply, housing, educational facilities, recreation facilities, churches, stores, motels and hospitals will be a major consideration for site selection. 


\subsection{SUPPORT SERVICE REQUIREMENTS}

\subsubsection{Security}

Security for the MHD-ETF will be self contained and there will be little requirement for local security forces. However, the easy availability to State Police or other qualified police organizations will be of benefit.

\subsubsection{Medical}

Reasonable proximity of the site to a local community having medical facilities and a qualified staff of physicians will be favored. Minor medical and first aid requirements will be handled at the facility itself.

\subsubsection{Site Personnel}

Housing requirements for construction and operating personnel should be available in the local community, to minimize any need for temporary or permanent facilities in conjunction with the MHD-ETF complex.

\subsubsection{Fire Protection}

The availability of a local qualified fire fighting organization to augment on-site provisions is preferred. Consideration shall be given to augmenting a local fire protection organization, if in close proximity, as a means of major fire fighting.

\subsubsection{Communications}

Communications systems such as telephone and telegraph will be required to be available in the site vicinity. 


\subsection{EUVIRONMENTAL REGULATIONS}

The National Environmental Policy Act established policies for environmental controls. It also established a procedure where in the Environmental Protection Agency would odminister the programs for the states only as long as it look the siates to provide their own environmenm hall programs. Once a state has legislated an environmental program, the EPA acts only in a supervisory capacity in assuring that the program is carried out in accordance with the requirem ments of the National Environmental Policy Act. Montana is one of the states which has adopted the appropriate legislation and has an overall environmental policy.

Existing Monianc laws defer their individual requirements when a project such as the ETF is constructed by an agency of the Federal Government. This creates an uncertainty as to the authority having jurisdiction over construction of the ETF. Nomally, when the states defer their environmental regulations to a Federal agency, the governing environmental regulations are a part of the National Clean Air and Pollution Act. The MHD Engineering Test Facility is a unique application of a fossil fue l buming pilot plant and has not been officially classified by the U.S. Environmental Protection Agency. Therefore, it is not actually covered under the National Clean Air and Pollution Act. Indications are that Federal agencies such as ERDA will cooperate with local and state governmental regulations in matters such as this. Thus, the following discussion will cover the appropriate Montana state laws.

\subsubsection{Montana Lows}

3.6.1.1 Montana Major Facillity Siting Bill - The State of Montona environmental requirements for an energy facility are contained in the Montana Utility Siting Act of 1973, House Bill 127. Chapter 327, Montana Session of Law of 1973. The reguirements were further amended in 1975 by the Montana Major Facility Siring Act, House Bill 581. Chapter 494, Montana Session of Law. The ETF can be defined as a "Facility" under Section 3 of the Major Facility Siring Act, paragraph (a), subparagraph (e), if it is "designed for or capable 
of producing 50 megawatts of electricity or more....". The following portions and requirements of the Montana Major Facility Act would be applicable to the construction of the ETF:

a. Certificate of Environmental Compatibility and Public Need - At least two years prior to anticipated commencement of construction of the utility facility, an application for a certificate shall be filed with the Board of the Montana Department of Natural Resources and Conservation. This application shall contain the following information:

1. A description of the location and the utility facility to be built thereon.

2. A summary of any studies which have been made of the environmental impact of the facility.

3. A statement explaining the need for the facility.

4. A description of any reasonable alternate location or locations for the propased facility, a description of the comparative merits and detriments of each location submitted, and a statement of the reasons why the primary proposed location is best suited for the facility.

5. Such other information as the applicant may consider relevant or as the department may by regulation or order require. A copy or copies of the studies referred to in clause 2 above shall be filed with the department, if ordered, and shall be available for public inspection.

Detailed instructions for the application and filing are included in the law.

Any certificate issued by the board shall include the following:

1. An environmental evaluation statement related to the facilities being certified. The statement shall include, but not be limited to, analysis of the following information:

- Environmental impact of the proposed facility. 
- Any adverse environmental efects which connot be avoided by issuance of the certificates.

- Problems and objections raised by other federal and state ageneies and interested groups.

- Altematives to the proposed facilities.

- Aplon for monitoring environmental effects of the proposed focility.

2. A stotement signed by the opplicant showing agreement to comply with the requirements of this act and the condirions of the certificote.

Thus, the state of Montana assumes the responsibility for compiling the Environmental Impact Statement. The cost of this cassumed work is paid for by the filing fee. The filling fee schedule is of the declining bolance type and is contained in Part 2, Section 6 of $\mathrm{HB}-127, \mathrm{CH} 327,11973$. It is based on the estimated project cost:

$3 \%$ to 1 million dollars

$1 \%$ from 1 million to 20 million

$0.5 \%$ from 20 million to 100 million

$0.25 \%$ from 100 million to 300 million

$0.1 \%$ over 300 million dollars

The state of Montana has legislated this right in the Montana Environmental Policy Act Chapter 65, L 1971. The Montona Environmental Policy Act also establishes the areas of responsibility of the completion of the Environ mental Impact Statement. This act created an Environmental Quality Council whose executive divector and staff are responsible for the overall gathering 
and assembling of the required information. In performing this task, they coordinated the input from various Montana State Agencies who have basic responsibility in the affected areas.

b. Long Range Planning Report - The Department of Natural Resources and Conservation requires, for its review, an annual long range plan for the construction and operation of the utility facilities. The requirement to file a long range planning report may be applicable to the ETF since power output is to be supplied to the Montana power grid. The report is due April Ist and shall include the following:

1. The general location, size and type of all utility facilities to be owned and operated by the urility whose construction is projected to commence during the ensuing 10 years, as well as those facilities to be removed from service during the planned period.

2. A description of efforts by the utility to coordinate the plan with other utilities so as to provide a coordinated regional plan for meeting the utility needs of the region.

3. A description of the efforts to involve environmental protection and land use planning agencies in the planning process, as well as other efforts to identify and minimize environmental problems at the earliest possible stage in the planning process.

4. Projections of the demand for the service rendered by the utility and explanation of the basis for such projections, and a description of the manner and extent to which the proposed facilities will meet the projected demand.

5. Additional information that the department on its own initiative or upon the advice of interested state agencies might request in order to carry out the purposes of this act. 
In evaluating the long range plans, the board will give considerations to the following major areas:

1. Energy needs

2. Land use impacts

3. Water resource impacts

4. Air quality impacts

5. Solid waste impacts

6. Radiation impacts

7. Noise impacts

3.6.1.2 Water Quality Standards - The state of Montane requirements for woter quality standards are contained in the Water Pollution Laws, Section 69-4801 e?. seq., RCM 1947 as amended by Water Quality Standards MAC 16-2,14(10)-\$14460. These cre administrated by the Montana State Deparment of Health and Environmental Sciences.

a. Montana Pollutant Discharge Elimination System (MPDES) Permit - "The ownar or operator of any proposed point source, which may discharge polluiants into state water, shall file a completed MPDES permit application no less than 180 days prior to the day on which it is desired to operate the point source". MAC 16-2.14(10)-S14960, Paragraph 4, subparagraph (c).

It is proposed that the MHD-ETF be a "zero discharge" site with a sewage treatment plant and a retention/evaporation pond. Thus, the permit will be issued for other sewage systems and treatiment plants. A report which should accompany the request for permit should contain as a minimum:

1. A general site plan, indicating topography, location and elevation of sewage systems, treatment works, disposal systems and feeding operations, 
location of adjacent state waters, 100 year flood elevation, seven day 10 year low flow point of discharge.

2. General design conditions and process descriptions, proposed alternatives, soil conditions and descriptions in areas proposed for location of treatment ponds and land disposal, geological conditions, groundwater characteristics, discussion of potential for and measures to be taken for emergency and accidental spills, data on toxicity assays of process water and waste water treatment chemicals to be used, etc.

3. For industrial wastes, a process and waste flow diagram showing water and material balances, chemical additions, and waste volumes and concentrations before and after treatment, including but not limited to, oil and other floating material, biochemical oxygen demand, settleable and suspended solids, acids, alkalies, dissolved salts, organic materials, toxic materials, compounds producing taste and odor in water or in the flesh of edible fish, and colored materials and dyes.

4. Ponds for waste treatment purposes are not to be located in drainage ways where the volume of drainage water from a 10 year storm entering the pond exceeds one-half of the pond volume.

b. Water Quality Standard - The overall water treatment requirements are contained in the following statement: "The department adopts as a rule the policy that best practicable treatment and control of waste, activity and flow is to be provided to maintain dissolved oxygen and overall water quality at the highest possible levels, and water temperatures, coliform bacteria concentrations, dissolved chemical substances, toxic materials, radioactivity, turbidities, color, odor and other deleterious substances at the lowest possible levels", MAC 16-2.14(10)-S14480, Paragraph 1. 
There are eight separate water classifications ranging from most restrichive A-Closed classification to the least restrictive EF classification. Each classia

fication hes a water use description and a liş of specific water quality criveria. The following A-Closed classification is exemplary of the eight classificotions:

\section{A-Closed Classification}

(a) Water-use description. Water supply for drinking, culinary and and food processing purposes suirable for use of âter simple disinfaction. Public access and activities such as livestock grazing and timber hervest are to be controlled by the witlity owner under conditrions prescribed and orders issued by the department. Only those waters on which access is presently controlled by the witility owner have been classified as AdClosed. If oiher uses ars permitted, the waters are to be reclassified $A=O p e n=D_{1}$.

(b) Specific water quality criteria

- The overage number of organisms in the coliform group is not to exceed 50 per 100 milliliters.

- Dissolved oxygen criteria are not applicable for the classification.

- No change from natural $\mathrm{pH}$ is allowed.

- No increase dove naturally oscurring furbidity is allowed.

- No increase above naturally accurring water temperature is allowed.

- No increases above naturally occurring concentrations of sediment, sertleable solids or residues, which adversely affect the use indicated, are allowed.

- No increases of toxic or other deleterious subsinances, pesti cides and organic and inorganic materials including heavy metals, above noturally occurring concentrations, are allowed. 
- No wastes are allowed which increase radioactivity above natural background levels.

Water Quality Standard MAC 16-2.14, 101 -S1448Q contains a detailed list of all Montana State drainage and the required water classification for each. Specific waste treatment plant retention pond operations will be determined upon actual site location and the water classification standard required for the affected state drainage.

3.6.1.3 Air Quality Standards - The state of Montana environmental requirements are contained in the Clean Air Act of Montana, Title 69, Chapter 39, R.C.M. 1947, revised July 1 , 1975. In addition, there are 19 additional MAC rules covering specific topics and/or industrial applications. Reference to the applicable rules will be made in the following text. These regulations are administered by the Montana State Department of Health and Environmental Sciences.

a. Permits, Construction and Operation of Equipment MAC 16-2.14(1)-51400This is the basic overall permit required in the state of Montana. The application is made to the Air Quality Bureau of the Environmental Sciences Division. Application must be made not later than 180 days prior to the time construction begins and no later than 120 days prior to the time the installation or use commences. Here again. Montana is somewhat unique in that the permit covers fugitive dust from both construction and plant operation as well as the discharge of process air pollution. Per Paragraph 3 of the subject rule, the application for permit should be accompanied by plans, specifications and other information deemed necessary by the administration of the Division of Environmental Sciences of the department for the construction, installation or alteration of any new equipment. Specific requirements for each application are contained in the following MAC rules. 
b. Porticulare Matier, Industrial Process MAC 16-2.14.(1)-\$14300 whe rule covers a maximum allowable wight discharge per hour of particulate mather bosed on the process weight pate. When and if the ETF is classified by the EPA, is will probobly be subject to subparagraph (b) or Paragraph 2 of this rule. This subparagraph transfers regulation to a different rule, MAC 16-2.14(1)-514082, Standards of Performance for New Stationary Sources. However, this new rule defers to the provisions of Tisle 40, Part 60, Code of Federal Regulations, July 1, 1975. Subparagraph 60.42, Standard for Particulare Matter, states that facility exhaust geses shall not contein particulare matter in excess of 0.18 grams per million calories heat input $(0.10 \mathrm{lb}$ per million Biu) delivered from fossil fuel. Opacity shall not exceed $20 \%$ except for a 2 minute per haur maximum of $40 \%$, unless the pressnee of uncombined water is the reason for the increased opacity.

c. Porticulate Matter Airborne, MAC 16-2.14(1)-51440 - This rule is very short and is included in its entirety in the next iwo paragraphs.

"(1) No person shall cause or permit the hand ling or tromsporing or storage of any material in a monner which allows or moy allow conirollable particulate matier to become aiborne.

(2) No person shall cause or permir a building or its appurtenances or a road, or a driveway, or an open area to be constructed, used, repaired or demolished without applying all such reasonoble measures as may be required to prevent particulate matter from becoming airborne. The director may require such reasonable measures as may be necessary to prevent particulah mather from becoming airborne, including, but not limised to, paving or trequent deaning of roads, driveways and parking lots; application of dust-free surfaces; application of warer; and the planting and maintenance of vegetative ground cover." 
d. Ambient Air Quality Standard MAC 16-2.14(1)-S14040 - The table lists both Montana standards and EPA standards. This is necessary as Montana does not have a standard for nitrogen oxides.

\begin{tabular}{|c|c|c|}
\hline Pollutant & Montana Standard & EPA Srandard \\
\hline \multirow[t]{2}{*}{ Particulate } & $\begin{array}{l}75 \mu \mathrm{g} / \mathrm{m}^{3} \\
\text { (annual geometric mean) }\end{array}$ & $\begin{array}{l}60 \mathrm{\mu g} / \mathrm{m}^{3} \\
\text { (annual geometric mean) }\end{array}$ \\
\hline & $\begin{array}{l}200 \mu \mathrm{g} / \mathrm{m}^{3} \\
(24 \text { hour maximum) }\end{array}$ & $\begin{array}{l}150 \mu \mathrm{g} / \mathrm{m}^{3} \\
(24 \text { hour maximum) }\end{array}$ \\
\hline \multirow[t]{4}{*}{ Sulfur Dioxide } & $\begin{array}{l}0.02 \mathrm{ppm} \\
\text { (annual arith. mean) }\end{array}$ & $\begin{array}{l}0.02 \mathrm{ppm} \\
\text { (annual arith. mean) }\end{array}$ \\
\hline & $\begin{array}{l}0.10 \mathrm{ppm} \\
\text { (24 hour average) }\end{array}$ & $\begin{array}{l}0.10 \mathrm{ppm} \\
\text { ( } 24 \text { hour overage) }\end{array}$ \\
\hline & $-\infty$ & $\begin{array}{l}0.50 \mathrm{ppm} \\
\text { ( } 3 \text { hour average) }\end{array}$ \\
\hline & $\begin{array}{l}0.25 \mathrm{ppm} \\
\text { (1 hour average) }\end{array}$ & -- \\
\hline Nitrogen Oxides & $--\infty$ & $\begin{array}{l}0.05 \mathrm{ppm} \\
\text { (annual arith. mean) }\end{array}$ \\
\hline
\end{tabular}

NOTE: The EPA standard for particulate is more restrictive; thus, it would be the governing requirement.

3.6.1.4 Solid Waste Laws - Montana does not have a Solid Waste Disposal Law at this time. There is a new law in the Montana State Legislature. Its passage is almost a certainty and its effective date is anticipated to be July 1, 1977. This information will have to be obtained at the appropriate time. At the present time, fly csh disposal is handled at existing sites by land fill methods. Prevention of fugitive dust, harmful surface runoff and water leaching are the only environmental considerations. 


\subsubsection{Federal Laws}

The following Federall lows are applicable to this project:

a. National Environmental Policy Act

b. National Clean Air and Pollution Act

c. New Source Performonce Standard 40 CFR 60.40

d. Federal Water Pollution Control Act

e. Refuse Act, U. S. Army Corps

f. National Pollutant Discharge Elimination System 38 CFR No. 128, Section III

Due to the undetermined classification of the ETF, discussion of the Federal regulations would be superfluous to those discussed under state requirements.

\subsection{LOCAL AND FEDERAL LAWS AND CODES}

In addition to the environmental controls identified in the previous section, the following laws and codes will be applicable to construction and operation of the MHD-ETF.

3.7.1 Health and Safery

a. Occupational Safely and Health Act

b. Montana State Occupational Safety and Health Standards

\subsubsection{Acquisition of Water Rights}

a. Montana Water Law, Chapters 8 and 29 
3.7.3 Water Treatment Standards

a. Montana State Water Quality Standards

b. County Health Department Water Treatment Regulations for the specific site.

3.7.4 Fire Protection Standards

a. National Fire Protection Association

3.7.5 Sewage Treatment Standards

a. Montana State Water Quality Standards

3.7.6 Electrical Codes

a. National Electrical Code

b. National Electrical Manufacturer's Association

3.7.7 Height Restrictions

a. Federal Aviation Administration, Regulation 77, Objects Affecting Navigable Airspace

3.7.8 Explosion Hazards

a. National Fire Protection Association

b. National Electrical Code

3.7.9 Acquisition of Right-of-Way for Power Line Corridor

a. Montana Major Facility Siting Bill 


\subsection{PLANT ENGINEERING CRTTERIA}

\subsection{PLANT FUNCTIONAL DESCRIPTION}

A simplified general arrangement of an MHD/steam plant is shown in figure $4-1$. The basic system consisis of an MHD cycle using poitassium seeded high temperature coal combustion products passing through a magnetic field to generate ele ctricity; heat recovery units to connect the heat from the hot gas leaving the MHD cycle into steam; a steam botroming plant to convert the steam energy to electricity; and support systems necessary to the efficient and acceptable integration of these basic functions into an opercting plant.

The MHD-ETF shall be designed to demonstrate this system on a pilot scale basis. A tentative judgement has been made* that if standard steam conditions are generated for use by the turbine generator, then the turbine generator set need not be a part of the MHD-ETF. The validity of this judgement shall be evaluated relative to its impact on the evaluation of systems interactions and program costs. It has also been determined that the high temperature air preheat by means of direct exchange from the MHD exhaust gas is of sufficient technical difficulty to warrant investigation of an indirectly fired preheater.

\subsection{CONFIGURATION SELECTION}

The following philosophy shall be followed in the evolution of the design configuration for the MHD-ETF:

a. Where technology development is not anticipated in an equipment item or a process, the specific design will be selected as early as possible based on performance, cost, compatibility with the total system, and ability to be scaled to larger size in the future.

*MHD-ETF conceptual design guidelines. 
b. Where technology development is foreseen but does not restrict the selection of an overall plant configuration or process (i.e. materials selection, internal configuration, chemical rates), the ETF configuration shall be selected as per (a) above, and the technology development identified. This technology development will then be planned to be compatible with the ETF schedular requirements.

c. Where major technology development is needed to the extent that alternate external configurations or processes are deemed necessary for consideration, the following philosophy shall be applied:

1. Based on a systematic evaluation of the existing data and judgements of the factors pertinent to ETF, a ranking for applicability to ETF will be made.

2. The highest ranked configuration or process shall be selected for incorporation in the base ETF design and priority shall be given to support this selection in technology development.

3. A "backup" program(s) will be identified and given a priority consistent with the best judgement of the uncertainties involved in the prime selection. The "backup" program(s) shall be selected to minimize impact to the ETF program if its eventual use becomes necessary.

4. Final resolution will be planned for by the following:

- Identification of development results on the prime selection which will allow discontinuing the "backup" efforts.

- Identification of adverse results on the prime selection which dictate changing to the "backup".

- Provision for incorporation of either the prime or "backup" selection with parallel development and potential evaluation of both in ETF. 


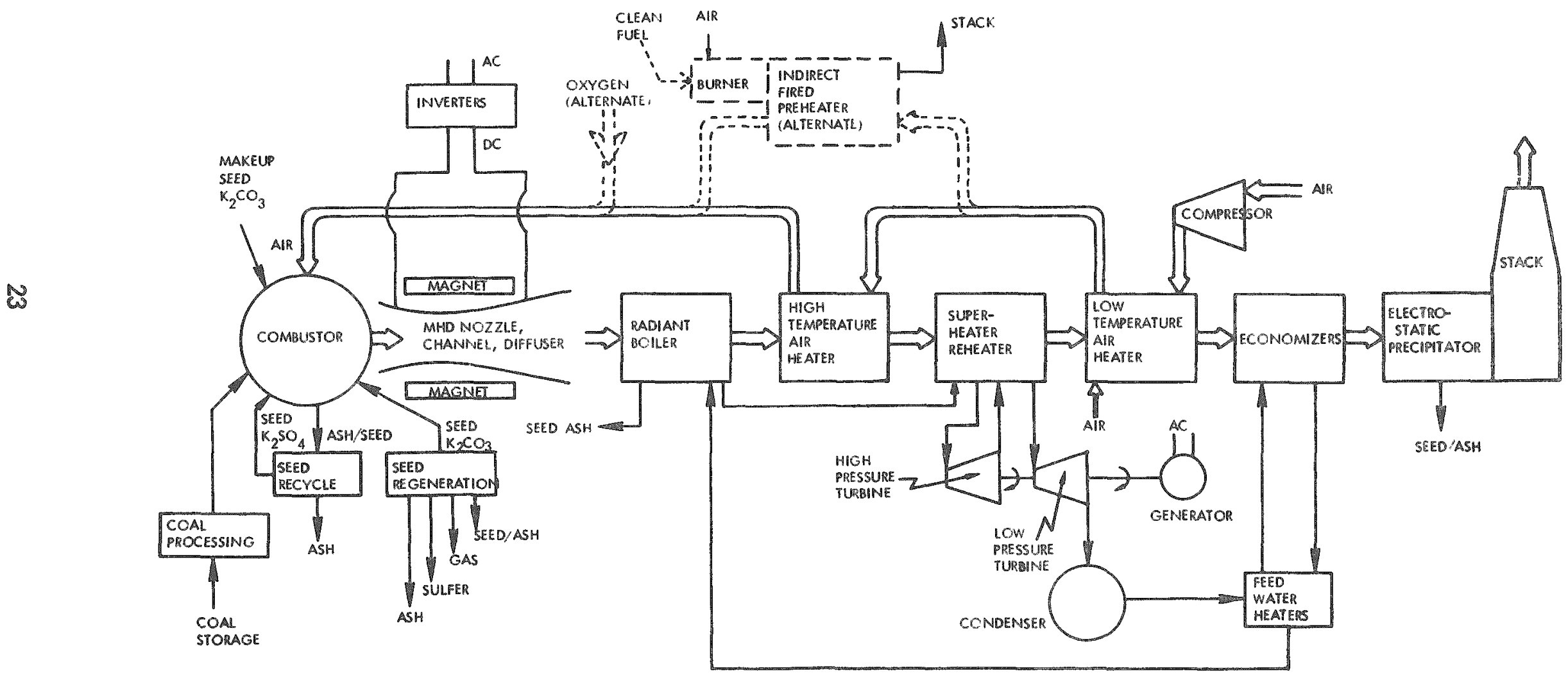

Figure 4-1. General Arrangement of an MHD/Steam Plant 


\subsection{OPERATING REQUIREMENTS AND DESIGN PARAMETERS}

Certain criteria specified in this section are predicated on experience and practice in existence for large size fossil and nuclear baseload power plants. The expectation of the use of MHD in large baseload plants makes it desirable to have the MHD-ETF demonstrate similar operational capability to these other types of plants. However, as conceptual design progresses, these desired capabilities will be weighed against the design difficulties and recommendations advanced. The requirements stated in the following paragraphs are based on a complete MHD/steam cycle plant.

\subsubsection{Steady State Operation}

The MHD-ETF will be designed to operate at rated load, steady state conditions of TBD MWt to the combustor. It will be designed to deliver power to an interconnected grid systern while operating at conditions that are similar to base loaded plants.

Components, controls and operating specifications and procedures shall be designed to encompass normal fluctuations that occur during steady state operation. Fluctuations in the electrical load on the plant can be caused by changes in grid use conditions, temperature or thermal input of the combustor and seed feed variations. The range of fluctuations to be compensated for by the control system will be determined and specified during the conceptual design phase.

The MHD-ETF shall be capable of supporting continuous operations for a minimum of 2000 hours and will have a design useful life of 15 years. The design goal shall be to have the facility operationally available for conducting tests and demonstration at least 60 percent of the time. The design should provide redundancy for short-lived or low reliability components to achieve the desired test availability and continuous operating time. 


\section{3 .2 Sturphup and Shutidown}

For design purposes, starhup and shuidown of the MHD ETF will be accomplished by urilizing alectric power drawn from the utillity's grid, and auxiliary steam if required.

4.3.2.1 Srartup from Ambient - Equipment and controls shall be designed to start subsystems and to ramp up the system temperature at a rate equal to that prescribed in the startup procedure. The ceramic materials of construction contained in the MHD components are expected to be the controlling factor in temperature rise rate. The rate of temperature rise will be specified according to the matericls used and their geometry, and will be of such a magnitude that functional damage will not occur from themel stress during stigrip.

\subsubsection{Startup from Hot Standby - The facility shall be designed with a hes standby} condition for use in operations and as a retreat point for certain specified events. When it is desired to restart from this hot standby condition, the fuel and oxidizer rate will be increased to ramp up the temperature at the rate prescribed in the operating procedure. This rate will be such as to assure that no functional damage oscurs to the system from thermal stresses.

4.3.2.3 Shutdown to Ambient - The facility shall be capable of being shut down from either steady state full operating condition, or from hot standby. The fuel and oxidizer must be reduced in a manner that prevents the cooldown rate from exceeding the rate prescribed in the operating procedure. As in startup, the controlling factor in cooldown rate is expected to be the cermic materials of construction. The cooling rate must be slow enough to prevent excessive thermal stresses and funcrional damage from occurring. Cosling water flow is mainrained through the equipment until ambient temperature is reached. There may be other modes of shutdown to ambient specifically designed to handle the "shutdown events" as defined in Paragraph 4.3.5.3. 


\subsubsection{Power Loading and Unlooding}

The design of the MHD-ETF systems and controls shall be such that the power generated by the MHD generator, when integrated into a total plant, can be delivered to the Utility's grid in a manner consistent with normal base load plant operation. This requires a uniform loading ramp of about $2 \%$ of rated power per minute from no load to full load. The design shall also include automaric load following controls over a base load operating range of 80 to $100 \%$ of rated load and network load fluctuations in this range will be accommodated by a $+3 \%$ per minute continuous and uni form ramp change.

The power generaling system and controls shall have the capability to change load in a stepwise fashion. Step changes of $10 \%$ of rated load will be accommodated within the load range of $40 \%$ to $100 \%$ of rated power at a rate change of $3 \%$ of rated power per minute.

The plant must be capable of withstanding a 100\% power load rejection.

\subsubsection{Allowable Electrical Power Output Parameter Variation}

The MHD-ETF shall be designed so the power output from the facility will be within acceprable limits for use in the local utility electrical network.

\subsubsection{Definition of Events}

Events that will/may occur during operation of the MHD-ETF have been classified as normal, off design, shutdown or uncontrolled. The facility shall be designed in accordance with the definitions and event classificarions given below.

\subsubsection{Normal Events - Normal events are those events experienced by the MHD-ETF which have been planned or programmed by operating personnel. It is anticipared that a number of tests will be made at off design conditions. However, when the ETF test program and operaring procedures schedule an off design condition for test purposes, it will be}


considered a normal event. Nomal events are all those events other than non-scheduled off design, shutodown, or uncontrolled events.

4.3.5.2 Off Design Events - An off design event is a deviation from normal conditions which is expected to occur frequently enough that the design shall include provisions to accommodate it without shutdown.

4.3.5.3 Shutdown Events - Shutdown events are those events of generally low probability which require the plant to discontinue operation until corrective action has been taken in order to prevent gross structural damage, to provide safety or to assure power producing conditions. Shutdow may be to ambient or standby conditions, depending on the specific event.

4.3.5.4 Uncontrolled Events - Uncontrolled events are very low probability events whose consequences are such that the integrity and operability of the system moy be impaired to the extent that considerction of public or personnel health and safely are involved. Shutdown and securing of operations under such conditions shall be required.

\subsubsection{Classification of Events}

\subsubsection{Normal Events}

- Stariup from ambient conditions

- Startup from hot standby

- Shutdown to hot stondby

- Shuidown to ambient

- Looding and unloading

- Losd fluctuations 
- Step lood changes

- Temperature fluctuations

- Pressure fluctuations

- Tests ot offrodesign conditions

\subsubsection{Off Design Events}

- Power load rejection

- Redundant equipment failures

- Cooling water leak at channel not in excess of TBD gpm

- Inverter failure

\subsubsection{Shutdown Events}

- Loss of air flow

- Loss of seed feed

- Loss of coal feed

- Loss of major component struchural integrity

- Loss of magnetic field

- Loss of cooling water

- Loss of site power

- Exceeding environmental discharge

4.3.6.4 Uncontrolled Events

- Major meteorological event

- Unquthorized seizure of plant, facilities or personnel 


\subsubsection{Essign Poramerers}

The following tabulation presents major parameters specified for design of the MHD-ETF:

\begin{tabular}{|c|c|}
\hline Thermal Power Input & $\begin{array}{l}150-300 \mathrm{MW} \\
\text { (Final selection to be based on scaling } \\
\text { shudy results.) }\end{array}$ \\
\hline Cool Type & $\begin{array}{l}\text { Montana sub-bituminous and Illinois " } 6 \\
\text { (See Paragraph } 4.4 .1 \text { ) }\end{array}$ \\
\hline Combustion Plasma Temperature & $4500^{\circ} \mathrm{F}$ Minimum \\
\hline Air Preheai Temparature & Up to $3000^{\circ} \mathrm{F}$ \\
\hline Combustor Slag Removal & 90 Percent Minimum \\
\hline Maximum Magnetic Field & 6 Tesla \\
\hline MHD Generator Pressure & 8 Atmospheres Maximum \\
\hline Steam Conditions & $\begin{array}{l}\text { Acceptable for use in state-of the the art turbine } \\
\text { generator units }\end{array}$ \\
\hline Stoichiomerry & $0.9-1.1$ \\
\hline
\end{tabular}

\subsection{FUNCTIONAL AND PROCESS DESIGN}

The MHD-ETF as a pilot-scale demonstration plant shall, to the maximum extent possible, incorporate all aspects of equipment and processes necessary to MHD which have unique or specific design features or requirements not previously used in commercial practice. In addition, the MHD-ETF shall incorporate combinations of equipment and processes which result in interactions important to the understanding and verification of control, operation, or the process itself.

It is the purpose of this section to describe design criteria for the MHD power conversion system, related components and support subsystems. This section has been prepared as a bosis for initiating equipment and process conceptual designs for the ETF. The criteria, 
therefore, are based on certain preliminary assumptions and in addition, in some areas, allow for alternative design approaches.

A schematic diagram showing a representative $\mathrm{MHD} /$ steam power plant and supporting subsystems was given in Figure 4-1. For establishing design criteria, the MHD/steam plant has been divided into major systems for which design criteria have been prepared. The major subsystems are:
a. Coal Handling
b. Coal Processing
c. Air and Oxidant Supply
d. Seed Storage and Feed
a. MHD Hot Gas Power Train
f. Superconducting Magnet Assembly
g. Air Preheat System
h. Clean Fuel Storage/Supply and Burner
i. Waste Heat Recovery
¡. Solids Recovery and Seed Reprocessing Systems
k. Heat Rejection
1. Stack and Exhaust Gas Systems
m. Waste Handling
n. Electrical Systems

Under each major system, criteria are presented and discussed on the basis of the system description, functional requirements, design basis, safety and operating safeguards, maintenance and instrumentation and controls. In the three areas relative to safery, maintenance 
TABLE 4- 1

COAL AND ASH ANALYSIS

\begin{tabular}{lcr} 
& $\begin{array}{c}\text { MONTANA } \\
\text { ROSEBUD }\end{array}$ & ILLIN \\
PROXIMATE ANALYSIS, COAL, AS RECEIVED, \% & & \\
\cline { 1 - 2 } Moisture & & \\
Volorile Matter & 22.7 & 8.9 \\
Fixed Carbon & 29.4 & 38.0 \\
Ash & 39.2 & 41.7 \\
& 8.7 & 11.4
\end{tabular}

ULTIMATE ANALYSIS, \%

$\begin{array}{lcr}\text { Hydrogen } & 6.0 & 5.4 \\ \text { Carbon } & 52.1 & 62.4 \\ \text { Nitrogen } & 0.79 & 1.2 \\ \text { Oxygen } & 31.5 & 16.3\end{array}$

ASH ANALYSIS

$\mathrm{SiO}_{2}$

37.6

$41.4 \pm 5.4$

$\mathrm{Al}_{2} \mathrm{O}_{3}$

17.3

$19.3 \pm 6.8$

$\mathrm{Fe}_{2} \mathrm{O}_{3}$

5.1

$22.3 \pm 6.8$

$\mathrm{T}_{1} \mathrm{O}_{2}$

0.7

0.9

$\mathrm{P}_{2} \mathrm{O}_{5}$

0.4

0.12

$\mathrm{CoO}$

11.0

$5.4 \pm 3.3$

$\mathrm{MgO}$

4.0

$1.7 \pm 1.3$

$\mathrm{Na}_{2} \mathrm{O}$

3.1

$0.6 \pm 0.2$

$\mathrm{K}_{2} \mathrm{O}$

0.5

$2.1 \pm 0.4$

$\mathrm{SO}_{3}$

17.5

$7.5 \pm 0.6$

Sulfur

Heating Value, Wot, Bu/lb

Heating Volue, Dry, Bru/b

Cool Reank

Initial Deformation Temperature, of

Soffening Temperofure, op

Fluid Temperature, of
0.25

3.3

8920

11560

Subbit

$2190+230$

$2230 \div 240$

$2280 \pm 240$
11265

12370

HVCB

$1960 \pm 70$

$2030+70$

$2250+200$ 
and instrumentation, specific requirements are ifemized for the area under discussion.

Where applicable, design criteria have been prepared premised on utillizing both the Montana sub-bituminous and lllinois bituminous coal as specified in Table 4-1. The principal design basis for the ETF will be the Montana Rosebud sub-bituminous coal.

\subsubsection{Coal Handling}

4.4.1.1 System Description - A railroad siding is to be provided for unloading coal from bottom dump hopper cars. The siding will hove a thow shed equipped with oil fired hecters to facilitate coal unloading during severe winter conditions. Unloading operations will be conducted in an enclosure adjacent to the thaw shed. The enclosure will provide weather protection for the unloading crew limit dust dispersion during unlocading and provide structural support for a car shaker. A car puller will be required for moving cars through the unloading station. The weight of inconing shipments will be recorded through the use of either a irack or bels scale.

Coal from the hopper cars will be discharged into a two compartment track hopper. Feeders located at the rrack hopper oullets will regulate the flow of coal to a stockpiling conveyor or conveyor system. Coal discharged from the stockpiling conveyor(s) will be automatically sampled for analysis on an "as received" basis, and deposited in a conical pile via telescoping chutes or lowering rubes designed to minimize dust dispersion. Rubber tired coal movers will transport coal from the conical pile and compact it in open storage piles. Separate storage piles will be maintained for each hype of coal to be tested in the ETF.

Coal will be reclaimed from storage and delivered to a reclaim hopper by rubber tired coal movers. Variable rate reclaim feeders at the reclaim feeder outlers will regulate flow to a 
conveyor or conveyor system for transportation to surge bins in the coal processing area. Cool delivered to the surge bins will be automatically sampled. A cross-belt magnetic separam for at the head of the surge bin supply conveyor will remove tremp iron from the coal stream.

The surge bins will provide segregated live storage for two types of coal. Feeders and conveyors from the surge bins to the coal crushers will have the capability of blending the cool being rested and delivering the blend to parallel crushermpulverizer channels.

Dust collection or suppression equipment will be provided at the supply and reclaim areas. Dust collection at the surge bins will be provided by the system serving the coal processing area.

4.4.1.2 Functional Requirements - The unloading equipment and conveyors delivering the coal to stockpile will be designed for operation 10 hours per day, seven days per week.

Reclaim feeders and conveyors to the surge bins will be designed for operation 16 hours per doy, seven doys per week.

The system delivering coal from the surge bins to the crushers will be designed for operation 24 hours per day, seven days per week.

4.4.1.3 Design Basis - The unloading system will have the capacity to unload $100 \mathrm{~T}$ hopper cars in an eight hour shift with conveyors operating of 75 percent efficiency.

Areas designated for open storage of coal shall provide a storage capacity equal to a 30 day (720 hour) supply at the ETF design rate.

Reclaim feeders and conveyors to the surge bins will be designed to handle the daily ETF design ralle coal requirement in 16 hours with conveyors operating at 75 percent efficiency. 
Surge bins providing live storage for the crushers shall have a capacity equal to 10 hours consumption at the ETF design rate. Surge copacity is required to provide operational flexim bility in testing a coal blend and to provide time for unscheduled maintenance. In addition, the capacity is infended to eliminate the need for reclaiming operations on the third shift.

Feeders and conveyors supplying the crusher-pulverizer channels shall have a capacity 25 percent greater than the ETF coal consumption design rate.

Automatic sampling systems are to be designed in accordance with ASTM standards.

4.4.1.4 Safety and Operating Safeguards - Conveyor and related equipment will be designed and installed in accordance with ANSI specification B20.1, 1972, "Safety Standards for Conveyors and Related Equipment".

Audible and visual alarms will be provided to alert personnel to car pulling operations and the impending startup of remotely controlled or automated belt conveyors.

The surge bins will be provided with high level and low level indicarion as well as "full bin" sensing to shut down reclaiming operations.

Conveyor transfers will incorporate plugged chute detection to shut down the conveying system and minimize spillage.

Electrical devices and wiring in Class 11 , Division 1 or 2, Group $F_{p}$ hazardous areas are to be explosionmproof.

4.4.1.5 Maintenance - Walkwoys are to be provided along one side, the entire length of each conveyor. 
Conveyor drives are to be accessible on three sides, from permanently installed maintenance platforms.

Monorails or hoist beams are to be provided to facilitate the replacement of conveyor drives and feeders.

Bin and hopper outlets will be equipped with manual cutoff gates to facilitate feeder maintenance or replacement.

4.4.1.6 Instrumentation and Controls - The car puller, car shaker, and unloading feeder and conveyors will be manually controlled from a local station. Conveyor(s) and feeders will be electrically interlocked to insure operator safety and prevent damage to equipment.

Controls for the reclaim system, feed system to the crushers, magnetic separator, and diverier gates will be located with the coal processing controls.

The control system will monitor the functions of the coal handling system and will alert the operator to abnormal conditions. The controls will provide interlocks and trip functions as required.

\subsubsection{Coal Processing}

4.4.2.1 System Description - An incoming belt conveyor from the coal handling system brings unwashed, wet and/or frozen coal from the storage pile reclaimer. Coal processing consists of crushing and pulverizing, drying, coal dust fines recovery, inert dry coal storage, and lock hopper pressurization. The processed coal is transported by a pneumatic flow pipe, or pipes, to the combustor. 
4.4.2.2 Functional Requirements - The coal processing facility must function to provide properly sized free flowing coal for the combustor at its design pressure. If will operate continuously for periods of up to 2000 hours. Component redundancy will be provided, where necessary, for reliability. Sufficient storage of sized dry coal will be provided so that normal maintenance for replacement of wear plates can be perfomed on the crushers or pulverizers. As specified in a subsequent section, in order to maintain normal system coal firing rate following a maintenance shutdown, it is necessary that some equipment be specified for greater than normal coal processing capability. In addition, dry coal feeding and pressurizing systems are not sufficiently reliable to expect 2000 hours continuous operation without shutdown for a single truin of equipment. Therefore, one spare set of lock hopper equipment should be installed to maintain flow to the combustors should starwheel feeder and/or isolaticn valve adjustment or replacement be required. However, belt conveyors, bucket elevators, dryers, etc. are normally reliable enough to function continuously for 2000 hours and receive major maintenance exclusively berween test runs.

4.4.2.3 Design Basis - Incoming coal conveyor, coal crusher, coal pulverizer, crushed or pulverized coal transporter, coal dryer, and dried coal transporters shall be designed with a $25 \%$ margin over nominal system design rate. Coal sizing and size distribution requirements are to be specified consistent with the type of combustor design and method of coal tronsport employed. The specification is to be based on weight percent passed through a specific sieve size.

Coal drying following sizing shall be performed in a fluidized bed dryer using either air heated by clean fuel, air heated by steam inside tubes in the fluidized bed, or hot products of MHD combustion. The choice of altematives is to be made based on cost effectiveness of each scheme plus an assessment of the reliability problems introduced. The degree of dryness is to be specified. Representasive minimum values of moisture would be $2 \%$ for the Montana Rosebud caal and $0 \%$ for the Illinois bituminous coal. More probable moisture based on cost and reliability moy be $5 \%$ and $2 \%$, respectively. 
Coal dust fines recovery shall be incopporated via cyclone and/or bag filter installations. This installation shall be speciried and designed to assure that particulate emissions are in compliance with regulatory requirements. In general, dust loss should be minimized to ciscoin high overall energy efficiency.

Sool storage following drying shall be for eight hours capacity, in bins ineried with products of combustion.

Coal is to be conveyed by belt conveyor or bucket elevator ot otmospheric pressure. Pul= verized coal conveying is to be by dense phase air transport.

Look hoppers shall be designed for 20 minutes or longer full-to=emply cycle rime, and shall be copable of operaring of half that cycle time. Pressurization is to be by compressed sîack gas.

System nominal capacity shall be bosed on a thermal input to the combustors which is 10 percent above that required to achieve full electrical output from the MHD channel. Nominal capaciries for feed rates and drying shall be based on the most demanding conditions represented by the use of either type of coal specified.

Turndown of the coal processing system to meet specified requiremenis shall be accomplished by reduction in coal rate from the reclaimer, reduction in dryer heat input, lengthening of lock hopper cycle time, and reduction in starwheel feeder rotation rate. The furndown capability will be sufficient to handle the extremes represented by the two coal types specified.

\subsubsection{Safety and Operating Safeguards - Areas containing coal dust in suspension with air must be designed in accordance with Class II, Group F electrical classification. Sources of fugitive dry coal dust shall be enelosed and mainfained under slight negative pressure via a bag filter/Blower installation to insure that dust emissions are held within EPA and OSHA}


rules. Suitable protection against respirable dust must be provided for personnel working in areas where those nuisances cannot be otherwise controlled.

4.4.2.5 Maintenance - Wear plates and other short life parts in the crushers or pulverizers must be capable of replacement in an eight hour period.

Special provisions shall be made to assure easy maintenance and replacement of lock hopper equipment on one unit while the other is in operation.

4.4.2.6 Instrumentation and Controls - Instrumentation shall be of a type suitable for service in dusty, high vibration environments. Local manual control, safery interlocks and fail safe design shall be incorponated into all conveyors, elevators, crushers, pulverizers, and lock hopper systems, so that local stations can permit shutdown of a malfunctioning unit with interlocks to prevent coal from feeding into shut down equipment.

A control station capable of controlling and monitoring coal operations from the reclaiming area to the lock hoppers shall be provided. This control station may be in the coal processing area or in the ETF central control area, but in any event must be integrated with central control to provide single point operations responsibility.

\subsubsection{Air and Oxidant Supply}

4.4.3.1 System Description - Normal atmospheric air at site conditions enters the system at the inlet to the air compression station suction filters, is compressed and delivered to the preheat equipment. If oxygen is used, it shall be obtained as $95 \%$ pure oxygen in liquid or gaseous form from local or remote facilities and fed as a pressurized gas for blending with the preheated air prior to combustion. 
The air compression system will consist of ambient air filtration, large oil-free axial flow air compressors without inter or after cooling, air flow control and measuring instrumentation, compressor drives, and cooling and mechanical lubrication equipment.

For those conceptual designs requiring $\mathrm{O}_{2}$ enrichment, the oxygen system will consist of receiving equipment from tank car or tank trucks, or supply piping from a supplier owned gaseous or liquid oxygen air separation facility, or possible combinations thereof. Other components of the system consist of any necessary oxygen storage tanks, liquid oxygen pumps and forced air or water heated liquid oxygen vaporizers, plus oxygen flow control and measuring instrumentation.

4.4.3.2 Functional Requirements - The air and oxygen facilities must function to provide oxidant at an appropriate pressure for the MHD combustor continuously for periods of up to 2000 hours at any one time.

The large air compression equipment shall be sufficiently reliable to permit 2000 hour test runs. Highly reliable multiple compressors and drives coupled with redundancy in such areas as lubrication pumps shall be used to achieve this. Because of their vulnerdbility to shaft seal problems, 100 percent redundant liquid oxygen pumps shall be provided. Liquid oxygen vaporizers that use forced draft ambient air may require auxiliary heating for the portion of the year that freezing rain is experienced at the site. Depending on the specific climatic conditions at the site, consideration should be given to the cost effectiveness of vaporizing axygen via a direct, clean fuel fired vaporization system using hot water or steam to transmi t heat from the bumers to the oxygen vaporizer tubing. 
The optimum supply arrangement for oxygen to the MHD-ETF, if utilized, will depend on the finally determined quantily needs and hest runs. Combinations of an on site air separation facility and delivery from a remote site coupled with the potential for reliquefaction from storage tanks should be investigated to determine the most cost effective solution.

4.4.3.3 Design Basis - Compressor air filters shall be designed for no more than five inches water $\triangle P$ at design rate when dirty. Provision for shanging primary elements in two stage filters shall be provided for installing clean primary elements while in operation.

Air compressor design capacity shall be five percent higher than the maximum air flow required; i.e., 1.1 x stoichiometric for the coal type (Illinois "It6 Seal) requiring the most air for combustion.

Air flow control based on venting, suction throttling and multi-compressor installation shall be used for anti-surge and tumdown. Priority consideration will be given to sieam rurbine drives using self-generated steam.

Oxygen gas shall be blended with the oil free air to provide the desired oxygen concentration in the gas flow to preheating.

\subsubsection{Safery and Operating Safeguards - Areas and equipment exposed to liquid} oxygen should be designed with full cognizance of the "Aerospace Safety Research and Data Institure (ASRDI) Oxygen Technological Survey, Volume IX, Oxygen Systems Engineering Review", National Bureau of Standards, Cryogenics Division, Boulder, Colorado. Cleaning for oxygen service should be rigorously observed, in accordance with "ASRDI Volume II, Cleaning Requirements, Procedures and Verification Techniques".

Strict control of smoking, open lights, fires and welding must be exercised to exclude them from areas where oxygen leakage may occur. 
4.4.3.5 Maintenance - Equipment provided with cooling water (air compressors, lube oil coolers, etc.) will be shellered to permis maintenance in the winter without freezing.

Major emphasis shall be placed on providing clean air and water as a means of reducing mainienance needs on the axial flow compressors. Dirt in inlet air reduces compressor efficiency and can seriously damage rotating parts. Dirt in cooling water can foul bearing and seal cooling passages resulting in the ir failure. Air and water filtration, coupled with adequate protective controls, shall be provided.

Systems handling oxygen and oxygen enriched air are to be kepi oil free and require special precoutions to eliminate organic materials. Gaskets, seals, etc., are to be non-combusible. The entire piping and equipment train from oxygen source through to the combustor is to be specially cleaned and sealed for oxygen service.

4.4.3.6 Instrumentation and Controls - Instrumentation shall be of a type suitable for service in oxygen and high vibration environments. Anti-surge control and failsafe design shall protect the axial flow compressors. Oxygen and air flow shall be interlocked so that oxygen cannot flow backwards through the air compressors.

The air and oxygen supply systems will be high reliability industrial equipment. As such, instrumentation should be primarily limited to that necessary for control. Instrumentation fo: diagnostics and verification will be minimized.

\subsubsection{Seed Storage and Feed}

4.4.4.1 System Description - Seed is available as a heavy industrial chemical, consumed in quantity by the glass industry as $99 \%$ pure $\mathrm{K}_{2} \mathrm{CO}_{3}$. It is manufactured by carbonating potash $(\mathrm{KCl})$, and is available "calcined" as the $99 \%$ pure material. 
The seed storage and feed system receives dry bulk carbonate of potash in free flowing granular form at a truck/rail lcar unloading station and delivers dry seed at the exit of lock hoppers in a pneumatic flow pipe at combustor pressure.

The seed receiving, storage and feeding facility will consist of railcar and/or truck unloading, inerted dry seed storage bins, seed material conveyors and elevators, and lock hopper seed pressurization equipment. It is assumed that the fresh seed, as purchased in bulk, is dry, granular, free flowing, and requires no grinding or drying in this facility.

\subsubsection{Functional Requirements - The seed storage and feed facility must function} to provide the regulated quantity of free flowing, fresh, dry carbonate of potash at combusior pressure. If will operate 24 hours per day, seven days per week, for periods of up to 2000 hours at any one time. Some equipment redundancy must be provided. Specifically, sufficient storage of seed must be provided so that normal deloys in receiving a railcar or truck load will not shut down an MHD test. Dry seed feeding is not sufficiently reliable to expect 2000 hours continuous operation withour shufdown of a single train of equipment. Therefore, one spare sei of lock hopper equipment should be installed to maintain seed flow to the combustors should starwheel feeder and/or isolation valve adjustment or replacement be required. Seed conveyors and elevators are normally reliable enough to function continuously for 2000 hours and to receive major maintenance exclusively between test runs.

\subsubsection{Design Bosis - Incoming seed hopper, conveyors, elevators and other transfer equipment shall be sized to transfer seed into dry inerted storage so that ai least two 100 ton nominal capacity railcars could be unloaded per shift.}


Fresh seed storage shall be provided for a minimum of two poillears capacity, or very approximately 240 rons of carbonate of portcsh. Two 120 zon silos would provide a railear plus a $20 \%$ heel in each tank, and would supply about two days* of seed makeup. Depending on logistics of supply, it may be necessary to supply much more than this minimum storage.

Seed is to be conveyed by screw conveyor or bucket elevator at atmospheric pressure. Seed conveying at pressure is to be by dense phase dry air transport.

Lock hoppers shall be designed for 20 minutes or longer full to-tompty cycle rime, and shall be capable of operating at half that cycle time. Pressurization is to be by compressed stack gas.

System nominal capacity shall be based on $10 \%$ above that required to achieve full system thermal input to the MHD channel, when the channel is fired on whichever coal requires the greatest seed flow rate.

Turndown shall be provided by lengthening of lock hopper cycle time and reduction in stapwheel feeder rotation rate.

4.4.4.4 Safety and Operating Safeguards - The system shall be provided with suitable dust control equipment such as bag filters, and with suitable moisture exclusion provisions to minimize caking of $\mathrm{K}_{2} \mathrm{CO}_{3}$ in the storage and conveying equipment. Areas containing $\mathrm{K}_{2} \mathrm{CO}_{3}$ dust in suspension with air such as railcar unloading, require the use of dust-tight electrical

*Based on $200 \mathrm{MW}$ thermal, with $15 \%$ fresh seed makeup. 
equipment. Sources of fugitive dust shall be enclosed and maintained under slight negative pressure via a bag filter/blower install lation to insure that dust emissions are held within EPA and OSHA rules. Suitable protection against respirable dust must be provided for personnel working in areas where those nuisances cannot be otherwise controlled.

4.4.4.5 Maintenance - Where, lock hopper feed equipment or solution pumping equipment is provided with redundancy, provision shall be made to do maintenance and checkout of one of the units while the other is operating.

4.4.4.6 Instrumentation and Controls - Instrumentation shall be of a type suitable for service in dusty, high vibration environments. Local manual control, safety interlocks and fail-safe design shall be incorporated into all conveyors, elevators, and lock hopper systems, so that local stations can permit shurdown of a malfunctioning unit with interlocks to prevent $\mathrm{K}_{2} \mathrm{CO}_{3}$ from feeding into shut down equipment. 


\subsubsection{MHD Hot Gas Power Train}

4.4.5.1 System Description The MHD Hot Gas Power Train in the MHD-ETF facility is defined here to include the combustor (or combustors), the nozzle, and MHD channel and finally, the diffuser. This sequence of components consititutes the major portion of the ropping cycle of the MHD/steam combined power cycle. As a unit, the power train must interface with the coal and seed feed systems, the preheated air ducting, the slag reject system, the magnet assembly, the recirculating cooling water system (or systems), the power conditioning apparatus, and finally, at the downstream end, the radiant boiler assembly. The power train flow axis is horizontal (except perhaps at the combustor) with each component intersaced end-to-end to allow the hot combustion gases to pass through each suscessive component without obstruction or leakage. The components themselves are pressure vesells that are heavy metal wall or rib-type construction, insulated or fire bricked and water cooled. The assembly is beam and girder supported and pad mounted.

\subsubsection{Functional Requirements - The overall functional requirement of the Hot Gas} Power Train is to first combust coal with preheated, high temperature air producing a high temperature, electrically conducting plasma. The addition of an easily ionizable seeding material is required to achieve adequate electrical conducting properties. Then, the plasma is accelerated to a high, subsonic Mach number to properly interact with the magnetic field that is imposed across the channel in order to produce an electric field from which energy can be extracied. The pressure and temperature of the plasma are reduced in this process. The final requirement of this power train is to decelerate the channel exhaust gas to recover its kinetic energy and provide a transition to the flow cross-section of the radiant boiler.

This power train cssembly must operate reliably 24 hours a day, seven days a week for periods up to 2000 hours, producing the rated dc electrical output. Part load operation of the power train is to be achieved consistent with requirements for operation to $40 \%$ of plant total rated output. This will at least involve reducing channel mass flow. In addition, the power train assembly must be capable of startup and shutdown in accordance with requirements and facility 
procedures. A rapid shutdown for certain events moy be required. Provisions and designs should be established that allow rapid shurdown of the power train with minimum structural damage.

Following scheduled tests, replacement, repair and/or inspection of power train components may be required. Disassembly procedures of the power train are to be established.

\subsubsection{Design Basis}

Combustor - A multi-stage combustor is assumed which receives the coal from the processing plant, the oxidant (air or $\mathrm{O}_{2}$ enriched air) from the oxidant preheating system and the seed material from the seed feed, regeneration and recycle systems. The flow rates of the incoming streams and the allowable pressure drops will be specified by the cycle designer. The fuel will be partially oxidized with obout $60 \%$ of stoichiometric oxygen in the first stage of the combustor. The resultant relatively low temperatures permit slag to be tapped from this stage. Sufficient additional oxidant to raise the oxidant fuel ratio to the desired value (between 0.9 and 0.95 of stoichiometric) will be injected, along with the makeup seed material, into the second stage of the combustor.

The pressure level in the combustor is essentially the same as the total pressure at the channel inlet.

The combustor must provide sufficient residence time for mixing of the fuel and oxidant to insure that the gases leaving each stage are essentially at chemical equilibrium and homogeneous.

The first stage of the combustor must have provisions for trapping and tapping more than $90 \%$ of the coal ash. Slag is normally rejected through a gravity tap to a quench and le tomn tank. These would normally be positioned benecth the combustor assembly. A cyclone type combustor is favored for this dury. 
A system for starting the combustor up from a cold condition must be provided. This will consist of an igniter (propane or natural gas fired), and a startup oil system capable of prom viding $25 \%$ of the full lood thermal input.

The combustor is a fired pressure vessel and all applicable codes and safety standards must be satisfied by its design.

The combustor casing will be formed by walls of tubing cooled by pressurized water. Wall heat losses moy be expected to be approximately $5-6 \%$ of the heating value of the fired cool. This heat may be recovered for use in the bottoming cycle as feedwater heat.

All combustor tubing must be designed and fabricated to satisfy the requirements of the ASME unfired pressure vessel code.

The combustion side surfaces of the tubes will be coated with ceramic or frozen slag under full load operation. Operating procedures must be designed to ensure that a satisfactory coating is established during startup (even with coals that vary from the design specification) and that its integrity is maintained during transients under all system operating conditions and during malfunctions of related equipment.

Nozzle - The nozzle provides the transition from the combustor to the shape of the MHD channel. The combustion products, which will be reducing, enter if from the exit of the second stage of the combustor and are accelerated up to the velocity required by the MHD channel. The transitions, both velocity and cross-section, should be smooth to provide a high efficiency acceleration. In addition to containing intemal pressure, the structure of the nozzle must be designed to resist the aerodynamic pressure forces (combustor pressure=nozzle exit pressures) across it, and the surface must cope with the extremely high heat and moss transfer coefficients that will accompany the acceleration of a dense plasma over a small length. The ash carried into the nozzle should be vaporized but, if the nozzle gas side surfaces are cooled below the 
dew point, there will be sondensation or freezing and the buildup of a layer until equilibrium is attained. The aerodynamic design must include and account for this phenomenon.

MHD Channel - The MHD channel itself serves as the gas expander. The total gas pressure and temperature will decrease along the channel length as de power is extracted from it.

The casing of the channel will have pressurized water cooling and the ASME unfired pressure vessel code will apply to its design. The channel must be structurally supported and constrained (from motion) within the magnet warm bore. Since the channel cross-section is diverging in the direction of flow, removal of the channel from the magnet would be from she downstream end.

Careful design of the MHD channel walls to accommodate the gas stream temperatures without rapid deterioration of performance will be required. The electrodes will be segmented and they may be diagonally connected.

As the expansion proceeds, some of the slag may condense spontaneously in the gas stream and will eventually diffuse to the walls. If a cold or warm wall design is used, the slag and seed will condense on the walls and form an equilibrium boundary layer. Provisions for handling this condensing or freezing slag must be provided without shorting of electrodes or insulators.

To avoid large magnet forces and shunting of flux lines, no magnetic materials should be used in the channel, nozzle, or in parts of the combustor or diffuser consistent with magnetic fringe field analysis.

Electrical leads must carry the current from the electrodes around or through the magnet and its dewar. Provisions must be made to provide a comparible environment (temperature level) for these leads and to electrically isolate them and their electrodes from each other, 
from the equipment and from personnel. The gas path of the channel must be isolated from ground through all possible paths (e.g., air lines, coal lines, water cooling lines).

Diffuser - The goses leaving the MHD channel enter the diffuser where their kinetic energy is converted to potential energy and the transition between the duct outlet and heat exchanger flow path occurs. The gases enter the diffuser at $3500-4000^{\circ} \mathrm{F}$. The pressure rises in the direction of flow and is desired to be near atmospheric when it enters the radiant boiler.

Provisions must be made for tapping any slag that deposits and flows on the diffuser surfaces.

\subsubsection{Safety and Operating Safeguards - A safety system including an inert gas system} for purging the combustor and a flame detector and interlock system to provide for failsafe shutdown of the combustor in the event of a loss of flame or other malfunction must be provided.

4.4.5.5 Maintenance - Due to the fact that the hot gas train components are in the very earliest stage of development, they will require frequent inspections and repair or replacement. These components shall be designed for ease of access and repair or replacement.

Provisions for removal of the duct from its location must include connecting and disconnecting the cooling water supply and electrical leads.

Access to the interior of the combustor will be required for removal of undesirable slag deposits and for repair of the wall structure.

\subsubsection{Instrumentation and Controls - The instrumentation and control of the hot gas} power train must provide adequate data and a range of operating conditions to verify the performance of these test articles. Instruments shall be capable of operating in an environment (temperature, dirt, grease, etc.) similar to that of a commercial power plant and in the electric and magnetic fields associated with the MHD generator and its magnet. 
For the combustor, instrumentation to meosure coal, air and seed flow rate and inlet air remperciture, ouller gas temperature and pressure and combustor wall temperatures and heat losses are needed. For the MHD generator, the gas pressures and temperatures along the duct, the voltage current characteristics of each electrode pair and the heat losses and wall temperatures along the duct should be meosured. In the diffuser, the gas temperature and pressures and the wall temperatures and heat losses along the diffuser length should be measured. The exit of the diffuser is probably a convenient location to take a gas sample to determine the stoichiometry and the seed percentage to verify the combustor controls and measure seed "hideout" characteristics.

The combustor must have controls to adjust coal, oxidant and seed flow rates to provide load following copability and to permit operation at controlled stoichiometries (in each stage) and with controlled seed fractions. Nomal combustor controls to provide for safe operation and fail-safe shusdown shall be provided.

Control of the cooling water flows of all components will be provided.

\subsubsection{Superconducting Magnet}

4.4.6.1 System Description - The magnet system consists of the conductor (windings), support structure for the windings, the dewar and insulation and the refrigeration system. The coil in a commercial application would be a saddle coil wound onto cylindrical surfaces where the superconductor is constrained against movement by the slots formed by the concentric surfaces. A cylindrical surface is selected to minimize the stroin on the conductor, to maximize the field uniformity within the duct and to maximize the mechanical restraint which can be provided. To minimize cost, the cylindrical surfaces are formed from segments which are bolted together to produce an integral support structure. Since a superconducting magnet operates at cryogenic temperatures, a vacuum insulated enclosure is also provided around the magnet. 
The superconducting magnet of an MHD generator has several principal interfaces. The bore of the superconducting magnet surrounds and interfaces with the MHD channel. It also interfaces with the floor where it imposes large loads. Interfacing is also required with a cryogenic refrigeration system and field exciters. The fringe field of the magnet is a significant interface with any magnetic materials in its proximity.

4.4.6.2 Functional Requirements - The magnet for the MHD generator will be superconducting to ensure high efficiency. The magnet should produce an on-axis (channel axis) peak field of approximately 6 telsa near the entrance to the duct and may taper to 2 to 3 telsa near the channel exit. Uniformity of the field within the channel cross-section must be maintained.

Provision and procedures for magnet charging, startup (cooldown) and emergency shutdown from steady state are required. It is not considered practical to vary the magnet field strength or taper to achieve part load channel operation. Maintaining magnet superconductivity during short term plant shutdown is required.

The dewar and refrigeration system must be capable of maintaining the magnet and its operational temperature with free air ambient temperatures corresponding to site conditions and with the anticipated elevation of remperatures due to the proximity of the MHD channel.

The magnet system must operate reliably for 2000 hours continuous duty at steady state conditions.

4.4.6.3 Design Basis - Since superconductivity exists only within a very small portion of the three dimensional phase space (current density-magnetic field-memperature phase space), sufficient thermal margin must be provided. This is achieved by utilizing a high critical remperature material or improving the conductor stabilization. Conductor stabilization can be improved by increasing the amount of high electrical conducting material in parallel with the superconductor, increasing the available cooling, and by decreasing the potential for conductor movement. 
In the MHD-ETF facility, high strength, light weight, ductile materials are desirable. Consideration of aluminum alloy structural parts and NbTi superconductors should be emphasized; however, steel structures and $\mathrm{Nb}_{3} \mathrm{Sn}$ superconductors should not be overlooked.

The superconductor will require materials tests which include short sample tests of both ends of all superconducting wires and voliage tests of the insulation to ensure the reliable performance of the conductor.

The magnet shall be designed based on the following operating parameters: a) level of vibration (which is usually small in the present MHD systems), b) operating current c) operating temperature, and d) peok magnetic fields within the windings. Selection of parameter values will be in consideration of materials, overall design philosophy and current state-of-the-art.

The superconductor must be constrained against sudden motions and the conductor plus cooling system must be designed to maintain superconductivity under any credible event which could cause conductor normalization.

The magnet system design will include provision for emergency energy discharge. This subsystem must be designed to accommodate the stored energy of the magnet system. The system will be capable of discharging the magnet within 2 minutes (or as otherwise determined).

The bore of the superconducting magnet and cryogenic insulation system must be designed to accommodate the shape of the duct which it encloses, to be compatible with the operating temperature of the duct wall, and under some circumstances to provide support for the duct. The weight and support mechanisms of the superconducting magnet system must be designed to be compatible with the floor load capacity. 
4.4.6.4 Safety and Operating Safeguards - There does not presently exist an accepted or recognized set of illes of siandards for superconducting magnet systems. However, many of the existing general codes and standards (as previously listed) are expected to be applicable to the design of the various magnet subsystems. In addition, the following general guidelines should be observed.

Adequate shielding and/or enforced (monitored) exclusion areas must be provided to protect operating and plant personnel from excessive exposure to magnetic fields.

All machinery, tools and personnel wear used within the magnet must be non-magnetic and personnel should be excluded from the high magnetic field area when the magnet is actuated.

4.4.6.5 Maintenance - Modular coil construction shall be used and access to the coils shall be provided to facilitate repair or replacement of coils.

Any routine maintenance required at intervals less than 2000 hours must be performed remotely. Sufficient excess or redundant capacity will need to be provided to permit plant operation during these intervals.

Major maintenance will center on the refrigeration system. Seals and valves should be routinely checked and/or replaced. Prior to plant startup, the refrigeration system will be operated to verify cleanliness.

Access areas to the magner coils should be provided for visual inspection purposes. Periodic voltage tests of the insulation are to be made to ensure integrity.

4.4.6.6 Instrumentation and Controls - During nomal ETF operation, it is anticipated that the only control required will be on the cooling system capacity. The remperature of the vented coolant will be monitored to insure that a safe operating margin is maintained. 
Controls and instrumentation will be supplied to provide for orderly charging of the magnet during plant startup or discharging at such times as may be necessary for plant maintenance.

\subsubsection{MHD Power Conditioning (Inverper)}

4.4.7.1 System Description - The ETF-MHD power conditioning system will consist of parallel arrangements of inverter circuits and elements. Comprising each inverter circuit are the solid state inverter themselves, inverter transformers, de interrupter, power transformer and an ac circuit breaker. The number of parallel circuits will depend on the channel-electrode design.

The powe: conditioning system will be pad mounted and located in the vicinity of the MHD channel assembly.

The primary interfaces of the power conditioning system are the MHD channel electrode leads and the three phase power transformer located in the facility switchyard.

\subsubsection{Funchional Requirements - The de output of the MHD generator must be inverted to} ac so that it can be transformed to the voltage level required by the grid it is feeding. For the MHD ETF, these inverters must be adaptable to segmented Faraday, two-terminal diagonal wall or multi-terminal diagonal wall generators. In the segmented Faraday generator, the voliage and current produced by each ser of electrodes is applied to an inverter set. Due to the hall potential along the generator length, each of these seis has a different potential with respect to ground and must be effectively isolated from ground. The potential across the inverter set is determined by generator design parameters and the voltage drop at the electrodes and may be different for each electrical pair. For a two terminal diagonal wall generator, all of the electrode segments are connected in series to produce a higher voltage level with a lower total current flow through the inverters. The voltage may not be equal to the sum of the voltages of the Faraday generator since the number of segments in the diagonal generator may not be the same as is the Farsdoy generator. The current and voltage leve!s of the 
multi-terminal generator lie between the other two. Again, all but one set of terminals will be at a potential level above or below ground.

The power conditioning equipment must function compatible with the MHD channel electrical characteristics, and operate reliably 24 hours per day, seven days a week for a period up to 2000 hours.

4.4.7.3 Design Basis - Insulated aluminum bus will connect the MHD channel to de circuit breakers and the solid state, dc-ac thyristor converter valves.

The thyristor failure rate per year shall be less than $0.25 \%$. Failure of one thyristor shall not be cumulative. The thyristors will be connected in series for high volroge and also in parallel to handle the current output.

The control system shall be capable of remote operation. Constant power, automatic current control mode, and manual control modes of operation shall be available. Automatic reduction in var consumption shall be provided under low ac voltage conditions.

The inverter system must include provisions to isolate the ETF facility, the inverters and the grid from each other for all anticipated failure modes and provide adequate energy dissipation or storage to permit orderly shutdown or recovery of the generator.

The inverter system (including transformers) must include power flow control capabilities to permit the MHD generator to continue to feed the grid at reduced loads and under other test conditions that result in an MHD voltage level as low as $1 / 4$ full output levels. 
The output woveform of the inverter system must be acceptable to the grid system being fed and a fail-safe phasing control must be provided for inserting the inverter output into the grid system. Careful consideration must be given to providing a system whose startup and shutdown characteristics are compatible with the MHD generator and the grid system. Success ful operation of thyristors requires a very rapid increase (<1 cycle) to significant current levels ( $\sim 1 / 4$ full load). Such a sudden increase in load on the MHD generator (particularly the two teminal diagonally connected generator) would require a very rapid increase in combustor pressure and temperature. Due to capacitances in the system, this could not be achieved. Some means of matching these choracteristics (such as a shunting resistance) must be provided.

\subsubsection{Safery and Operational Safeguards - A fail-safe system to prevent access to the} inverters and their associated equipment when the MHD generator is operating or the inverters are connected to the grid system will be provided.

Adequate circuit protection must be provided against short circuits, volloge spikes, lightning strokes and switching transients.

4.4.7.5 Maintenance - Reasonable access for maintenance, inspection or replacement of modules will be provided in the design.

\subsubsection{Instrumentation and Control - Measurements of input power and output power} will be needed to determine the efficiency of the inverter system over a range of operating conditions and generator configurations. Adequate element temperature measurements should be made to provide an indication of element overheating.

The inverter system and its associated equipment provide the control of the MHD generator (i.e., for fixed grid system voltage, thyristor firing angles determine the te minal voltages 
seen by the MHD generator terminals). A remote means of controlling these voltages to the exrent required by the generator test program will be provided.

A conirol system for storting up, loading, inserting in the grid, unloading and shutting down the MHD generator will be included in the inverter system design. This system shall be designed to provide maximum protection to the grid system in the event of any malfunction. Maximum protection of experimental hardware will also be provided to the extent it is comparible with protection of the grid system.

Coordination of the control and filtering systems of the dc=ac converters ond the static var control unit shall be provided.

\subsubsection{Air Preheat System}

4.4.8.1 System Description - The air preheat system includes all yalves, ducts, piping and manifolding for air and combustion product gases that are directly related to the heat exchange process. Several alternative approaches to design of the air preheat system will be investigated in the MHD-ETF study. These all will most likely involve a two stage process. The first preheater stage (a low temperature air preheater) will employ the more conventional shell and tube metallic recuperative hear exchanger using as the heat source the MHD exhaust gases. The physical interfacing of this "low remperature preheater system" will be specified from overall power cycle design considerations.

The second stage of air preheat, (the high temperature air preheat system) as assumed in this discussion, will be accomplished in a regenerative (cyclic) type heat exchanger with a ceramic heat storage bed. The bed is alternately heated and cooled by hot gas and air streams. The system consists of multiple vessels where each vessel contains a cored ceremic bed, support struciure for the bed, metallic shell and insulation, and air and hof gas manifolding and sequencing valves. Several regenerator units will operate in parallel to producs a continuous flow of hot air while other units are being reheated by the hot gas stream. For units on air, 
pressurized air from the low temperature air preheater system passes into the air inler manifold and upward through the bed, exhausting into the air outlet manifold. For units onmgas, hor gas enters the gas inlet manifold and passes downward (countercurrent to the air flow direction) through the bed, exhausting into the gas outlet manifold. A set of four main valves per vessel serves to route and sequence the flows through each vessel. Because of the technical uncep= tainties in the direct fired high temperature air preheater, alternate provisions shall be made for a high temperature preheater utilizing combustion products from a clean oil fired burner. Therefore, the following criteria have been generalized to include both types of heater systems. Consideration of the indirect fired preheater would require criteria as specified in Section 4.4 .9$.

\subsubsection{Functional Requirements - The highest anticipoted fllow of compressed air (at} compressor discharge temperatue and pressure) must be heated to the temperature required by the combustor, with limited pressure drop and contamination. This will be accomplished in two stages.

The low temperature air heater system receives air at the compressor discharge temperature and must provide sufficient heat transfer surface to heat the air to the temperature specified for the inlel to the high temperature air heater. Specification of this "crossmover" temperature and allowable deviation is required by design analysis.

The preheoter system will be designed to allow rum-down by approximately $60 \%$ or as otherwise determined. The low temperature air preheater system is required to operate reliably in an ash/seed laden environment, for periods up to 2000 hours continuously.

The high temperature air heater will receive the air from the low temperature heater at specified conditions and must provide sufficient heat capacity to heat the air to the temperarure specified by the power cycle requirements. The air inlet temperature and allowable deviation are to be specified based on design analysis and to be comparible with the low 
temperature air preheater capability. The high temperature air preheater must operate continuously and reliably for up to 2000 hours, delivering the preheated air at the specified flow and peak temperahure and temperature ripple. Tumdown of the system is required consistent with part-load requirements. The air heater system designs must provide capability for startup, shutdown and maintaining integrity during design events as specified in Paragraph 4.3 .6$.

\subsubsection{Design Basis}

a. Low Temperature Air Heater - Construction shall be of the shell and tube type, materials will be compatible with temperature and flow conditions, and the entire unit must be capable for operating for 2000 hours continuously. The temperature levels, gas compositions, pressures and heat duty are to be specified based on system studies. Factors to be considered in these studies are: metal remperature limits; the high temperature preheater design limits; effects associated with seed/slag condensation; consideration of integrating the preheater in the system such as to maximize overall plant performance. The system pressure drop is to be determined from design analysis and consistent with overall facility requirements. Nominal values are expected to be in the range of $1 / 2$ to 1 psi.

b. High Temperature Air Heater - System temperoture level, gas composition, pressure and heat duty will be specified based on the results of systems studies as indicated above for the low temperature air heater.

The checker brick materials utilized in the heaters shall be designed for a design life of 10,000 hours at full rated duty.

The system temparature ripple due to the use of multiple high temperature stored heat bed units shall not exceed $+36^{\circ} \mathrm{F}$ or as otherwise determined. 
Valve cooling water circuitry and valve design shall be established to minimize water requirements. Valves shall also be designed to conform to specified air side/gas side leak losses.

4.4.8.4 Safery and Operating Safeguards - Provisions shall be made to limit access of personnel in the vicinity of valves and piping of the high temperature heaters when in operation. Provision shall be made to safely maintain a single unit if defermined to be necessary for meeting continuous operation requirements.

4.4.8.5 Maintenance - The air preheater systerns will be field erected. Assembly and access, and equipment for in-field service repair must be provided. Such provisions should include both replacement of refractory, cooling tubes and valves.

Provision is to be made for in-field repairs of refractories in ducts and manifolds and removal of accumulation of slag and seed deposits.

Periodic inspection of valves and bed support structure is required.

For the high temperature air heaters, one or more standby heaters will be required.

Bed material and hot gas duct and heater valves will need replacement after some years of service. Provision for change-out should be included in maintenance schedules.

Shell side access will be required on the low temperature heater for soot blowing and steam lancing equipment.

4.4.8.6 Instrumentation and Controls - Gas and air valve controls must be established in accordance to required valve sequencing and timing. Electric motor or pneumatic drive will be required. 
Combustion air and fuel controls system will be required for the separately fired air preheater design. In this case, these controls must also be sequenced with the exhaust gas and air control system.

In-line measurement of pressure drop, temperatures and flow sampling should be provided.

\subsubsection{Clean Fuel Storage/Supply and Burner}

4.4.9.1 System Description - A clean fuel (oil) is to be used for plant startup and for indirect air preheating. The oil comes from railroad tank cars and/or highway tank trucks which are unloaded and the fuel stored. From storage, it is delivered to burners and combusted to provide heat to regenerative air heaters and to coal dryers.

The fuel oil facilities will consist of unloading stations, transfer pumps, starage tanks, supply pumps and filters, and bumers with appropriate air/fuel flow controls and air supply blowers.

\subsubsection{Functional Requirements - The fuel oil facilities must function to provide} hot products of combustion at appropriate pressures and temperatures to heat ceramic bed materials in the regenerative air hearers and as a potential source to dry and thaw coal. They will operate 24 hours per day, seven days per week for periods of up to three months at any one fime. Sufficient storage of oil may be required to permit continuous air preheating for 2000 hours. Studies will determine the role of indirect fired preheaters in testing and development to meet the final MHD-ETF test objectives. If the fuel supply is sufficiently reliable so that de livery of fuel during a rest run can be assured, storage of less than $100 \%$ of that required for the test may be permissible. The supply of fuel oil for utility use in Montana, based on current FPC data, is not a normal procedure so that supply reliability must be carefully considered in sizing oil storage. Oil tanks and oil burners are considered to be sufficiently reliable when handling clean, low sulfur fuels to permit multi-thousand hour hest runs without redundancy other than that normally required such as spare pumps and dual filters. Because of the 
specific climatic conditions at the site, it will be necessary to provide for pump, pipe and tank heating via steam or electric means since No. 2 fuel oil, the most likely oil to be used for MHD-ETF clean fuel, has a pour point of $+20^{\circ} \mathrm{F}$ and will freeze at the minimum ambient of $-40^{\circ} \mathrm{F}$ specified for the site.

In addition to the test run supply mose, if it is decided to use fuel oil for space heating and hot water supply in the MHD-ETF service facilities, separate pumps and piping should be provided for this purpose so that stops and starts in the primary test will not disturb the flow of oil for building services.

Based on decisions relative to the supply of heat for coal drying facilities, fuel oil could be used full time, and not only during startup, in those facilities. This would have a very small $(\sim 2 \%)$ impact on fuel oil consumption if it is also being used for preheater operation.

4.4.9.3 Design Basis - Approximately two 75,000 BBL storage tanks would be required to provide oil for 2,000 hours of air preheat for a $200 \mathrm{MW}$ thermal facility. This represents approximately 200 rail cars or 300 to 400 truckloads of fuel oil.

Facilities for unloading two cars or four trucks per hour would permit day shift only unloading of oil for a 2000 hour test run in two weeks.

Oil pumps and filters shall be provided for at least $50 \%$ over nominal demand to accommodate peak loads from air preheater bumers when low temperature air preheat is not functioning effectively, as at startup.

The design shall provide individual bumers for each regenerative air preheater.

Fuel flow controls shall be provided so that coal drying demand and single burner air preheater

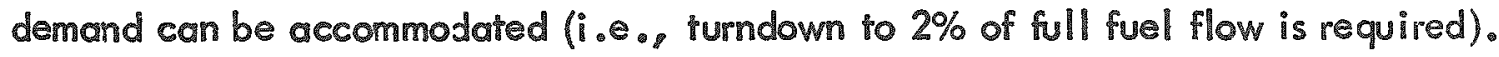


Air supply to the preheater burners at the pressure ( $\sim 5$ to 8 psig) required to promote flow through preheaters, piping and heat recovery equipment should be provided by a multi-stage forced draft Sturtevant type high efficiency blower.

Burners should be ail atomizing single fuel units suitable for No. 2 fuel oil. If required, burners and auxiliary equipment could be provided to use a range of fuel oil, up to No. 6 . However, the cost sovings for low sulfur No. 6 oil compared with No. 2 oil are small or non-existent, and No. 6 oil would not generally be suitable for space heating and other such service facility applications since it is not a free flowing fluid at ambient temparature.

4.4.9.4 Safety and Operating Safeguards - The facility shall be provided with suitable dikes, pump houses, buried fire water supply, and hose stations and extinguishers to meet the requirements of agencies and standards applicable to all storage and transfer areas. Areas containing oil normally in contact with air shall be provided with appropriate NEMA classification electrical equipment. Burners must be supplied with factory mutual approved flame failure safeguards. Suitable protection against noise and hydrocarbon liquids and vapors must be provided for personnel working in areas where those nuisances cannot be otherwise controlled.

\subsubsection{Maintenance - Air blower and burner maintenance can be reduced to a low level not only by protective controls but also by clean air, cooling water and oil. Good filtration of inlet air, cooling water, and oil to the burners is strongly recommended.}

\footnotetext{
4.4.9.6 Instrumentation and Controls - All instrumentation shall be suitable for service in high vibration and hydrocarbon containing environments. Anti-surge control and failsafe design shall protect the combustion air blowers. Air and oil flow controls shall be interlocked so that fuel oil/air explosive mixtures cannot be established prior to ignition excitation.
} 


\subsubsection{Waste Hear Recovery}

4.4.10.1 System Description - The heat remaining in the combustion gas exhausting from the section of the hot gas train is utilized in two ways; first, to regeneratively preheat the combustion air, and secondly, to produce steam for the bottoming plant.

The usual arrangement and succession of components in the direction of gas flow is as follows:

- Radiant steam boiler

- High temperature air heater

- Superheater/reheater/secondary furnace

- Low temperature air heater

- Sream plant economizer

Other componenis in general may be interposed between these (for example, an electrostatic precipitator), but these are not designed to transfer or exchange heat. Design criteria for the high and low temperature air heaters is given in Section 4.4.8. Design criteria in this section deal with the radiant boiler, the superheater/reheater/fumace assembly and the economizer.

In large commercial utility applications of an MHD power plant, these components would all be large, field erected (or modular) structures that would be similar to conventional fossil boilers. The major component materials would be pipe, insulating brick, sheet steel and structural beams and girders.

The waste heat recovery assembly sits in line with the combustion gas flow, interfacing with the diffuser at the upstream end and the stack at the downstream end. Water pipe circuitry interfaces with each system component. The design of the piping systems will depend on the mechanism for heat transfer (convective, radiation or combined). 
4.4.10.2 Functional Requirements - The waste heat recovery train accepts the gas from the diffuser exit (at approximately $4000^{\circ} \mathrm{F}$ and approximately $1 \mathrm{am}$ ) and cools it below the temperature required by the particulare and seed removal system to stack conditions, transferring this heat to a steam bottom plant (or some other heat recovery or rejection system to be determined). In addition, within these components, condisions for gas phase $\mathrm{NO}_{x}$ decomposition must be established and maintained. The decomposition of the $\mathrm{NO}_{x}$ must be to sufficient levels to meet regulatory requirements.

The temperature and pressure of steam generated by the heat recovery system must be at conditions useful to a standard state of the technology turbine generotor unit.

The waste heat recovery train must operate reliably 24 hours per day, seven days per week for as long as 2000 continuous hours at design conditions. Turndown capability and the capability for startup, shutdown and maintaining integrity during emergency events is required, consistent with overall plant requirements.

\subsubsection{Design Basis}

a. Radiant Boiler - The first heat exchanger entered by the gases will be a radiant section. The gas path boundaries will be the tubing carrying the pressurized water coolant. A leak tight casing must be provided. In the full scale plant, this section will be a boiler designed to provide the residence time at temperature needed for decomposition of the $\mathrm{NO}_{x}$ and the gas stream cooling for condensation and tapping of the remaining slag. Gas residence time will be 1 to 3 seconds. The gases will enter at $3500-4000^{\circ} \mathrm{F}$ and should be cooled below the slag melting temperature in this section. The MHD-ETF shall demonstrate the feasibility of the $\mathrm{NO}_{x}$ control scheme, the adequacy of the rechniques for handling the slag and the seed and the integrity of the component designs under commercial operating conditions. To do this, the time-temperature history of the gas, 
the surface remperatures, the flow pattersns, the gas composition and the heat fluxes in the MHD-ETF heat recovery system should simulate or scale those of a commercial sized MHD power plant.

Design of the radiant boiler will require provision for slagging water walls. Collection of the ash that is condensing on the walls of the radiant boiler and rejection of this liquid slag is required. A slag tap and quench tank (or pit) must be provided.

The heat load to the radiant boiler section will be specified. Both the inlet and exit gas temperatures of the radiant section are constrained. This inlet gas remperature is fixed by consideration of the temperature of the gas at the exit of the diffuser. This would normally be maintained above a level where the gas is still electrically conducting. This in part depends on seeding level, gas composition and pressure. The temperature of the gases exiting the radiant section must be below the level required by $\mathrm{NO}_{x}$ control. Selection of materials for design must be based on reducing gas at elevated temperature conditions. Corrosion/erosion allowances must be established through design analysis.

Pressure drop allowance is to be specified from system considerations. The inlet pressure level, however, will be limited to only slightly above atmospheric conditions, compardble to conventional fossil boiler designs.

b. High Temperalure Air Preheater - Substitute - Provision must be considered for placement of a substitute for the direct fired air preheater in the ETF in the event it lags development of the rest of the system. The interfacing conditions between this component must be identical to those that would be encountered if a direct fired air heater were employed. The design of this component and its cooling equipment must recognize these constraints. The 
cooling system, however, may be designed to reject its heat directly to the cooling tower and be independent of the steam bottom plant heat recovery system.

c. Superheater/Reheater and Secondary Furnace - Design heat loads, temperature level, pressure and gas composition will be specified. Steam conditions are to be specified based on selection of the bottom plant configuration. The inlet gas temperature to the superheater/reheater assembly will be above the condensation level of the seed vapor. The remparature at the exit of this section will be below the seed condensation levels. Also, these temperature levels will be such that equilibrium levels of $\mathrm{NO}_{x}$ should satisfy EPA require- . ments. For these reasons, it is convenient at this station to inject sufficiunt secondary air to raise the oxygen to fuel ratio to approximately 1.05 times its stoichiometric value. Sufficient mixing of the two streams and residence time of the products must be provided to complete combustion of the $\mathrm{CO}$ and to insure homogeneity of the products. These criteria will be utilized to establish secondary furnace design.

Once the combustion gases hove been cooled below the freezing point of the seed, and decomposition of $\mathrm{NO}_{x}$ established, modeling of the time temperature patterns, surface temperatures and heat fluxes in subsequent components is not required.

Designs must account for deposition and/or agglomeration of the seed and ash particles. Dust loadings are to be specified. Material selection and design gas velocities are to be specified in consideration of corrosion/erosion allowance.

Gas side pressure lasses on these heat exchangers will be determined by tradeoff studies. Warer side pressure drope are to be determined by accepted design practice. 
Provision for collection and recovery of seed/ash particles will be made.

d. Economizer(s) - Heat loads, temperature level, pressure and gas composition will be specified. Design of the economizer section will be in accordance to parameter values specified.

Water side conditions will be specified based on cycle tradeoff studies. The design shall be tube and shell, with tube spacing and gas flows in consideration of specified dust loadings.

Tube wall temperatures shall not exceed values that promote condensation of corrosive forming sulfur compounds from the combustion goses.

4.4.10.4 Safety and Operating Safeguards - All components must satisfy ASME unfired pressure vessel codes.

4.4.10.5 Maintenance - Fouling, blockage and corrosion of tubes and walls of channel passages is anticipated. Each component design of the waste heat recovery system will provicie access areas for soot blowing and/or steam lancing equipment.

The waste heat recovery system will consist of field erected assemblies and must be designed for in-field service such as tube replacement and other minor repairs.

4.4.10.6 Instrumentation and Control - The following system instrumentation is required:

- Instrumentation to measure gas pressure drop and temperatures.

- Measurement of water coolant flow and temperatures.

- On-line gas sampling and analysis to determine stoichiometry and $\mathrm{NO}_{x}$ levels.

Controls to regulate secondary air flow and water coolant flow rates shall be provided. Control points and control logic will be determined from cycle definition. 


\subsubsection{Solids Recovery and Seed Reprocessing Systems}

There are five separate seed reprocessing systems to be considered. One, termed seed regeneration, converts potassium sulfate seed to potassium carbonate. The converted seed is added to the second stage of the combustor. This system replaces the $\mathrm{SO}_{x}$ scrubber, and can be economically substituted for a scrubber for low sulfur coals. Operation of this system san be either concurrent with, or independent of, the operation of the MHD plant. The second system, termed seed recycle, recovers potassium sulfate seẹd from the seed-slag strean from the seed removal systems and returns a dried, powdered seed to the second stage of the combustor. This system lowers the loss of seed from the MHD plant and decreases the amount of readily soluble material in the slag. If a hot gas stream for drying is provided, this system may be run independently of the MHD plant; otherwise, it must be run as part of the MHD system. Figure $4-2$ shows a schematic diagram of these two systems and the three major interface systems (seed quench, seed transport to processing, and processing seed transport) and components of these systems with the MHD hot gas power train. Either one or both of these systems may be operated. The MHD system may be operated without either of these systems provided sufficient seed is available on site in the proper chemical form.

\subsubsection{System Description}

a. Seed Regeneration - A seed/ash powdered mixture from the electrostatic precipitator, and seed/ash slag lumps from other intermediate equipment, will be recovered using the seed quench system and transported to either the seed recycle system, seed regeneration system, or the processed seed system. Regenerated seed/ash mixtures, in the form of four mesh pellets, will be transported pneumatically to either storage or the combustor using the processed seed transport system.

This facility will consist of pelletizing, seed regeneration, fuel gas generation, and gas cleanup systems. The pelletizer, fed by the seed 


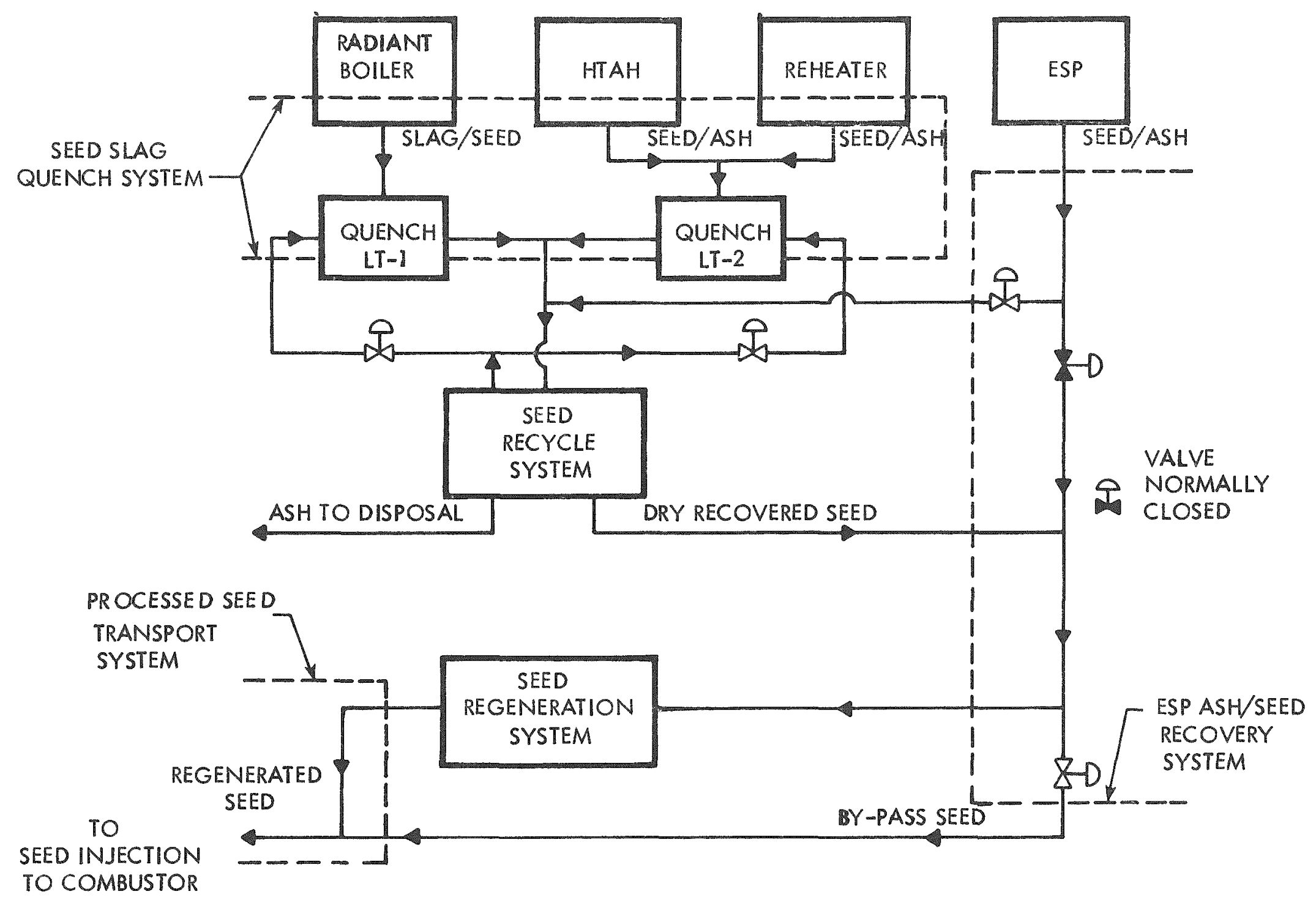

Figure 4-2. Seed Ash Processing (Overall) Flow Diagram 
quench system, provides approximately four mesh pelleis. The four mesh pellets are then fed to lock hoppers, and then into the regeneration vessel Regeneration is by means of the following chemical processes:

$$
\left.\begin{array}{l}
\mathrm{K}_{2} \mathrm{SO}_{4}+4 \mathrm{CO} \rightarrow \mathrm{K}_{2} \mathrm{~S}+\mathrm{CO}_{2} \\
\mathrm{~K}_{2} \mathrm{SO}_{4}+4 \mathrm{H}_{2} \rightarrow \mathrm{K}_{2} \mathrm{~S}+2 \mathrm{H}_{2} \mathrm{O} \\
\mathrm{K}_{2} \mathrm{~S}+\mathrm{H}_{2} \mathrm{O}+\mathrm{CO}_{2} \rightarrow \mathrm{K}_{2} \mathrm{CO}_{3}+\mathrm{H}_{2} \mathrm{~S}
\end{array}\right\} \text { Reduction }
$$

The iegeneration vessel, a fixed bed reactor, then discharges its pruduct to the processsed seed transport system. Gas for the regenerator, at rbout $1100^{\circ} \mathrm{K}$ and I atmosphere is supplied by an air blown cool gasifier The gas cleanup system is a Stretford unit which removes $\mathrm{H}_{2} 5$ from the process gas stream, and produces a solid sulfur product.

b. Secil Recycle - Recycled process water is used to dissolve the solubte ... ponents of the slag (mainly $\mathrm{K}_{2} \mathrm{SO}_{4}$ ), which are then dired und sent to th. seed transport system.

Seed/slag mixtures from the MHD seed quench system will be conveyed to the mixing tank. The final product, powdered seed, will be pneumaticall, conveyed by the seed tranport system to seed regeneration or the process:ae: sced transport system. The waste solids will be removed from the process stream by a rotary filter and conveyed to the ash disposal pits.

The seed recycle facility consists of:

- A warer preheater to preheat the inlet process water to about $180^{\circ} \mathrm{F}$ using steam.

- A mixing tank to produce a saturated solution of potussium sulfate. 
- The pressurized, rotary filter, fed by a pump connected to the storage tank, which removes ash entrained with the saturated seed solution.

- An Oslo type crystallizer for producing $\mathrm{K}_{2} \mathrm{SO}_{4}$ crystals by lowering the process stream temperature to $130^{\circ} \mathrm{F}$.

- A rotary filter and turbo dryer to remove the crystals and dry them.

The MHD exhaust gas used in the above process is split from the main MHD exhaust stream after the electrostatic precipitator. After the gas is used, it is refurned to the waste heat recovery unit.

\subsubsection{Functional Requirements}

a. Seed Regeneration - The seed regeneration facility must function to provide regenerated seed (potassium carbonate). It may operate 24 hours per day, seven days per week, for periods of up to 2000 hours at any one time. Some equipment redundancy must be provided. Specifically, sufficient storage of regenerated seed will be provided so that normal maintenance can be performed on the seed regenerator and gas supply facilities. A larger stockpile of regenerated seed may be provided if it is desired to operate the MHD plant independently of the seed regeneration system. Belt conveyors, penumatic conveyors, etc., are nomally reliable enough to function continuously for three months and receive major maintenance exclusively between test runs.

b. Seed Recycle - The seed recycle system delivers powdered seed material to the seed transport system at atmospheric pressure. It may operate 24 hours per day, seven days per week, for periods of up to 2000 hours at any one time. To satisfy anticipated maintenance requirements in the rotary filters, stockpiles of $\mathrm{K}_{2} \mathrm{SO}_{2}$ are required. If operation of the MHD plant independent of the seed recycle system is desired, then a larger stockpile of 
reclaimed seed may be required. The seed processing section is sized for a greater than nominal processing rate. The redundant component are the feed pumps and rotary filters. Other equipment such os the conveyors, turbo dryer, crystallizer, and heat exchangers are considered reliable enough to function continuously for three months and receive major maintenance exclusively between test runs.

4.4.11.3 Design Basis - Incoming seed/ash pneumatic conveyor, pelletizer, peller conveyor, seed regenerator, gas supply system, gas cleanup system, and regenerated seed conveyor shall be at least $25 \%$ over nominal system design rate.

a. Seed Regeneration - Seed regeneration shall be performed in a countercurrent fixed bed reactor using fuel gas formed in an air blown gasifier, methane or other petro-chemical feedstock. The choice of alternatives is to be made based on cost effectiveness of each scheme plus an assessment of the reliability problems introduced by using a coal gasifier as a source of gas in an MHD unit of developmental nature.

Seed is to be conveyed by pneumatic or water systems at atmospheric pressure. Seed/ash conveying from the electrostatic precipitator is to be by low pressure air transport.

Tumdown versus intermittent operation at design shall be provided for the gas supply, and cleanup conditions shall be examined to meet the specified requirement of the MHD-ETF to operate at rated and part power conditions. In general, furndown of the seed regeneration system, if necessary, shall be accomplished by reduction in the seed feed rate to the pelletizer, and reduction in fuel gas input.

b. Seed Recycle - The incoming seed/slag quench system, the water preheate, and the mixer shall be sized of the nominal system design rate. 
The pump rotary pressure filters, crystallizer, rotary vacuum filter, and turbo dryer are to be sized at least $25 \%$ over nominal system design rate.

Water heating shall use steam and seed drying shall use the hot MHD exhaust from the electrostatic precipitator. After use, this gas will be returned to the waste heat recovery system.

The seed recycle system, will operate at a little above atmospheric pressure. The rate of seed recycle shall be normally dictated by the rate of seed/slag input. However, the processing section of the seed recycle system can be operated at a different rate by a decrease or increase of the flow rate from the solution supply pump. If a tundown of the whole system is desired, the supply pump flow rate, and the hot MHD combustion gas supply rates are lowered proportionately.

4.4.11.4 Safety and Operating Safeguards - Sources of fugitive seed dust shall be. enclosed and maintained under slight negative pressure via a bag filter/blower installation to insure that dust emissions are held within EPA and OSHA rules. Suitable protection against noise and respirable dust must be provided for personnel working in areas where those factors cannot be otherwise controlled.

4.4.11.5 Maintenance - If a coal gasification plant is used to supply the needed fuel gas to the regeneration system, additional between shutdown maintenance will be needed for the coal and slag handling equipment (especially lock hopper systems).

Maintenance on items in the recycle system between shutdowns include the filter media on the rotary filter and the pumps. However, these should be easily replaced within the une day inventory time and should not cause a disruption of the MHD system.

4.4.11.6 Instrumentation and Control - No specialized requirements or criteria have buen identified at this time. 


\subsubsection{Heat Rejection}

\subsubsection{System Description - Steam at conditions of pressure and temperature which could}

be used in a "state of the technology" turbine generator set will be generated by the waste heat recovery system. (It is assumed in the remainder of this discussion on the heat rejection system that this is 2500 psia, $1000^{\circ} \mathrm{F}$ ) 0.0 the basis that a turbine generator is not initially planned in MitD-ETF, the design objectives will be to investigate a baseline heat rejection system that will allow for easy installation of the $T / G$ unit at a future date. An alternate heat rejection system is considered on the assumption that no $T / E$ unit would be added during the useful life of ETF.

a. System for Future Turbine Generator Installation - In this case, steam will be pressure reduced, desuperheated and then condensed. This will require the same condenser as if a turbine-generator were imposed in the system. Cooling water for this condenser will be provided by a water cooling tower and pump system which will reject the system heat to the atmosphere.

b. $\quad$ No Frovision for Future Turbine Generator Installation - If no iurbine generator is used in the ETF, the steam to be condensed will be available at high temperature and pressure (low specific volume). This condition lends itself to the use of direct air cooling. The high temperature differentials reduce surface area required and the high temperature levels should be conducive to use of natural convection. Furthermore, high pressure condensation reduces the need for flashing (throttling), pumping requirements, water consumption, and air ejection. Consideration will be given to a dry cooling system sperating at an elevated temperature and pressure.

\subsubsection{Functional Requirements - Each component of the system has an interrelated duty} which must be satisfied for total system functioning. To the extent possible, this interrelationship will simulate that which would occur with an actual turbine generator installed in the plant. 
Pressure Reducing - Steam pressure will be reduced to protect condenser from overpressure. Components will automatically function to deliver the proper condenser pressure with varying steam flow and cooling water temperature. Components must sustain pressure reducing function for the entire 2000 hour test run.

Desuperheating - Steam will be continuously desuperheated to provide predictable conditions in the condenser within the operating capability of the condenser design.

Steam Condenser - The steam condenser must be capable of operation of the initial higher $\Delta T$ across the heat exchange surface without cooling water side fouling. Unit must be capable of handling initial heat flux and condensate drain out duty as compared to functioning with turbine generator. Pressure drop on steam side must be sized to maintain

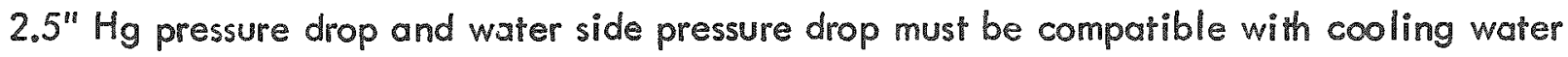
pumping system. Under conditions of cooling water temperatures and chemistry, the condenser must have the capability of sustaining the minimum heat transfer system rate for 2000 hours.

Cooling Tower - This atmospheric heat exchanger must be large enough to reject the total condenser heat load under the most difficult conditions of temperature and humidity. Ces ing tower structure to be designed for wind pressure of 25 to $30 \mathrm{lbs} / \mathrm{ft}^{2}$ depending on M.sntane. location. Unit must have a life expectancy of total project life. Chemical feed to protect all materials must be provided plus algicide to control algae growth.

Cooling Water Pumping System - Pump capacity must be large enough to handle initial operation of heat to condensers af total system pressure drop new, plus a reserve pressure for system fouling. NPSH requirements of circulating pumps must be satisfied for greatest cooling water temperature expected.

4.4.12.3 Design Basis - The following design parameters shall be used in developing the Cooling Water Heat Rejection System if a future turbine generator installation is planned: 
- Initial steam conditions - 2500 psia at $1000^{\circ} \mathrm{F}$.

- Steam condensing conditions - $2.5^{\prime \prime} \mathrm{Hg}$ at $109^{\circ} \mathrm{F}$ (with turbine generator) and $2.9^{\prime \prime} \mathrm{Hg}$ at $114^{\circ} \mathrm{F}$ (without turbine generator).

- Dasuperheat condition - saturated at $114^{\circ} \mathrm{F}$ at $2.9^{\prime \prime} \mathrm{Hg}$.

- Condenser surface quantity - Sufficient to hold $2.5^{\prime \prime} \mathrm{Hg}$ at $109^{\circ} \mathrm{F}$ steam with maximum cooling water temperature with turbine generator installed.

- Condenser cooling water flow - Hold $2.5^{\prime \prime ~ H g ~ a t ~ f u l l ~ l o a d ~ w i t h ~ h o t t e s t ~}$ water.

- NPSH temperature limitation - $120^{\circ} \mathrm{F}$.

- Cooling tower blowdown shall be sufficient to hold circulating water mineral content low enough to prevent precipitation with in the condenser.

- Cooling tower location to be chosen with consideration for fog, plum a and drift.

- Winter icing of towar inlet shall be anticipated in tower design.

If the dry cooling system is used, the heat rejection system will be an integral part of the feedwater loop and must be capable of operating with the same chemistry without undue corrosion or fouling. Within the limits imposed by modelling restraints, the pressure and temperature levels of the heat recovery exchangers and heat rejection can be set to reducc cusi, simplify design, increase reliability and reduce maintenance reguirements. The flow rates will be set, primarily by the quantity of heat to be rejected.

4.4.12,4 Safety and Operational Safeguards - Ni mujor ones identified other than those used in standard steam plants.

4.4.12.5 Maintenance - No special maintenance features identified other than stand .: d practice in central station steam equipment. 
4.4.12.6 Instrumentation and Control - A system of control using back pressure control valves, desuperheaters, and devices for changing the rate of heat rejection shall be devised to simulate true turbine generator plant operation as a means of assuring proper test conditions and responses to the MHD plant.

\subsubsection{Stack and Exhaust Gas Systems}

4.4.13.1 System Description - Gaseous emissions to the atmosphere are produced from the MUD combustion, the seed processing facilities, and any auxiliary combustors used in cual drying or air preheating. Interposed between the source of the gas and its venting to the atmosphere are items for emission control such as mist eliminators, $\mathrm{SO}_{2}$ removal scrubbers, electrostatic precipitators as well as gas handling equipment such as ducis, fans, and stacks. This system concerns itself with the ducts, fans, and stacks. Previous systems include equipment design criteria for removal of specific pollutants. In addition, the total plant must $b$. designed to control stack emissions to meet regulatory requirements.

4.4.13.2 Funcrional Requirements - The functional requirements for the stack and exhaust systems are to provide the appropriate means to move the stack gases from their point of origin to the top of the stack or stacks as required to disperse those effluent gases into the atmosphere. These systems will function 24 hours per day, seven days per week for continuous periods of 2000 hours or more at any one time. Sufficient capacity to move the gases must be available to permit continous flow for the 2000 hour test run plus the rime necessary to start, preheat, and cool the facilities.

Coal drying will require a duty cycle beginning well before MHD combustion, and will extend into the period between test runs should drying of coal be required to restock storage silos at that time.

Air preheating using clean (low sulfur) fuel will be required only during those rest runs not using a direct fired high temperature air heat exchanger. 
Seed processing exhoust gas will be exhousted only during those test runs chosen to recover sulfur from the recycled potassium sulfate.

Induced draff blowers to move products of combustion from the MHD channel to the stack outlet will be required during all MHD combustor operating periods.

\subsubsection{Design Basis - Coal drying could produce an effluent stream with $10 \%$ or less} oxygen, at $200^{\circ} \mathrm{F}$ to $300^{\circ} \mathrm{F}$, containing trace amounts of fine particulates (such as may penetrate a bag filter) and trace quantities of $\mathrm{SO}_{2}$ and hydrocarbons generated in the coal drying step. The amount of this stream could approach $10,000 * \mathrm{lbs} / \mathrm{hr}$ flow at pressures donn to $-75^{\prime \prime} \mathrm{H}_{2} \mathrm{O}$.

Separately fired air preheating could produce an effluent stream with a few percent oxygen, at several hundred degrees $F$, and at a sufficiently high pressure to provide motive force for flow through ducts to the stack. Pressure would be supplied from the preheater burner air blowers. This stream, at up to $150,000 \% \mathrm{lbs} / \mathrm{hr}$ flow, would contain $\mathrm{SO}_{2}$ to the extent indicated by the sulfur content of the fuel oil.

Exhaust gases from seed regeneration would be combusted in a system external to the regeneration process to yield a $\mathrm{CO}_{2} / \mathrm{H}_{2} \mathrm{O} / \mathrm{N}_{2}$ flue gas. The exhaust gas quantity and flow conditions should be part of the seed/ash processing system criteria. Traces of $\mathrm{SO}_{2}$ sulfur and hydrocarbons as well as fine particulates will be in this stream.

MHD products of combustion at about $300^{\circ} \mathrm{F}$ and in an amount exceeding $600,000^{*} \mathrm{lbs} / \mathrm{hr}$ need to be injected into a stack, high enough for effective dispersion, by induced draft fans or blowers with the capability of providing adequate force for moving the combustion products from a high temperature air heater heat exchanger) through a waste heat recovery unit, a low temperature air heat exchanger, an economizer, an electrostatic precipitator and a stack gas scrubber. This series of equipment could provide a pressure drop of from 1 psi to 10 psi

\footnotetext{
* Numbers shown are based on $200 \mathrm{MW}$ thermal input to the MHD combustor.
} 
or more. The high temperature cir heater is to be maintained at close to ambient pressure, and thus the inlet to the induced draft blowers could be at substantially sub-atmospheric pressure. The use of more than one stage of induction blower, possibly at the economizer outlet, should be considered.

4.4.13.4 Safery and Operating Safeguards - No unique requirements exist above that used in standard fossil fueled power plants.

4.4.13.5 Mainienance - No unique requirements exist above that used in standard fossil fueled power plants.

4.4.13.6 Instrumentation and Controls - No unique requirements exist above that used in standard fossil fueled power plants.

\subsubsection{Waste Handling}

4.4.14.1 System Dsscription - Coal ash will continuously be forming and withdrawn trom the MiHD system for disposal. All liquid slag will have been first granulated by contact with sprayed water and through appropriate grinding. This will allow hydraulic transportation by pipelines to the area of the land fill site. Distribution of the granulated coal ash slag at the disposal site shall be in accordance with proper land reclaim procedures as dictated by the site topography and ultimate land use plan.

\subsubsection{Funcrional Requirements - Slag from the combustion chamber must leave the} pressurized chamber by gravity and meet a high velocity water spray in another pressurized chamber. A slurry pipeline will carry the granulated slag slurry to the disposal site. Flow of the slag slurry shall consume the pressure differential between the granulator chamber and the disposal site. Sufficient water will be continuously added to the granulator chamber to assure complete quenching, granulation and adequate transportation water. 
4.4.14.3 Design Basis - The design of the waste disposal system must be held within relatively narrow physical confines. Quantification of slag from the source must be relatively accurate for economic design.

4.4.14.4 Safery and Operating Safeguards - Slag granulation must be carried on in a
confining chamber.

Wester addition to the slag granulating chamber must be controlled to be always adequati: and a means must be supplied to prevent filling the granulation chamber with water causing overflow up the molten slag tap hole into the combustion chamber.

4.4.14.5 Maintenance Criteria - Slurry transportation of coal ash requires a minimum of maintenance attention with a properly designed system. Pipe and pump wear are the major considerations with pipe rotation a common wear defense procedure. Where pumps or other equipment have a low potential for 2000 hours of continuous operation, redundancy will be provided with provision for maintenance of a faulted unit while the other is operating.

\subsubsection{Instrumentation and Control - Granulation systems require the monitoring of} spray water pressure and flow. A water level control in the granulation chamber is required when operating without a discharge pump as proposed for the combustor granulator. 


\subsection{EQUIPMENT AND SYSTEMS DESIGN}

\subsubsection{Equipment Specifications}

Consistent with the systems engineering approach, design specifications shall be planned for each piece of equipment, or for equipment as defined by an assembly of components, designared for use within the MHD-ETF. The format to be followed shall be uniform and shall consist of major sections pertaining to Scope, Applicable Documents, Technical Requirements, Materials, Manufacturing, Testing, Quality Assurance and Delivery preparations.

\subsubsection{Codes and Standards}

Codes and standards from the following recognized sources will be used to the extent specified in individual design specifications. In general, established codes and standards for fossil fired power plants will be utilized rather than initiating new requirements or requiring specialized designs.

Occupational Safely and Health Adninistration (OSHA)

American Society of Mechanical Engineers (ASME)

American Society for Testing Materials (ASTM)

American National Standards Institưte (ANSI)

American Society of Heating, Refrigeration and Air Conditioning Engineers (ASHRAE)

National Electric Code (ANSI-CI-1971)

Specification for Electric Overhead Traveling Cranes (CMAA Spec "70)

American Institute of Steel Construction (AISC)

American Petroleum Institute (API)

American Water Works Association (AWWA)

American Welding Society (AWS)

Electronic Industries Association (EIA)

Environmental Protection Administration (EPA)

Fluid Controls Institute ( $\mathrm{FCl}$ )

Instrument Society of America (ISA) 
Institute of Electrical and Electronic Engineers (IEEE)

Insulated Power Cable Engineers Associattion (IPCEA)

International Standards Organization (ISO)

Manufacturers Standardization Society (MSS)

National Bureau of Standards

National Electrical Manufacturers Association (NEMA)

Natiunal Fire Protection Association

Power Piping Code

Scientific Apparatus Makers Association (SAMA)

Underwriters" Laboratories, Inc.

Uniform Building Code

Local and Stare Codes

\subsubsection{Drawings}

During the conceptual design phase, diagrams shall be prepared providing an overall description of the MHD cycle configuration under study and its major components and subsystems. When a reference conceptual design is selected, process flow diagrams for each major process will be prepared showing the flow scheme, process conditions, equipment size and type and material balances. Drawings for all major components of the MHD system will be prepared showing interface requirements, materials of construction, shipping sizes, weights and C.G.'s.

Detail drawing lists will be formulated in the preliminary design phase based on the reference design selected.

\subsubsection{Design Analysis}

Design analysis to the extent possible shall utilize standard methods in engineering practi e. Inelastic structural analysis shall be avoided except for potential faulted events where the purpose of analysis is to prove safe shutdown without disruptive failure. 
Where standard analysis procedures do not exist, the methods utilized shall be documented and any computer codes used shall be identified as to specific revision.

\subsubsection{Design Margins}

Design margins shall be provided consistent with good engineering practice for commercial practice. All margins shall be with respect to rated design conditions. No arbitrary margins shall be provided for future uprating or growth.

\subsubsection{Reliability}

High reliability will be provided by the application of sufficient margins and by the designers being required to perform Failure Modes and Effects Analysis and raking appropriare design ciction where deemed to be required. Extensive numerical reliability analysis shall not be emploped.

\subsubsection{Design Reviews and Audits}

All major designs and design documents will be subjected to periodic design review and technical audit during the evolutionary process to minimize major problems of overlooked items. Signoff of drawings and documents will be conducted on a multi-disciplinary approach, with certain disciplines being mandatory and others participating as deemed necessary by the cognizant engineer.

In addition, formal design reviews will be scheduled on major items utilizing higher management from the discipline groups and independent special ists.

\subsubsection{Quality Assurance}

Programs of plans and actions shall be implemented to control and verify quality attainment throughout design, procurement, manufacture, installation, and operations. Specifications for system components, materials and services shall contain requirements for quality assuranct programs and special quality assurance practices appropricte to the item or scope of work 
being defined. These specifications shall also define quality control practices such as inspection, examinations and tests appropriate to the specific item or service. 


\subsection{PLANT CONTROL AND INSTRUMENTATION}

\subsubsection{Control}

4.6.1.1 Design Basis - The basis for plant control design shall be the eventual development of a system consistent with a commercially operated plant on a uility network system. Such a plant will consist of the following major configuration faatures:

a. An MHD cycle burring coal with potassium seeding.

b. Heat recovery and steam generation from the MHD cycle exhaust.

c. A steam bottoming plant utilizing a turbine generator for the generation of electricity.

d. A steam rurbine driven air compressor for the supply of combustion air to the MHD cycle through a recuperative preheater and a regenerative bed direct fired air preheater. Steam for the turbine is obrained from that generated by the MiHD exhaust.

e. Support and auxiliary systems for the steam bottoming plant and the MHD cycle.

The MHD-ETF plant will be operated by local control in response to dispatcher demand. The intent is to provide the control capability, within the constraints imposed by the general criteria for use as a test facility and as a generating plant in a utility network recognizing the unique features of the M.HD sycle. When the MHD-ETF plant is coupled to the utility network it should comply with conventional power plant operational characteristics and dispatcher requirements to the maximum practical extent. Those control characteristics of the MHD-ETF plant which differ from a conventional power plant must be precisely identified and quantified to permit the use of the results in the development of optimum control systems needed to integrate full scale open cycle MitD power planis with utility systems.

4.6.1.2 Plant Control Philosophy - The plant control system shall be designed considering a "hierarchy of control" point of view. The first level of control shall be a total Integrated 
Plant Control System (IPCS) capable of communicating with an automatic load dispatcher. Automatic load disparch capability may be an eventual development option for the MHD-ETF plant, with local control as the primary control mode during test operations. However, the hierarchical approach beginning with the automatic load disparch capability should be used to establish the design. In such a mode critical plant parameters would be monitored by the central controller to determine the total change of power available from the plant and the maximum rate of change of power available from the plant. This capacity information would then be made ivailable to the central dispatcher. The integrated plant control system would monitor grid dumand requirements to determine if they are with in the capability of the plant. Demand signals which can be sarisfied by the plant would be processed immediately. If a demand signal exceeds the capability of the plant, the IPCS would decouple from the automatic dispatcher and return control to the local plant, maintaining load at the level prior to decoupling from the dispatcher. The decoupling from the dispatcher would be alarmed. Automatic dispatcher control would be reestablished by local operator action with the consent of the load dispatcher and with the load demand from the dispatcher equal to the output of the MHD-ETF plant. In the event of a MHD-ETF plant failure, the integrated plant control system would inform the load dispatcher of the plant status at the same time plant corrective action is raken.

The second level of control shall be total automatic control of the MHD-ETF plant by a local operator. This level of control is identical to control of the plant by an automatic load disparcher except the total load demand is generated locally. The system shall be designed for bumpless switching between local and automatic dispatcher control using the integrated plant control system.

The third level of control shall be total individual control of the MHD cycle and the steam botroming plant. This mode of control allows separate control of each system in as independent a manner as possible. The rotal power demand for each system is generated locally. 
Each of the power generation unit control systems will be multiplied input systems with a control actuator associated with each input. The individual control systems shall be designed such that each control input variable actuator can be individually controlled in either an automatic or manual mode. The system shall have the capability of selecting automatic or manual control of each actuator independent of the operating mode of any other actuator. The system shall be designed for bumpless transfer between manual and automatic control of each actuator.

In order to increase or decrease the level of automatic control in the plant, the system shall be designed using a series of interlocks and defined logic sequences. The interlocks and sequences will be alarmed to inform the plant operators of the plant status and capability at all times.

4.6.1.3 Machanization - The plant control systems shall be mechanized using currently available state-of-the-art hardware. The product lines of major control hardware manufacturers are now being updared to designs which utilize microprocessor based hardware. Such a system will allow various control system designs to be tested by changing software rather than hardware.

The cost and availability of microprocessor based hardware is such that a dual channel system will be incorpolated into the integrated plant control system design to sartisfy the criterion that any single failure will not result in a plant shutdown or requirement to revert to a lower level of control. Failures will be alarmed to inform plant personnel. This redundancy will be carried through to, but not include, the final actuators.

\subsubsection{Control of System Transients - The MitD-ETF plant control system shall be designed to respond to step changes in load demand and ramp loading and unloading. In addition, the system shall have the capability to automatically respond to grid load changes within specified ranges which are bounded by the established step and ramp load changes.}


The control system shall be designed to minimize the error between the desired load profile and the plant output. However, physical constraints of the plant will be considered when establishing control system gains and dynamic response capability.

The plant control system shall be designed to accept plant load rejection without damage to the plant equipment. Such a load rejection will require special equipment to reject heat from the process and special control profiles for the control input variables. Therefore, part of the control system design effort shall be to define acceptable control input profiles in response to rejection of load. In designing for transient capability, consideration shall be given to the distribution of load between the MHD generator and the turbine generator. The response capability of both generators should be considered and an algorithm developed which is a function of generator operating parameters and demand requirements to distribute the load. The potential for fast response of one generating unit to load change requirements and a redistribution of the load between the two generators once steady state operation is established should be considered. Overall plant efficiency, part load efficiency of the MHD and the steam bottoming cycle, thermal stress limits, and other operating limits will have to be evaluated to determine such load change allocations.

\subsubsection{Steady State Operation - Contral system design studies shall establish system} performance suecifications based on the dynamic capabilities of the M.4D-ETF system and operaring requirements. These specifications shall be used to define the control system configuration anc to evaluate the performance of various potential designs.

The control system shall be designed such that the theoretical steady state error of each control loop is zero. Equipment specifications shall establish the allowable tolerances on hardware to ensure satisfactory steady state operation.

The optimum distribution of load between the MHD generator and the steam turbine during part load operation shall be established. Consideration in this effort will be to balance the cost, complexity, plant integrity, and overall plant efficiency at all power levels of operation. 
The utilization of the results of this effort would be automatic when the plant is operating in total automatic control. If the plant were not in total automatic control, the information on optimum load distribution could be provided to the operator. By proper selection of control system demand functions the operator could accomplish the optimum load distribution.

Any oscillations or limit cycles of individual system components must be such that the closed loop control system including the component will not respond to the disturbance. This requires that the magnitude and frequency of such disturbances be limited. The performance specification effort shall define the desired frequency range of operation of each control loop. This frequency range information will be used to establish oscillation or limit cycle criteria for each system component?

\subsubsection{Equipment and Emission Protection - Critical plant variables will be instrumented} and allowable operating ranges, which include a safery margin, established. The plant control system shall be designed to monitor these critical variables and, in the event that an operating limit is violated, take corrective action to return the plant to a safe condition. All limits will be alarmed to inform plant personnel of potential operating problems. Some of the unique monitoring requirements for the MHD plant are as follows:

a. The temperature of the gas leaving the MitD diffuser is an important parameter to monitor. If it is too high, the downstream heat exchangers may be damaged and $N D_{x}$ emission levels might exceed standards. In addition, rapid increases in this parameter would be one of the quickest and most reliable indications of a loss of MHD load. The loss of load could be due to a seed flow failure, electrode damage, shorting of electrodes, an inverter system failure or loss of load on the electrical system. In any event, the control system should be designed to control this temperature level. Any sudden changes should be countered by coordinated changes in fuel, air, and seed flow rate. 
b. The viability of the two stage combustor needed for efficient slag removal requires that the stoichiometry of the first stage be controlled within narrow limits. The $\mathrm{NO}_{x}$ control scheme and plant efficiency require that overall stoichiometry of the combustor also be closely controlled. To insure that these conditions are met with varying operating conditions (e.g. coal composition, ambient temperature, coal flow rate perturbations) it will be necessary to monitor some indicator of overall stoichiometry and closely control the apportioning of air between the first and second stage combustor. It may be necessary to remove a sample of gas from the stream to determine its composition but it seems likely that a system could be developed to obtain a real time indication of the $\mathrm{CO}$ concentration in the rich stream by measuring the radiation in a narrow band corresponding to one of its characteristic frequencies. The supplementary air injection rate should also be closely controlled to insure efficient operation. This can be monitored in real time by using an oxygen partial pressure gauge in the stock gases.

c. The air preheat temperature will need to be monitored to obrain an indication of overheating or malfunctioning of the regenerative heater system and is required to estimate combustor temperatures.

d. The current voltage characteristic of the MHD channel circuits will need to be monitored for indications of duct problems such as electrode deterioration, arcing, slagging or insulator breakdown. If the malfunction is restricted to a small percentage of the circuits, it may be possible to take corrective action (e.g. an arc might be extinguished by opening a circuit, or insulato breakdown could be alleviated by reducing the electric field).

\subsubsection{Instrumentation and Data System}

Cabling for electrical needs, instrumentation and control can significantly affect cost and 
construction time in power plants and must be continuously managed. Priority shall therefore be given to obtaining detailed engineering information on testing performed in support of MHD-ETF at other facilities. Within the MHD-ETF, priority shall be given to instrumentation needed for control, diagnostics and information in that order. In addition, wherever possible, diagnostic and engineering information will be gathered at stations local to the component or system being investigated for later processing as a means to reduce cost, complexity and construction time.

4.6.2.1 System Definition - The test instrumentation and data system includes the following items:

a. All sensors which are responsive to parameters that are of interest in operating the Engineering Test Facility and in evaluating the performa we of the various subsystems such as the MHD rest assembly, the magnet, the seed recovery system, the various heat exchangers, etc.

b. High voltage isolators which prevent high voltages from appearing at inputs to the data acquisition systems or in the control room.

c. Sensor readouts which do not pass through the dara acquisition systems.

d. The central data acquisition system plus any local data acquisition systems.

e. Visible readouts which are generated by the data acquisition systems, e.g. CRD displays.

f. Data printers and graphic output printers.

g. Tape recorders for storage of raw and processed data.

The test instrumentation and data system does not include: 
a. The non-sensor portions of the plant control system including control loops, interlocks, control actuators, control consoles, etc.

b. The non-sensor portions of the plant safery system.

c. Annunciator boards used to give visible and audible warnings of offstandard operating conditions.

Each instrumentation channel of the fest instrumentation and data system shall be assigned to one of the following categories:

Category 1 - Instrumentation required for control of the ETF processes.

Category II - Instrumentation required to diagnose failures.

Category III - Instrumentation used for collection of scientific and engineering data.

4.6.2.2 Objectives - The test instrumentation and data system shall meet the following objectives:

a. Provide information which will enable protection of personnel from consequences of failures in the ETF or its components.

b. Provide information which will enable protection of ETF and its components from destruction caused by failures or out-of-limits operations.

c. Provide information needed for automatic or manual control of ETF operafions.

d. Provide visible readouts for human monitoring of ETF operating conditions.

e. Provide information needed for audible and visible annunciation of out-oflimits operations.

f. Provide diagnostic information needed to analyze foilures and their causes. 
9. Provide engineering information not otherwise obtainable for evaluating design and analysis techniques and their applicability to larger size plants.

The amount of cabling required for meeting the above objectives shall be minimized by using techniques such as multiplexing where applicable.

\subsubsection{Constraints - The test instrumentation and data system shall meet the following} constraints:

a. A single failure of a Category I sensor or data channel must not cause a shutdown of the MHD rest assembly. Redundancy shall be used to avoid shutdowns caused by such failures.

b. High voltages normally present on instrument components and high voltages present on instrument components as a result of system failures are to be limited locally and are not to be allowed to propagate to the data acquisition systems or to the control room.

c. System components shall be capable of operating in the presence of the stray magnetic field anticipated at that component. Components shall be anchored against displacement by the magnetic field.

d. System components shall be capable of functioning properly over the extreme range of temperatures recorded in Montana, $216^{\circ} \mathrm{K}$ to $320^{\circ} \mathrm{K}\left(-70^{\circ} \mathrm{F}\right.$ to $\left.117^{\circ} \mathrm{F}\right)$.

e. Reliability of the test instrumentation and data system shall be consistent with the anticipated uninterrupted test run duration of 2,000 hours and with the anticipated facility lifetime of 15 years.

4.6.2.4 Probes and Primary Sensors - All probes and sensors shall be compatible with the expected ranges of ambient conditions (temperature, pressure, fuel flow rate, seed flow rate, 
coolant flow rate, slag flow rate, etc.) expected at their respective locations with a $10 \%$ margin.

Sensors shall be provided which are capable of sensing potentially hazardous conditions which could threaten human life. Examples are:

a. Explosive mixiures such as coal dust and oxygen or propane and air.

b. Asphyxiating atmospheres such as excessive carbon monoxide or insufficient oxygen.

Dedicated sensors shall be provided which are capable of sensing out-of-limits conditions which could damage the MitD test assembly, the magnet, the heat exchangers, or other ETF components. Examples are:

a. Pressure in the combustor too high.

b. Inadequare seed flow rate.

c. Temperature of gas flowing into a heat exchanger too high.

d. Inadequate coolant flow into a heat exchanger.

e. Magnet temperature too high.

4.6.2.5 Data Acquisition System - There will be a high voltage isolation device in each data channel which has high volrage on it or which has under fault conditions the potential of having high voltage on it so as to prevent high voltages from propagating to a data acqui sition system or to the control room.

The design of the data acquisition system shall permit future expansion of the number of data channels by a factor of two.

The channel scanning rate shall be fast enough to follow the fastest transient that is to be monitored, TBD. 
Techniques such as multiplexing shall be used where applicable to minimize the amount of cabling required.

The central data acquisition system shall include the capability of reducing the raw data to:

a. Forms suitable for real-time input to the control system.

b. Forms suitable for real-time input to visible readouts of system performance parameters.

c. Forms suitable for output to printers, graphical presentation devices, and magnetic tape recorders.

d. Forms suitable for real time input to audible and visible alarm systems.

Readouts of important operating parameters shall be provided independent of the data acquisifion system. These readouts shall be visible to the operators in remote locations and/or in the control room in accordance with operating philosophy.

4.6.2.6 Dxta Formating and Dissemination - The data shall be reduced and disseminated in the following forms:

a. Forms that are suitable for real-time input to the control system.

b. Forms that are suitable for real-time visible presentations to the operator, via gauges or recorders.

c. Forms that have been processed and are visibly presented to the operators via printers or CRT's as data displays.

d. Forms that are suitable for data recording via magnetic tape recorders or printers.

e. Forms that are suitable for real-time input to audible and visible alarm systems. 


\subsection{PLANT ARRANGEMENT AND CIVIL DESIGN}

Overall plant designs shall be developed to assure the proper interfacing and interaction of all components. Process flow sheets and system designs will be developed to identify the proper equipment to meet plant operating requirements. The equipment and materials normally associated with balance of plant will also be identified. Drawings will be prepared to establish the interface requirements for major components.

Plant arrangements shall be developed with the objective of integrating the major system components, subsystems, support systems, and balance of plant facilities into a balanced and functionally optimum plant design. Major equipment shall be located to provide access to resource storage facilities, adequate room for maintenance and access to diagnostic test components, and flexibility for ease of modification and expansion. While implementing these requirements, the arrangements must reflect the necessity to minimize the expense of high temperature inter-connections and valving.

The electrical inter-connection and piping requirements for major system components, power conditioning equipment, support systems, diagnostics "and instrumentation and controls have been identified as a major consideration in the arrangement of an MHD cycle plant. The facilities and equipment shall be arranged to minimize plant wiring and piping requirements to reduce both costs and the construction duration.

Buildings, structures and civil improvements shall be designed in accordance with specified criteria based on proven practices and applicable federal state and local codes. Archirectural and civil designs shall be executed in a manner that is compatible with existing land use and minimizes environmental intrusion.

The process flow diagrams, equipment lists, component design drawings, plant arrangement drawings, and civil/structural design criteria provide the basis for preparation of the capital cost estimate. 


\subsubsection{Equipment Lists}

Equipment lists shall be prepared to aid in establishing overall plant complexity, identify the functional requirements of essential subsystems and provide readily available checklists in defining spare parts requirements and in reordering components. Information to be provided on the equipment lists shall include:

a. Equipment descriptive name and account code.

b. Cross-reference to specification and descriptive drowings.

c. Recommendations for spare parts.

Equipment lists shall be prepared for all process, instrumentation, control, support and balance of plant equipment for the ETF. The lists shall be itemized according to the following subsystem groupings and will in final form be made consistent with the specific account numbus and line items utilized for costing.

\subsubsection{MHD Cycle}

- Air compressor system, primary and standby with any necessary drives and condensers

- Combustor and slag separator with immediate coal and seed injection system

- Nozzle

- Generator channel

- Magnet system, including power, cryogenic, and vacuum supply

- Diffuser

- High temperature air heater

- Low temperature air preheater 
- Oxygen feed system

- Preheater combustor (separately fired)

- Associated instrumentation and controls

- Main gas stream piping

4.7.1.2 Heat Recovery System

- Economizer

- Radiant boiler and slag separator

- Superheater

- Reheater

- Secondary Furnace

- Any seed and slag heat recovery equipment

- Associated instrumentation and control

4.7.1.3 Steam Bottoming Plant

- Turbine generator (if used)

- Main condenser

- Boiler feed pump turbine

- Boiler feed pump condenser

- Gland steam condenser (if turbine generator is used)

- Condensate pumps

- Cooling tower system

- Steam dump

- Deaerator 
- Decerator or storage tanks

- Reject heat exchangers (if turbine generator not used)

- Primary valves

- Associated instrumentation and control

4.7 .1 .4 Support Systems

- Slag removal, from combustor and radiant heater

- Auxiliary steam system

- Auxiliary combustor

- Coal receiving, storage, and reclaim

- Conl preparation and storage

- Seed receipt, storage and preparation

- Nitrogen supply system

- Oxygen receipt and storage

- Slag-seed separation, regeneration and recycle

- Stack gas cleanup

- Induced draft fan and stack

- Water conditioning

- Associated instrumentation and controls

4.7.1.5 Accessory Electric Equipment

- Swirchgear

- STation service equipment 
- Swi íchboards

- Protective

- Electrical structures and wiring container

- Power and control wiring

4.7.1.6 Miscellaneous Power Plant Equipment (Balance of Plant)

- Water storage

- Ash and waste disposal

- Fuel oil storage and supply system

- Instrument stations

- Circulating water system

- Emergency diesel generator

- Auxiliary power transformer

- Fire protection

- Communications system

- Maintenance equipment

- Valves not identified in other categories

- Piping not identified in other categories

- All equipment not otherwise identified

\subsubsection{Transmission Plant}

- Transfomer substation (if turbine generator used)

- Inverter system 


\subsubsection{Overall Plant Descriptive Drowings}

The drawings that shall be prepared to describe the interfacing and interaction of major system components, subsystems, support systems and balance of plant facilities are defined as follows:

*: Plot Plan - The site boundaries and the location of all permanent facilities, structures, roadways, railroads, and resource storage areas to be constructed on the site will be shown.

** General Arrangements - The relationship of major system components, subsystems, support systems and process related balance of plant facilities will be shown in plan and elevation views.

*:Electrical Single-Line Diagrams - Will be prepared of the overall electrical power generation and power distribution systems. Major equipment items such as generators, transformers, converters, switchgear, motors, controllers, relaying and metering will be shown.

*Piping and Instrumentation - A diagramatic arrangement of equipment showing major piping, valving, pump stations and related instrumentation.

* Major Process Piping - A diagram illustrating intermconnecting piping between major system components showing preliminary line sizes.

\footnotetext{
* Prepared for evaluating alternate conceptual designs.

*Prepared for Reference design.
} 


\subsubsection{Electrical Design Criteria}

4.7.3.1 Codes and Standards - The electrical design shall be based on the latest codes, standards and regulations of the following organizations:
a. American National Standards Institute (ANSI)
b. National Fire Protection Association (NFPA)
c. Institute of Electrical and Electronics Engineers (IEEE)
d. Local, State and National Regulatory Agencies

However, in absence of any codes, standards and regulations, the latest available technology and manufactured products, consistent with sound engineering practice, economy and safety aspects, shall be used.

The facilities shall be in accordance with standards and recommended practices developed by the IEEE for power plants to increase plant availability and reliability.

\subsubsection{Unility Power for Startup and Operation - Two main overhead subtransmission} circuits, rated $69.0 \mathrm{kV} *$ will be brought into the MHD-ETF switchyard area. The two $59.0 \mathrm{kV}$ circuits will deadmend in a steel structure equipped with lighining arresters, line-isolating swirches and fused switches for transformer primaries.

A primary distribution substation with two $100 \%$ rated transformers and normally open tie breaker is connected to the two main overhead subtransmission circuits. (Refer to Figure 4-3, MHD-ETF Electrical Power System, Simplified One-Line Diagram). The primary distribution substation will supply the power requirements for plant startup and plant operation.

\footnotetext{
*Note: All system parameters are conceptual. This applies to all ratings given in this criteria.
} 


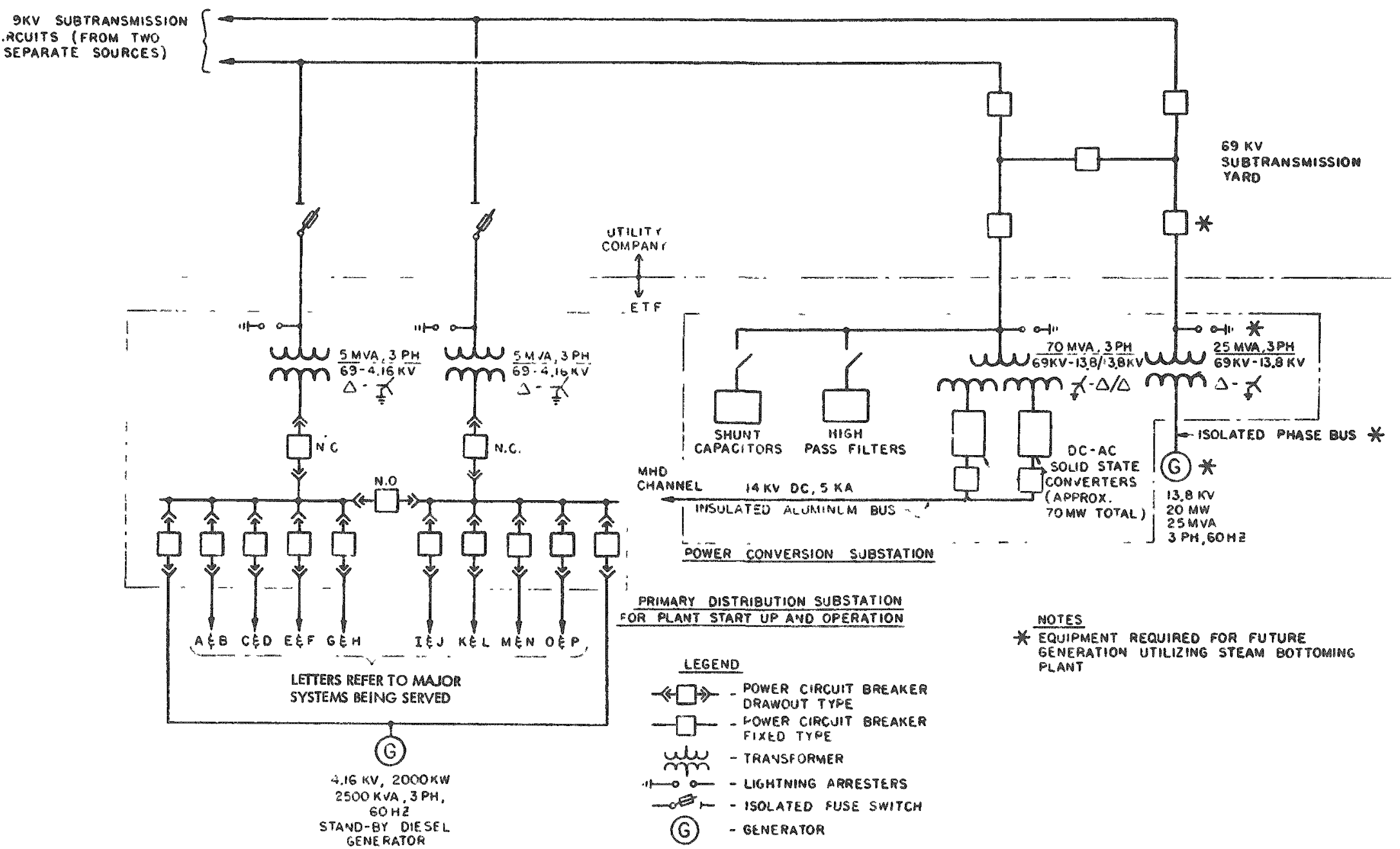

Figure 4-3. MHD-ETF Electrical Power System - Simplified One-Line Diagram 
The two primary distribution transformers shall be located outdoors and the 4160 volt metal clad switchgear shall be located in a building. Normally, the two transformers will each share $50 \%$ load. However, during the unavailability of one of the two transfomers due to maintenance or power outage, the other transformer will supply 100\% lood. The substation building shall be provided with an air conditioning system to protect the equipment from dirt and dust, very high and low temperatures, and moisture. The transformers shall be rated: $5000 \mathrm{kVa}, 69.0 \mathrm{kV}$, Delta-Wye (grounded), $3 \mathrm{ph}, 60 \mathrm{~Hz}$, oil-immersed, self-cooled.

The 4160 volt system supplied by the secondaries of the two transformers shall be based on a secondary selective arrangement with automatic switching for rapid service restoration consisting of two main circuit breakers, one tie circuit breaker and ten feeder circuit breakers, five connected to each bus. At least one spare feeder circuit breaker shall be provided on each bus for any future load addition. This arrangement will divide the load equally between she two bus sections. The $5 \mathrm{kV}$ feeder cables shall be connected to the load side of the 4160 volt cir circuit breakers. The cables shall be carried in cable trays and shall be designed for protection against fire and thermal loading by using IEEE cable separation and loading criteria.

\subsubsection{Power Conversion - The MHD channel will generate power as a direct current} (dc). Insulated aluminum bus will connect the MHD channel to de circuit breakers and thu solid state thysistor converter valves.

A $69 \mathrm{kV}-13.8 \mathrm{kV}$, Delta-Wye, $3 \mathrm{ph}, 60 \mathrm{~Hz}$ transformer shall be included in the power conversion substation for the steam turbine generator output. The transformer and generation shall be connected by a $13.8 \mathrm{kV}, 1200 \mathrm{~A}$, self-cooled, non-segregared phase bus. This installation will be required if the MHD-ETF utilizes the steam bottoming plant turbine generator. 
4.7.3.4 MHD-ETF Switchyard - The power conversion substation transformers shall be connected to the two $59.0 \mathrm{kV}$ subtransmission circuits through the loop subtransmission arrangem ment shown on Figure 4-3. With this scheme, a subtransmission line fault, depending on whare it occurs, will not interrupt service to the primary distribution substation. The fault is isolated from the system by the opening of the circuit breaker nearest the fault.

The conventional breakermand-a-half scheme is nomally used for considerably higher capacity than the one under consideration.

The $69.0 \mathrm{kV}$ subtransmission yard outdoor oil circuit breakers shall be rated $69.0 \mathrm{kV}, 2000 \mathrm{~A}_{8}$ and 5000 MVA, 3 phase interrupting duty.

Carrier-current equipment shall also be installed in the subtransmission yard for communications with other interconnecting substations. This will facilitate ease of power transfer, load shedding, and voltage control.

4.7.3.5 Standby Diesel Generator - A standby diesel generator unit designed to start automatically, upon detection of loss of voltage on the MHD-ETF $4160 \mathrm{~V}$ switchgear bus, shall be providad to meet Article 750 of National Electrical Code, NFPA No. 70.

The diesel generator unit shall be self-starting and shall be rated $4160 \mathrm{~V}, 2000 \mathrm{~kW}, 3 \mathrm{ph}$, $60 \mathrm{~Hz}$. The rating shall meet all the critical load requirements. The unit shall be able to start and accept load within ten seconds after loss of voltage on the 4160 volt bus. The critical loads shall be connected sequentially after the diesel generator breaker on the 4160 volt bus is closed upon reaching the correct voltage and frequency.

The exciter and the voltage regulator shall be of the static, solid state type. Control battery, fuel tank, and a compressed air tank with compressor for starting the engine shall also be installed in the engine generator room. In addition, a generator grounding 
fransformer and a relay shall be provided to protect the generator from ground faults. Generator differential relays shall be provided to protect the windings from intemal shorts.

The generotor shall be connected to the $4160 \mathrm{~V}$ buses through a breaker connected to each bus. Upon failure of one of the two breakers to close, the tie breaker will close keeping the failed breaker open.

The unit shall also have manual starting capability. The MHD-ETF shall have a fuel storage tank with a fuel transfer pump capable of supplying the engine requirements for seven days continuous operation at full load.

\subsubsection{Uninterruptible Power Supply - Emergency loads such as computer, emergency} lighting, control power for switchgear, turbine turning gear, and bearing oil supply power systems shall be supplied from the uninterruptible power system (UPS). Such a system shall be in accordance with Article 700 of National Electrical Code, NFPA No. 70.

The system shall be a non-redundant UPS system consisting of rectifier/charge $r_{p}$ stationary bottery including rack, static inverter, non-redundant static bypass swirch, and remote monitor panel. The UPS output shall be rated $250 \mathrm{kVA}, 0.8 \mathrm{pf}$ lagging $(200 \mathrm{~kW}), 60 \mathrm{~Hz}, 3 \mathrm{ph}, 4$ wire.

The battery shall be lead calcium type, with ampare hour capability to provide 30 minute prorection time for emergency loads.

The UPS system input may be subject to the items stated below; however, the output shall be essentially free from these conditions:
a. Voltage dips
b. Frequency variations
c. Monentary interruptions 


\section{d. Transient disturbances \\ e. Prolonged power interruptions}

The UPS shall nomally be connected to the regular 480 volt, $3 \mathrm{ph}, 60 \mathrm{~Hz}$ supply and during that time the battery shall be floated on the de bus and kept fully charged. In the event of a momentary or prolonged interruption, the battery shall supply sufficient power to the inverter to maintain its output.

Provision shall also be made to connect the UPS to the standby generator for power interruptions of over 30 minutes.

4.7.3.7 Secondary Unit Substation - Load center unit substations, consisting of 4160 volt incoming line section, transformer and 480 volt section with metal enclosed, horizontal drawout power circuit breakers, shall be installed in the center of each group of loads.

The breakers shall have stored energy closing mechanisms and shall be provided with solid staie instantaneous and overcurrent trip devices. The construction shall be dead front consisting of a solid steel protective barrier for maximum safety of operating personnel and also to reduce the dust contamination in the breaker compartments.

The transformer shall be dry type, 1000 kVA (maximum), 480 volt, 3 ph, air cooled, indoor type. The transformer impedance shall be sufficient to limit the three phase short circuit level to 480 volt breaker rating.

The rooms in which the secondary unit substations are located shall be provided with an airconditioning system to protect the equipment from dirt, dust, very high and low temperatures and moisture.

The 480 volt power circuit breakers will feed various 480 volt motor control centers located nearest each group of loads. 
Coordination of 4160 volt breakers, 480 volt switchgear breakers and 480 volt motor control center breakers shall be provided to isolate the faulted load by the breaker nearest to the fault.

\subsubsection{Cables, Cable Trays and Conduits - The selection of cables, cable troys and} conduits shall be governed by several Articles of National Electrical Code, NFPA No. 70.

The cable conductors shall be of copper for small power and control circuits and copper or aluminum for power circuits of comparatively larger current carrying capacity. The cable insulation and jackets shall be for the proper voltage levels and of fire retardant material.

The selection of the cable shall be based on voltage, current capacity, short circuit capability, voltage drop, emergency overload and thermal loading.

Cable trays shall be used where practical within and outside the plant areas. The outside cables subject to weather conditions shall be designed to meet those conditions. Where required, cables shall be in conduits.

Industry standards shall be used to segregate the medium voltage circuits, low voltage power circuits and control and instrument circuits. Cables shall be color coordinated for cable layout and wiring identification.

The $13.9 \mathrm{kV}$ cables shall be shielded. The $5 \mathrm{kV}$ cables shall be nonshielded cables except in special conditions stated in IEEE Std. 141-1976. The 480 volt, and 120 volt cables shall be nonshielded.

Open wire of type ACSR shall be used for the $69.0 \mathrm{kV}$ transmission lines on insulators, with proper air separation between the conductors and between conductors and surrounding uninsulated structures and ground. 
4.7.3.9 Fire Protection - Fire protection pumps shall be connected to the normal power source and also to the power supply originating with the standby diesel generator set. The fire alarm and fire pump switches, circuits and motors shall be designed in accordance with National Electric Code, NFPA No. 70. The fire alam and annunciator equipment shall be located in the control room. Fire alarms shall also be located in each general area for personnel protection. Fire extinguishing system shall initiate automatically upon fire detection in a given area.

Equipment and cable separation shall be designed such that the fire in a given equipment or a room shall be confined to the equipment or the room, and shall not be able to spread into adjoining areas.

\subsubsection{General Criteria - The major electrical equipment discussed earlier and all} motors, lighting and welding receptacle load centers shall be designed for a 15 year life span based on continuous operation at rated load and temperature rise without any major sign of deterioration.

All motors shall be full voltage, across the line starting, Class B insulation. The enclosure and the temparature rise limit shall be dependent upon the environmental condition for the motor locarion.

All major equipment shall be given the standard factory tests as well as some special tests as indicated by the respective equipment specifications and industry standards.

Rotating equipment noise, transformer humming noise and noise produced by solid state converters and UPS equipment shall be restricted to allowable limits under codes and regulations. 
Proper relaying, grounding, lightning and surge protection methods and equipment shall be employed to protect equipment and personnel from excessive currents, voltage surges, lightning surges and short circuits and ground faults.

Lighting circuits and equipment shall be designed such that recommended, safe illumination levels are obtained in work areas $s_{p}$ around vital areas of importance to intrusion detection system, and on plant access roads and driveways. Economics and aesthetic aspects of lighting designs shall be considered.

Emergency lights shall be provided in strategic work, operation and control, and exit areas to protect the personnel against sudden power failures. Emergency lighting shall be connected to UPS and the standby generator.

A sufficient number of power outlets for welding, cleaning and maintenance shall be provided throughout the plant.

Metering shall be provided on the primary distribution substation input, MHD generator output. steam bottoming plant output, standby generator output and UPS output feeders to measure the power supply and demand to and from the utility. Ammeters, voltmeters, frequency meters and a synchroscope shall be used on $4160 \mathrm{~V}$ switchgear.

4.7.3.11 Safety - In addition to the safety aspects delineated earlier (such as emergency lighting, adequate protective and grounding methods, caution signs, protective enclosures, and electrical separation) adequate safety fertures as described below shall be incorporated in the electrical design.

Interrupting devices shall be able to function safely and properly under the most severe duty to which they may be exposed. 
Isolating switches shall not be operated while they are carrying current. Circuit breakers and switches on the alternate sources of supply shall be key interlocked and warning signs shall be insialled.

Electric equipment rooms for secondary unit substations, primary distribution centers, power conversion substation, and switchyard shall be locared to eliminate or minimize the need for access by non-electrical maintenance or operating personnel. Conveniently located doors must be provided to allow quick exit during emergency.

Electric apparatus located outside special electrical equipment rooms shall be provided with protection against mechanical damage. The area shall be accessible to electrical personnel for emergency operation.

Equipment shall be properly identified by identification numbers and nameplates so that shutdown and maintenance can be done effectively and safely.

No temporary wiring or electrical apparatus hookup shall be done after the plant starts operation, except for maintenance, repair and testing equipment and cables which shall be properly grounded and equipped with ground sensors.

4.7.3.12 Maintenance - The system shall be designed so that maintenance work on circuits and equipment can be accomplished with the particular circuits and equipment de-energized and grounded. System design shall provide for locking out circuits or equipment for maintenance. A written procedure shall be established to provide instructions on lagging or locking out the circuits during maintenance and re-energizing after completion.

Maintenance personnel must be provided with complete operating and maintenance instructions including wiring diagrams, equipment ratings, and protective device settings. Spare fuses of the correct ratings shall be stocked. 


\subsubsection{Civil/Structural Design Criteria}

4.7.4.1 Codes and Standards - The facilities shall be designed to conform to the applicable portions of the following codes and standards as last revised and promulgated:

American Concrete Institute ( $\mathrm{ACl}$ Manual of Concrete Practice)

American Instituie of Steel Construction (AISC)

American Welding Society (AWS)

Uniform Building Code (UBC)

American National Standard "Building Code Requirements for Minimum

Design Loads in Buildings and Other Structures" (ANSI A58.1)

Applicable Building Codes of State of Montana and Local Governments

American Society of Civil Engineers (ASCE) - Transactions; 1961

Paper No. 3269, "Wind Forces on Structures"

American Petroleum Institute (API 620 and 650) - Welded Steel Tanks

American Society for Testing and Materials (ASTM)

Occupational Safety and Health Administration (OSHA)

Mining Enforcement and Safety Administration (MESA)

Conveyor Equipment Manufacturers Association (CEMA)

American Association of State Highway and Transportation Officials (AASHTO)

American Railroad Engineers Association (AREA)

4.7.4.2 Structural Design and Analysis Procedures and Guides - The methods used to analyze the structural elements of the plant shall be based upon elastic theory conforming to conventional codes and practices. 
4.7.4.3 Loads and Loading Combinations - Analysis of all structures shall be performed to predict the structural responses to normal loads. Major loads to be encountered are listed herein; however, all of the loads are not necessarily applicable to all structures. Loads and applicable load combinations for which each structure has to be designed will depend on the conditions to which that particular structure may be subjected.

The loads normally applicable or most likely to be encountered during normal plant operation include the following:

a. Dead loads (D) or their related moments and forces including any permanent equipment loads and hydrostatic loads.

b. Live loads ( $L$ ) or their related internal moments and forces including any impact from moveable equipment loads and other loads which vary with intensity and occurrence.

c. Wind $(W)$ loads or their related horizontal and uplift pressure generated by the design wind.

e. Seismic (E) generated based on structural and geographic considerations.

The loads above and their possible combinations are generally applicable to all types of structures. Other site related loads such as hydrostatic uplift due to flood waters might also be applicable.

The following load combinations will be considered for steel structures or concrete structures not recommended to be designed by the ultimate strength design method:

$$
\begin{array}{ll}
- & D+L \\
- & D+L+W \\
- & D+L+E \\
- & D+W
\end{array}
$$


Where the load combinations listed above include wind or earthquake, the allowable stress will be increased by one third.

The ultimate strength design method shall be used for all concrete structures except structures designed to be water leak resistant. The load combinations for ultimate strength design shall be as specified in $\mathrm{ACl} 318$, "Building Code Requirements for Reinforced Concrete", as lost revised and promulgated. In addition, all cases regardless of design method will be investigated with live load $(L)$ having its full value or being completely absent to defermine the most severe loading condition.

a. Floor Loads - The minimum floor load for any structure or element will be based on ANSI A58.1, "Building Code Requirements for Minimum Design Loads in Buildings and Other Structures". Design floor loads shall be developed based on these minimum building code requirements and other special floor loading criteria common to power plant design. Where required, grating as well as concrete floor areas above grade floor level will be designed for a 5 ton axle load for lift truck travel.

Similarly, maintenance aisles on the basement floors of the boiler and turbine buildings will be designed to accommodate a 5 ron axle load.

b. Wind Forces - Wind forces will depend on site wind conditions and shape, size and exposure of the structure. All structures will be designed to withstand the minimum horizontal and uplift pressures set forth by the "American National Standard Institute A58.1 Building Code Requiremențs for Minimum Design Loads in Buildings and Other Structures". The provisions of local codes will also be investigated and will be used in lieu of ANSI A58.1 if found to be more stringent.

c. Snow Loads - The roofs of all plant structures will be designed to withstand minimum predicted snow loads as set forth by United States Department of Commerce-Weather Bureau, "Greatest Snow Laad on Graund at One Time", 
and in accordance with reductions set forth by ANSI A58.1. As alwoys, local codes will be investigated and used if their provisions are found to govern. Snow load intensities will vary with roof slope as well as geographical location of the plant site.

d. Seismic Loads - Seismic analysis and design will be required for the plant as western Montana is designated to be in zones of severe and frequent seismic activity. Depending on the location of the site, the design will conform to either Zone 2 or 3 on earthquake maps illustrated in the Uniform Building Code. Design work performed prior to selection of a specific site shall be based on zone 3 requirements.

The local geological data will be investigated to verify the seismicity of the site. Upon verification, structures critical to the operation of the plant will be designed to resist stresses produced by lateral forces frum postulated ground motion utilizing the procedures outlined in ANSI A58.1. Stresses will be calculated as the effect of a force applied horizontally and/or vertically at each floor or roof level above the foundation. The force will be assumed to come from any horizonial direction. All portions of structures will be designed to act as an integral unit in resisting horizontal and/or vertical forces unless structurally separated by a distance sufficient to avoid contact under deflection from seismic action. In computing the effect of seismic loads, other normal loads will be combined as stated herein.

e. Other Loads - Other loads used to predict the structural response of structures include hypothetical uniformly distributed loads representing the influence of piping and of electrical installations not previously included in dead or live loads.

Pressure or suction loads such as encountered in ductwork will be taken into account as well as dynamic loads from operating equipment. 


\subsubsection{Reinforced Concrete Design}

a. Portland cement concrete will be used on this project with $\mathrm{fl}^{\prime} \mathrm{c}=4500 \mathrm{psi}$ for floor slabs on grade and $f^{\prime} c=3000$ psi for foundations, footings, pedestals and grade beams and super-structure concrete.

b. All reinforcing steel shall have a minimum yield strength of 60,000 psi .

\subsubsection{Structural Steel Design}

a. Structural steel shall be ASTM A36 or equivalent.

b. All main connections are to be shop welded and field bolted with ASTM A325 or A490 high strength bolts.

c. Secondary field connections, e.g. railing ladders, may be welded or made with ASTM A307 bolts.

\subsubsection{Foundation Design}

a. The type of foundation, allowable soil bearing pressures, and frost depth will be determined after a geotechnical investigation of the site is completed.

\subsubsection{Civil Design}

4.7.4.7.1 Roads - The road system shall provide access to all areas of the ETF and shall consider separation distance between vehicle access and personnel in hazardous areas.

Roads will be designed as two-lane with bituminous paved 12-foot wide lanes and 4-foot wide shoulders. Pavement thickness will be selected based on the California Bearing Ratio value of the subgrade material, frost considerations, and anticipated vehicular axle loads. 
Highway loading for all culverts and structures will be AASHTO HS20-44.

Road cross sections will be crowned to achieve positive drainage. A cross slope of at least $2 \%$ will be required for travel lanes and shoulders.

Road alignment and geometry will be designed based on turning movements for a standard single unit AASHTO truck. Design speed will be $25 \mathrm{mph}$ for plant roads and $50 \mathrm{mph}$ for access roads. Maximum gradient for all roads will not exceed $8 \%$. Lesser grades will be used, where possible.

Vertical curves will be governed by stopping or passing sight distance. Vertical curves are not required for a grade difference of $2 \%$ or less. Cut and fill slopes will be determined based on a geotechnical investigation of soils available on site.

4.7.4.7.2 Railroads - Railroad siding(s) shall be provided which meet the requirements of:

a. The manual of Railway Engineering, Volumes 1 and 2, of the American Railway Engineering Association.

b. The design and construction standards of the connecting railroad.

\subsection{Sanitary Sewer - Sanitary sewage will be removed from the ETF site via a} connection with an existing municipal sewage or will be treated on site in accordance with the State of Montana and federal environmental regulations.

4.7.4.7.4 Drainage - The facility shall be designed and constructed to conform with existing drainage pattems and contours at the site.

The storm drainage system will consist of open ditches and culverts throughout the plant area. The grading and drainage system shall intercept and direct all water away from the test complex to natural drainage and will control drainage to prevent off-site damage. Specific provisions shall be made for directing and handling contaminated waste water. 
4.7.4.7.5 Fence - The boundaries of the facility will be completely enclosed with 7 foot high galvanized wire fabric with three strands of barbed wire above the fabric.

4.7.4.7.6 Fire Protection - On site wells will not be used unless an adequate water supply is not available at the site boundary via a connection to the local water company system. If a well is required, it will be sized for a minimum 24 hour demand plus a 1.5 safety factor excluding fire water demand. On site storage will be provided if the peak fire demands cannot be met by the existing water supply system by the local water company.

Site water piping will be so arranged so as to provide a fire loop to allow water fo flow from either or both of two directions to supply a demand point.

The facility shall be provided with suitable fire extinguishers as required to meet the standards of a recognized industrial fire insurance agency. 


\subsection{TESTING CRITERIA}

\subsection{TEST PROGRAM}

The MHD-ETF rest program shall be based on the top level test abjective of a long duration run of continuous rated power. The specific duration for the top level test objective is to be determined.

A systems approach to component and major subsystem development will be utilized to delegate this rest objective downward to the component level. Programs shall be developed to support analysis, subscale, and full scale testing at the component or subsystem level and lead to component and subsystem testing in the MHD-ETF itself which will accomplish the rop level objective. In some cases where the component or subsystem is not able to meet its objective or demonstrates different characteristics than anticipated, the feedback will be utilized to re-examine the top level MHD-ETF test objective.

In establishing supportive programs to the MHD-ETF, existing and planned MHD facilities, analytical tools, and component research and development programs being conducted and directly applicable to open cycle coal-fired MHD should be evaluated and, in most cases, directed toward objectives and priorities to support the MHD-ETF program as a major National goal.

\subsection{TEST OBJECTIVES}

The top level objective of the MHD-ETF as stated in Paragroph 5.1 is to demonstrate performance and endurance capability of an open cycle, coal fired MHD system operating under baseload power plant conditions. Testing conducted in the ETF program will be designed to evaluate the durability of MHD components and support systems, determine operating characteristics and efficiency, and to provide information for component upgrading and scaling to commercial plant sizes. 
The following specific overall test objectives have been identified for the ETF program and as such are considered to be approximately equivalent in priority:

- Demonstrate safe and reliable operation and control of the MHD power cycle under utility baseload conditions, startup and scheduled and unscheduled shutdown conditions.

- Demonstrate high efficiency operation of the MHD power cycle for long term continuous operation including the MHD channel, a large superconducting magnet, a reliable air preheat system, and a coal fired combustor that has the capability of producing combustion gas of at least $4500^{\circ} \mathrm{F}$.

- Demonstrate reliable operation of the coal handling and processing system and the ability of the MHD combustor to operate with the specified types of coal.

- Demonstrate acceptable environmental operation of the integrated MHD power cycle such that the exhaust gases and waste products meet appropriate environmental protection standards.

- Demonstrate viable recovery, processing and recycling of seed material from the MHD exhaust stream and coal slag.

- Demonstrate stable output, control, switching and protection of the MHD inverter while operating on an appropriate utility grid.

\subsection{TEST TYPES}

The following subparagraphs define the various types of tests which shall be considered in defining the development rest program.

\subsubsection{Materials or Supportive Information Tests}

This category of test will support the development of materials engineering data and the screening or evaluation of materials in environments simulating that expected in the MHD-ETF. The configuration of test specimens may or may not be similar to the application depending on the specific purpose of the test and the method of testing. Also included in this category are basic tests deemed necessary to verify analytical tools, either from a mechonical, electrical or themodynamic viewpoint. 


\subsubsection{Subscale Component and Subsystems Tesis}

Because of the developmental nature of many of the major components and the need to prove out design features and analytical tools, it will be necessary to test certain components and subsystems in a smaller scale than MHD-ETF. The scale size will be dictated by the capability of MHD testing facilities available in time to support MHD-ETF. Such subscale component and subsystem tests will generally be to the configuration of the MHD-ETF, and have the planned MHD-ETF environment imposed on it to the extent possible.

The capability for subscale testing is of sufficient importance that the MHD-ETF should be sized to not exceed the ability to reasonably extrapolate from anticipated subscale facilities.

\subsubsection{Full Scale Component and Subsystem Tests}

Where possible and deemed necessary, full scale component and subsystem tests will be conducted. Such tests can be on the actual hardware eventually scheduled for the MHD-ETF, or on duplicate hardware segregated for use in the component test program. Where spares are appropriate and damage is not expected in the component test, it may be possible to utilize the spare unit for component or subsystem testing.

\subsubsection{MHD-ETF Preliminary Testing}

In preparation and leading to the major objective of the MHD-ETF will be a series of preliminary tests on components and subsystems. This series of tests should be planned to the extent possible to sequentially test out major components and subsystems leading to an eventually complete system. It may consist of subsystem or total plant tests with less severe duty than full rated, or even to the resting of a complete system with alternate configuration of major components needed for evaluation prior to the initiation of the full endurance demonstration test.

\subsection{CATEGORIZATION OF TESTS}

All of the tests identified for the MHD-ETF shall be categorized on the basis of their ultimate purpose and relationship to the top level test objective. 


\subsubsection{Development Tests}

Development tests are those conducted to obtain basic input data where rigid configuration or materials accountability are not necessary.

\subsubsection{Qualification Tests}

Tests which are necessary to prove a characteristic prior to proceeding in an activity, be it design, procurement, delivery or test, shall be deemed qualification tests with identification of what it is they qualify such that appropriate schedule sequencing can be performed. In general, qualification tests occur in a series path where subsequent activim ties cannot proceed unless the qualification test has been successful.

\subsubsection{Pre-Requisite Tests}

Where it is deemed that the probability of test failure is reasonably low, the qualification test may be done in parallel with the event it controls, thus becoming a pre-requisite test to another event further along in the program. This latter event is usually chosen as one which limits the risk of redoing hardware or design work and incurring a schedule slippage in the case of pre-requisite test failure.

\subsection{TEST PLANNING AND DOCUMENTATION}

A systematic approach will be implemented in planning the ETF test program. An overall test plan will be prepared as the basic governing document along with specific test plans for development, qualification and pre-requisite tests of the component, subsystem and plant level. These test plans will be organized so as to include the following information as a minimum.

- General Requirements - This section shall discuss pertinent background information, a brief overall description, overall responsibilities for conduct of the test program and overall test schedules. 
- Purpose - This section shall describe the overall objectives of the rest program or portions thereof as appropriate. It shall indicate the caregorim zation of the test as to development, qualification or pre-requisite and shall define generally its relation to the fotal MHD-ETF program.

- Description - This section shall indicate the major features of the rest and its test assemblies via use of system design descriptions, functional diagrams and schematics as appropriate.

- Participating Organizations - This section shall list the participating organizations, their assigned responsibility and tasks. A breakdown of the resting functional organizations and a time phased listing of test personnel requirements shall be included.

- Milestones and Schedules - This section shall indicate the time phasing of all significant actions related to the conduct of the planned rests.

- Priority and Precedence - This section shall indicate importance and priority ratings within the test program as assigned by ERDA and the test organization.

- Test Support Requirements - This section shall identify the technical and Togistic support required to perform the tests along with special facilities, equipment and personnel to support the tests. A schedule shall be provided for critical support requirements showing time, duration and organization responsible for furnishing the support items.

- Specific Test Objectives - This section shall describe in detail the specific test objectives needed to fulfill the requirements of the test program.

- Test Methods - This section shall outline in general terms how the tests are to be conducted and shall identify the requirements for detailed test and/or operating procedures. In addition, this section shall identify requirements for data processing, analyses of test results, special equipment (e.g. computers) for dato reduction and software packages. The organizations responsible for preparation of software and analysis of data shall be identified.

- Instrumentation - This section shall indicate the instrumentation (transducers signal conditioning) and other accessory electronics (. .9 . high voltage isolation) required to collect the data identified above and the responsible organizations. A block diogram identifying instrumentation points shall be included.

- Test Reports - This section shall identify the type, frequency and distribution of required reports. 


\subsection{PLANT OPERATIONS CRITERIA}

\subsection{MAINTAINABILITY}

\subsubsection{Maintenance Repair Cycles}

The plant shall be designed to reduce the maintenance outages to a level consistent with similar pilot scale plants using developmental technology.

Planning of component maintenance shall consider the following steps in a manner which minimize plant unavailability:

- Adjust or repair the component in place.

- Replace component with a spare.

- Remove, repair, and reinstall the component.

\subsubsection{Service and Access Design Criteria}

The following criteria shall be applied to the design of the overall plant:

a. All components shall be made readily accessible and maintainable with a logical removal path defined and documented. Provisions shall be included, where practicable, for isolating components to permit continued operation of the plant.

b. The plant design shall be such that hands-on maintenance can be performed with adequate maintenance access for personnel and for required tools, and with minimization of scaffolding and rigging, required to facilitate the work for both scheduled and unscheduled events.

c. Maintenance access for servicing and/or removal or replacement shall be provided for each component that is to be maintained. All system components shall be designed for removal and replacement. 
d. Clearance shall be provided between adjacent components and structures for personnel access and installation and operation of tooling. Overhead room shall be provided for equipment removal and replacement.

\subsubsection{Maintenance Facilities}

Facilities shall be provided for convenient inspection, removal, and repair or replacement of major components. Provision for interim storage of components to be replaced shall be considered.

Adequate local loy-down space shall be provided for all equipment, required for maintenanc: operations. On-site storage space shall be provided for maintenance equipment and tooling, spare parts, temporary shielding, etc.

Adequate lighting shall be available for all maintenance operations in accordance with Visual Examination Standard T.9.23, ASME Boiler and Pressure Vessel Code, Section V.

\subsubsection{Routine Maintenance}

Rourine maintenance, removal and replacement of components or parts in general will be performed during scheduled facility shutdown periods or a limited shutdown of a portion of an auxiliary system. Detailed written maintenance procedures shall be provided in the individual system operating and maintenance manuals.

\subsection{SAFETY}

\subsubsection{Safefy Design}

During the design phase of MHD-ETF, Fault Tree Analysis shall be used as a technique to identify potentially hazardous events and appropriate action taken to assure safety of adjoining equipment and of personnel. 
Local manual controls shall be provided with lock-out devices to assure that maintenance can be performed without fear of remote equipment starts.

Emergency lighting shall be provided to assure safety to operating personnel during power failure.

The facility shall be provided with a suitable buried fire water supply, plus hose stations and extinguishers to meet the requirements of a recognized fire insurance agency.

Areas and equipment exposed to hot gases should be designed with full cognizance of personnel heat protection standards suggested by NIOSH. Noise protection must be provided for personnel working in areas where noise levels in excess of OSHA standards cannot be otherwise controlled.

\subsubsection{Fence Barriers}

An inner fence or fences shall be provided in the facility to enclose all facilities and equipment capable of initiating a destructive force, or otherwise deemed to be dangerous to personnel when in operation. Intrusion during operation will be protected against by warning lights, alarms and TV coverage. Any admittance during operation will be by controlled procedure and authorized by the central control operator only.

As a precautionary measure for the general public and to protect against possible vandalism or other intrusion events, an exterior security fence will enclose the entire plant, and entrance will be through controlled access areas.

\subsubsection{Safety Program}

A safety program shall be an integral part of plant operations. Operating and emergency procedures shall be defined, documented and implemented consistent with an overall plan. 


\subsection{OPERATING STAFF}

The staffing of the ETF shall be predicated on the normal requirements for pilot scale power planis supplemented by an appropriate engineering staff for analysis and assessment of the plant's performance. This engineering staff will be made up of resident engineers along with ad hoc members (non-residents) who represent the various organizations involved in the national MHD program. Requirements for staffing discussed herein will be confined to the plant's resident staff. Three primary groups will be required on site: operational personnel, maintenance personnel and technical support.

The operations group will consist of personnel responsible for the day-to-day operation of the station. The plant will have a Shift Supervisor assisted by a Shift Foreman directing the operations of each shift through the control rcom operators and auxiliary operators. As a minimum, one of the two will always be available on-site directing station operations. The Shift Supervisor will report to the Operations Manager.

The maintenance staff will consist of men experienced in mechanical, electrical or instrumenicontrol maintenance of large steam-electric generating stations. The force will be supervised by a Maintenance Foreman, who will report to the Maintenance Manager. If required, the maintenance siaff will be supplemented by additional competent maintenance personnel from other utility power stations or outside contractors for large maintenance jobs, such as may be necessary on major heat transfer apparatus, the MHD generator, the magnet or the turbine generator (if included).

The Technical Support Group will consist of a Plant Engineer, with a staff of engineers and technicians who will function in the areas of physics, thermodynamics and station performance, mechanical, and electrical engineering. 


\subsection{PLANT COSTING CRITERIA}

The approach for preparing cost estimates for the MHD-ETF shall be predicated on the general principles established by the U.S. Government. For capital costs, the usual governing document is the Federal Power Commission's Uniform System of Accounts. However, since FPC Code of Accounts is not addressed specifically to MHD power plants, it is appropriate, as part of this document, to specify a code of accounts tailored to MHD plants.

\subsection{CAPITAL COSTS APPROACH}

The following overall code of accounts and format shall be used in preparing capital cost estimates for the ETF:

DIRECT COSTS:

$\begin{array}{cl}\text { Account No. } & \frac{\text { Non Depreciating Assets }}{20} \\ & \text { Land and Land Rights } \\ 21 & \text { Depreciating Assets } \\ 22 & \text { Structures and Improvements } \\ 23 & \text { MHD Cycle Equipment } \\ 24 & \text { Heat Recovery Equipment } \\ 25 & \text { Support System Equipment } \\ 26 & \text { Steam Bottoming Plant Equipment } \\ 27 & \text { Accessory Electric Equipment } \\ 30 & \text { Miscellaneous Power Plant Equipment (Balance of Plant) } \\ & \text { Transmission Plant } \\ & \text { Subtotal (Direct) }\end{array}$




\section{INDIRECT COSTS:}

Account No.

91

92

93

94
Construction Facilities, Equipment and Services

Engineering Services

Other Costs

Interest During Construction

Subtotal (Indirect)

Subtotal (Total Depreciating Assets)

Total Plant Capital Investment

(Direct and Indirect)

\subsubsection{Breakdown of Depreciating Assets Accounts}

Each of the major two-digit accounts listed above in Section 7.1 will be made up of more detailed three and four digit accounts. To the extent possible, accounts $20,21,25,26$ and 30 shall consist of items as defined in the FPC code of accounts for Steam Producrion Plants. A tentarive listing of major items to be included in each major account is as follows:

\begin{tabular}{ll} 
Account No. & Description \\
\hline 21 & STRUCTURES AND IMPROVEMENTS \\
Improvements to Site \\
Main Building \\
Steam Turbine Building \\
Coal Bunker/Processing Area \\
Air Compressor or Building \\
Accessory Buildings \\
Service Buildings \\
Other Buildings and Structures
\end{tabular}


Account No. Description

MHD CYCLE EQUIPMENT

Air Compressor System (Primary and Standby with Drive and Condensers)

Combustor and Slag Separator with Immediate Seed and Coal Injection System

Nozzle

Generator Channel

Magnet System (Power, Cryogenic and Vacuum Supply)

Diffuser

High Temperature Air Heater

Low Temperature Air Heater

Oxygen Feed System

Preheater Combustor (Separately Fired)

Associated Instrumentation and Controls

Main Gas Stream Piping

HEAT RECOVERY EQUIPMENT

Economizer

Rodiant Boiler and Slag Separator

Superheater

Reheater

Steam-Air Prehearer and Blower

Any Seed and Slag Heat Recovery Equipment

Associated Instrumentation and Control 


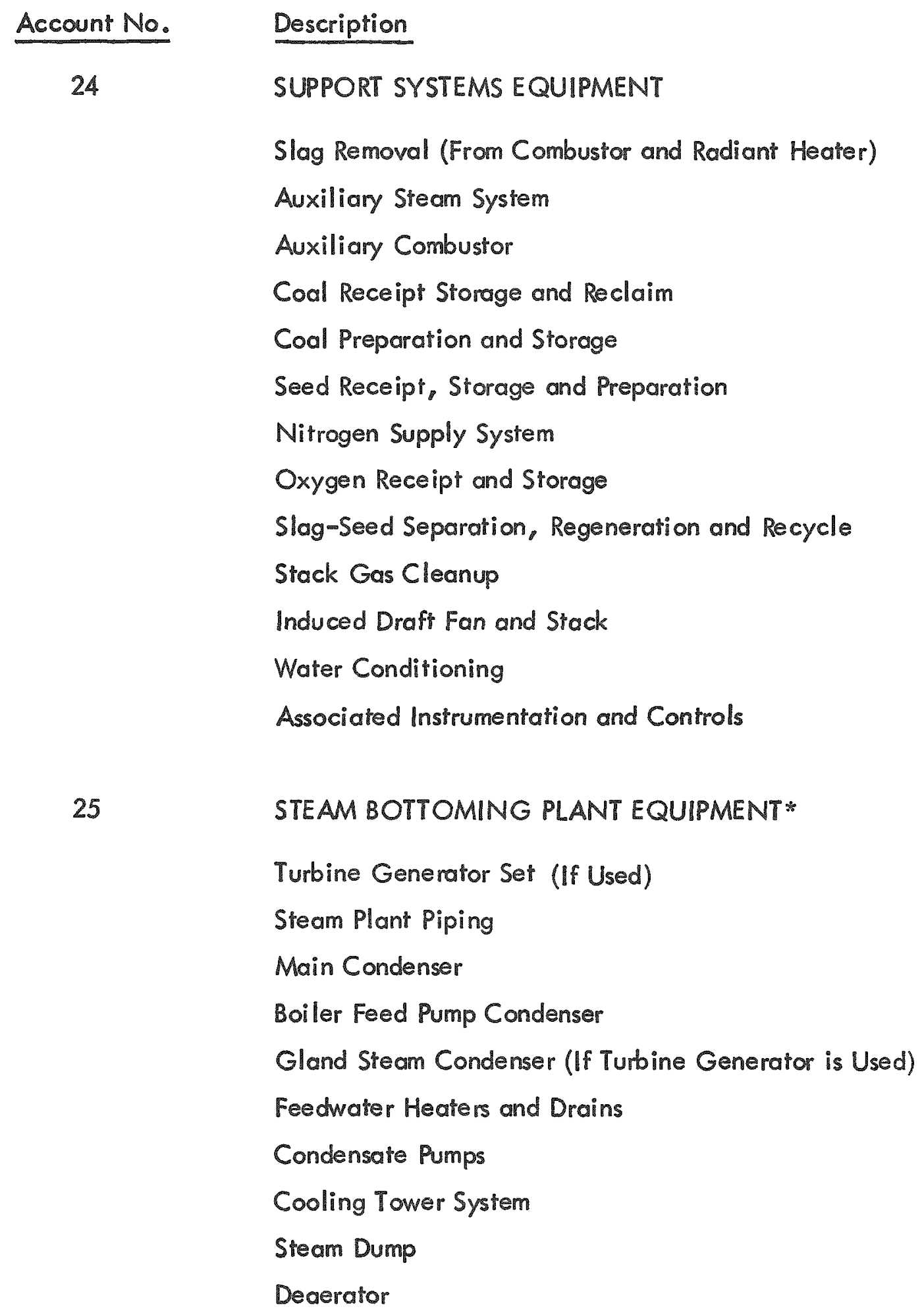

\% In the event a turbine-generator is not used in the MHD-ETF, this account will include the heat rejection equipment and all other equipment that would normally be included here. 
Account No. Description

Deaerator or Storage Tanks

Reject Heat Exchanger (If Turbine Generator is not Used)

Primary Valves

Associated Instrumentation and Control

ACCESSORY ELECTRIC EQUIPMENT

Switchgear

Station Service Equipment

Switchboards

Protective

Electrical Structures and Wiring Container

Power and Control Wiring

Water Storage

Ash and Waste Disposal

Fuel Oil Storage and Supply System

Instrument Stations

Circulating Water System

Emergency Diesel Generator

Auxiliary Power Transformer

Valves not Identified in Other Categories

Piping not Identified in Other Categories

All Equipment not Otherwise Identified

Transformer Substation

Inverter System 


\subsubsection{Basis for Indirect Cost Accounts}

The indirect capital costs, listed in Section 7.1 as accounts 91 through 94 , shall be determined on a basis of percentage of the total direct costs. In actual practice, these accounts are determined on the basis of bid information and the existing cost of money. In addition, actual experience with prior planis allows reasonable estimating.

In contrast, the MHD-ETF is a developmental facility without precedent in several areas. Beccuse of this situation, the indirect accounts will be factored into the MHD-ETF capital costs in the form of typical percentages of the direct costs based on best available background information. This approach will permit a consistent basis of comparison of the capitalization of more mature technologies while ensuring that ETF indirects are adequately taken into account.

\subsection{OPERATING AND MAINTENANCE COSTS}

The basis for estimating operation and maintenance costs for the ETF shall be a set of direct annual costs plus indirect or working capital costs. The format for the direct costs is summarized in Table 7-1. The working capital, which is a nondepreciating investment, has annual fixed charges which must be accounted for. Table 7-2 summarizes the format for the working capital cost estimates.

The total annual O\&M costs are determined by adding the annual direct costs' (litem 9 from Table 7-1) and the annual charge on working capital (Line 5 from Table 7-2). This approach is adapted from that normally used for nuclear plants. Additional details concerning the various items in Tables 7-1 and 7-2 can be found in the document NUS-531, Guide for Economic Evaluation of Nuclear Reactor Power Plants, January 1969, along with explanation of the mechanics of preparing the O\&M estimates. 
TABLE 7-1

\section{SUMMARY OF DIRECT COSTS \\ FOR \\ ETF OPERATION AND MAINTENANCE}

ITEM

1. Staff Payroll \& Benefits

2. Consumable Supplies \& Equipment

3. Outside Support Services

4. Miscellaneous

5. SUBTOTAL (ltems 1 through 4)

6. General and Administrative

7. Material Make-Up Purchases

8. Plant Liability Insurance

9. TOTAL ANNUAL DIRECT COSTS (ltems 5 through 8)
ANNUAL COST

$\$$

$\$$ 
TABLE 7-2

\section{WORKING CAPITAL REQUIREMENTS \\ FOR \\ ETF OPERATION AND MAINTENANCE}

ITEM

1. Average Net Cash Required

1.1 thd\% of annual direct costs excluding

$\$$ pTant liability insurance

$1.2 \frac{t b d \%}{\cos t}$ of plant liability insurance annual

2. Materials and Supplies in Inventory

3. tbd \% of Annual Cost of Materials and Supplies

4. Total O\&M Working Capital (Item I plus ltem 3)

$\$$

Fixed Charge Rate on Working Capital

rbd $\%$

5. Annual Charge on Working Capital

$\$$ 


\subsection{SCHEDULING CRITERIA}

Scheduling shall be developed with an objective of meeting the major milestone dates of the Magnetohydrodynamics Program as outlined in the Program Approval Document (PAD) Fiscal Year 1977. Where excessive costs or technical difficulties are foreseen, they shall be identified and adjustments recommended based on study results.

\subsection{EQUIPMENT}

\subsubsection{Demand Dates}

Equipment demand dates for the MHD-ETF will be integrated to be consistent with an overall schedule of construction, activation and testing. Emphasis will be placed on meeting demand dates consistent with the major milestone dates of the National Magnetohydrodynamics Program.

\subsubsection{Schedule Elements}

Scheduling of equipment shall consider the following elements:

a. Component Design and Development - The time frame from initiation of design to release of specifications and drawings for procurement.

b. Procurement Time - The time from release of specifications and drawings through the quotation, evaluation, negotiation and ERDA approval cycles to date of subcontract placement. For purposes of planning, this element of time shall be assumed to be 12 weeks.

c. Supplier fabrication and delivery time.

d. Equipment installation and checkout.

\subsubsection{Schedular Detail}

In establishing the estimated component design/development leadrimes for the major items of MHD-ETF equipment, the Equipment Application Rating Criteria of Table 8-1 shall be 
TABLE 8-1

EQUIPMENT APPLICATION RATING CRITERIA

\begin{tabular}{|c|c|c|c|c|c|c|}
\hline \multirow[b]{2}{*}{$\begin{array}{l}\text { APPLICATION } \\
\text { RATING }\end{array}$} & \multirow[b]{2}{*}{ EQUIPMENT STATUS } & \multirow[b]{2}{*}{$\begin{array}{l}\text { PERFORMANCE } \\
\text { DATA BASE }\end{array}$} & \multirow{2}{*}{$\begin{array}{l}\text { EXTRAPOLATION } \\
\text { FROM PERFORMANCE } \\
\text { DATA BASE }\end{array}$} & \multirow[b]{2}{*}{ WORK REQUIRED } & \multicolumn{2}{|c|}{ R\&D PROGRAM CHARACTERISTICS } \\
\hline & & & & & RATIONALE & $\begin{array}{c}\text { SUCCESS } \\
\text { PROBABILITY }\end{array}$ \\
\hline $\begin{array}{l}\text { Established } \\
\text { (A) }\end{array}$ & $\begin{array}{l}\text { Firm selections can be } \\
\text { made. Equipment is } \\
\text { commercially availatole } \\
\text { in form required. }\end{array}$ & Sufficient & None & $\begin{array}{l}\text { Mininal, routine } \\
\text { applications engineering. }\end{array}$ & Nor Applicable & Not Applicable \\
\hline $\begin{array}{l}\text { Near Term } \\
\text { (B) }\end{array}$ & $\begin{array}{l}\text { A number of equipment } \\
\text { condidates are identi- } \\
\text { fied. Candidates are } \\
\text { commercial or near } \\
\text { commercial. }\end{array}$ & Incompleie & $\begin{array}{l}\text { Short extrcpolations from } \\
\text { existing data bose are } \\
\text { involved. }\end{array}$ & $\begin{array}{l}\text { Confirmatory resting } \\
\text { and minimal R\&D. }\end{array}$ & Straight-forward & Virtually Certain \\
\hline $\begin{array}{l}\text { Developmental } \\
\text { (C) }\end{array}$ & $\begin{array}{l}\text { Equipment not previously } \\
\text { designed, but engineer- } \\
\text { ing dara base exists for } \\
\text { design. }\end{array}$ & $\begin{array}{l}\text { Incomplese; important } \\
\text { gops exist. }\end{array}$ & $\begin{array}{l}\text { Large extropolations } \\
\text { from existing dafa } \\
\text { required. }\end{array}$ & $\begin{array}{l}\text { Considerable R\&D is } \\
\text { required. }\end{array}$ & $\begin{array}{l}\text { A credible rarionale } \\
\text { exists. Alternative } \\
\text { ovenues are evident. }\end{array}$ & Good to excellent. \\
\hline $\begin{array}{l}\text { Speculative } \\
\text { (D) }\end{array}$ & $\begin{array}{l}\text { Equipment not previously } \\
\text { designed with major } \\
\text { materials, design or } \\
\text { manufacturing uncer- } \\
\text { tainfies. }\end{array}$ & Sporse or Absent & $\begin{array}{l}\text { Highly speculative or } \\
\text { not possible. }\end{array}$ & $\begin{array}{l}\text { Extensive R\&D is } \\
\text { required. }\end{array}$ & $\begin{array}{l}\text { Rationale is not clear, } \\
\text { or requires a break- } \\
\text { through or serendipity. }\end{array}$ & Foir to poor. \\
\hline
\end{tabular}


utilized to determine the degree of schedular detail required. Where the criteria indicates "Established", available supplier information can be used to stablish the schedule. At the other end of the scale, where the rating is "Developmental" or "Speculative", schedular detail will require best estimates of design, development and manufacturing actions ne cessary before release to procurement. Action will also be required to identify potential sources of supply and their estimated fabrication/delivery times.

\subsubsection{Schedule Minimization}

A number of techniques for minimizing schedule have been utilized on past demonstration programs. Consistent with acceptable costs and risks, these same methods should be utilized where applicable. Where both major schedule advantage and increased costs are involved in alternate approaches without a clear means of decision evident, the alternates should be identified. Some of the techniques for minimized schedule are identified below.

\subsubsection{Long Lead Material Release - Where material specification is firm or fairly} certain, the release for procurement moy precede the equipment design and be furnished to the final selected equipment fabricator.

\subsubsection{Risk Release - Based on a preliminary design, the decision can be made to release for fabrication with specified hold points. Holds are then released based on design, development or manufacturing results. If the risk is deemed to be sufficiently low, no hold points need be specified.}

\subsubsection{Alternate Supply - Where schedule is sufficiently critical, it may be desirable} to initiate two sources of equipment supply with termination provisions. This is most applicable to items where there may be considerable uncertainty in the manufacturing process and two vendors are utilizing different approaches. 


\subsection{CONSTRUCTION}

The plant construction schedule is to consider activities necessary to implement the preliminary engineering, final design, detail design, procurement and construction of the MHD Engineering Test Facility.

Final design of principal and ancillary structures and the balance of plant equipment is to be interfaced with the scheduled availability of certified vendor drawings of MHD cycle components, support systems and instrumentation and control systems.

The schedule is to consider activities in the procurement, fabrication and erection of each structure comprising the Engineering Test Facility. Construction activities will be interfaced with the installation of MHD cycle components, support systems and balance of plant equipment. Time will be allocated for on site inspections and quality assurance testing as well as operational testing of support systems and balance of plant equipment.

Engineering, procurement and construction activities will be positioned in their logical order of occurrence to establish the combined duration of all activities.

\subsubsection{Program Required Daies}

Construction shall be planned to begin in mid 1982 and is desired to be complete in 1985. All requirements for site and construction approval shall have been accomplished prior to the mid 1982 start of construction.

\subsubsection{Construction Methods}

The plant design will be in concert with construction methods and concepts that optimize constructibility, enhance the construction schedule, and minimize construction cosis. The following constructibility requirements derived from proven experience and based upon ease and simplicity of construction shall be incorporated into the plant design to the extent practicable. 
8.2.2.1 Construction Sequence - Designs and schedules shall consider the planned sequencing of construction and equipment installation so as to reduce the need for temporary structures, multiple connections and firups, and preinstallation storage requirements.

\subsubsection{Site Preparation and Construction Temporary Facilities - The femporary facilities} for site preparation and construction will follow standard construction industry practices. However, emphasis shall be applied to areas defined below where increased constructibility opportunities exist.

a. Site Access and Temporary On-Site Roads - Upon completion of construction, these roads will be refurbished to accommodate the plant's operational needs.

b. Railroads and Railroad Spurs - Upon completion of construction, the railroads will be refurbished to accommodate the plant's operational needs.

c. Construction Parking - Upon completion of construction, the construction parking shall be considered for refurbishment as an auxiliary parking area.

d. On-Sire Fobrication Facilities - On-site fabrication facilities will be utilized where economically feasible to reduce in-place work. Construction of on-site fabrication facilities will constiture a substantial investment. Each requirement will be evaluated for retention as a permanent maintenance or service facility and will be constructed accordingly. On-site fabrication facilities shall be provided for the following:

1. Rebar - Bend reinforcing bars and prefabricate assemblies for pedestals, footings, walls and slabs.

2. Electrical - Make up cables, wire bundles and assemble test consoles and equipment. Prefabricate conduit runs and bends. Repair construction equipment.

3. Sheet Metal - Prefabricate ducis, walls and cells.

4. Welding - Perconnel kegining and testing, ircluding radiography. 
5. Pipe - Prefabricate pipe runs and loops. Perform welding cerhificatrions and test assemblies.

6. Insuletion - Precut and form.

7. Carpentry - Prefab concrete forms, building modules, and mockups.

8. Structural Steel - Prefabricate struchural members, hangers and supporits.

9. Paint - Notices, signs and small prefabricated components.

10. Precast Concrese - Prefabricate forms and precast concrete.

e. Construction Buildings - All temporary buildings are to be pre-engineered and of modular construction.

f. Storage Facilities - Temporary facilities for pre-install lation warehousing and storage of plant components and materials should minimize storage area expense by providing protection to the level necessary resulting in three areas:

1. For critical plant components, one or more sections of the warehouse will require a predetermined level of humidity and temperature control ro protect components.

2. The remainder of the warehouse will be ventilated and used for noncritical componen ts that require weather protection and can withstand the site"s ambient emvironmenial conditions.

3. Other non-Gritical items will be stored in a fenced storage area.

\footnotetext{
8.2.2.3 Construction Techniques - New and current consiruction techniques shall be reflected in the design. These techniques shall consider previous industry experience; any completely new techniques of consiruction shall be verified by analysis and test before being applied to the plont.
} 


\subsection{Civil/Structural}

a. Selection and Placement of Reinforcing Steel

1. All reinforcing bars shall have a minimum yield strength of 60,000 psi.

2. Rebar placement designs shall minimize the number of different size rebars. Use the following rebar sizes only: $4,6,8$ and 11 . Thermite type welds shall be eliminated.

3. Rebar placement design shall be such that splices and construction joints are coordinated to the greatest exient possible with maximum bar lengths.

4. Embedded anchors shall be used in lieu of dowels wherever possible.

5. Green cutting and other expensive joint treatments will be eliminated except for specific foundations for vibrating equipment.

6. A program will be established for minimizing concrete splash to reduce the need for cleaning rebar.

b. Selection and Placement of Concrete

1. Specify the elimination of water curing of concrete in areas where shortened times for stripping forms will produce large savings.

2. A composite floor design shall be used to the greatest extent possible. This is the use of structural steel framing with metal decking as forms which are left in place after concrete placement.

3. Care shall be taken to design continuous walls and floors of constant thickness with a minimum of jogs and curved surfaces. Staggered platforms, haunches, and inclined surfaces shall be minimized.

4. The number of concrete walls and floors shall be minimized. Walls with no structural or shielding function should normally be constructed of a material other than cast-in-place concrete with du regard for safety related equipment. 
5. Design and specification shall be oriented toward placing concrete by pumping or conveyor.

6. Generous blockouts will be provided for all mechanical and electrical penetrations to eliminate the need for retrofir.

7. The design of slabs and walls shall be standardized to allow maximum use of precast concrete.

8. Foundations and footing will be detailed to reduce secondary pour and to allow pouring against earth in lieu of forming.

c. Structural Steel

1. Labor soving connectors simillar to "Bethlehem N Drive Bolits" shall be used for bolted connections, where possible. Washers that indicate tighiness of the applied bolt shall be used.

2. Designs will incorporate standard building components such as doors, windows, stairs, handrails and grating. Access and equipment hatches, and designs in steel members will be standardized to the fullest practical extent.

3. Structural steel detailing, fabrication and delivery will be scheduled to minimize yarding and additional handling.

4. Quality assurance will be provided at the structural level fabrication facility to eliminate on-site distuptions.

5. A uniform system of erection coding structural members will be specified to facilitate identification and reduce handling.

\subsection{Mechanical and Piping \\ a. Assemblies and Fitups \\ 1. Prefabricate or preassemble off-site as much mechanical equipment and}


pipe as practical. The use of on-site shops to reduce in-place work shall be used where off-site assembly is not practical.

2. The number of in-place welds shall be minimized by prefabrication into large assemblies in an on-site shop.

3. Construction openings shall be sized to allow the largest possible assemblies to be used.

4. Accomplish critical field welds by automatic welding machines to reduce labor and improve quality.

5. Standardized valves, fittings and hangers will be utilized.

6. Spool drawings will be checked by on-site measurement prior to fabrication.

b. Identification

1. A piping system and line number designation scheme will be established to aid constructibility.

2. Pipe spools and weld numbers will be identified for each pipe system and line number. Identification of weld joint locations will be retained for permanent weld records.

c. Penetrations and Embedments

1. Penetrations and sealing methods will be standardized where possible.

2. In areas where hangers cannot be connected to structural or plate steel, a structural grid will be provided for connecting pipe hangers.

\subsection{Electrical}

a. Lighting - Lighting designs are to be released early enough to allow the installation (where possible) of permanent lighting or the remporary positioning of the permanent lighting, thereby reducing the need for temporary lighting. 
b. Service Elevators and Cranes - Designs for electric service to elevators and building cranes shall be released early enough to allow the elevators and cranes to be used during construction without having to rewire them for plant operations.

c. Embedments and Seals - Tray and conduit penetration methods will be standardized where possible.

d. Pre-Packaging

1. Designs and specificarions shall be oriented toward factory testing of assemblies when purchased as a unit.

2. Equipment shall be delivered pre-wired to the greatest extent possible, with preassembled cable harnesses, limit switches, terminal box, and "plug-in" terminals where appropriate.

3. Factory installed connectors should be used where possible to reduce the number of field connections and to allow normal handling and installation of cable.

4. Ample spare wire and conduit will be provided in long runs and ductwork.

\subsection{Instrumentation}

a. Project lists of instruments and valves shall provide space for the field forces to keep status records (or complementary lists will be issued). If possible, at least one mechanical and electrical and one vendor drawing should be identified to each item listed.

b. Local instruments shall be grouped in panels and racks as much as pessible to permit shop installation, wiring and tubing into pre-assembled units. 
c. The number of different tubing sizes shall be kept to a minimum. Only one wall thickness shall be specified for each size and kind of tubing used.

d. All tubing and tubing trays that are not safety related shall be "field run".

e. Tubing should be purchased pre-assembled into bundles where possible. 


\subsection{APPENDICES}




\section{APPENDIXA}

\section{DESCRIPTION OF A HYPOTHETICAL SITE FOR AN MHD ENGINEERING TEST FACILITY}

The hypothetical plant site described in this report has been established for use in the preparation of conceptual MHD power plant studies related to the design, construction, and operation of an MHD Engineering Test Facility (ETF). The hypothetical site described herein shall be used as the location for conceptual design of the conceptual facility.

\section{Topography}

The site is located in western Montana. The region is characterized by mountain ranges (elevation $8,000-10,000$ feet asl.) separated by relatively wide (5-40 miles) flat valleys. The relief from valley to peak varies from 2000-4000 feet. The foothills located berween the valleys and mountains are widely dissected by streams and consequently have strong local relief. The streams, most intermittent, leave the foothills and cut into the valley floors causing streamside relief of 5-50 feet. In controst, streamless areas of the valley floors are quite flat and relatively large.

The valley in which the hypothetical site is located is generally oriented north-south is relatively large and flat, is located approximately 10 miles east of Centertown, the nearest large city. The valley stretches 50 miles southward and is 8-10 miles wide in most place. A small stream, Rocky Creek, flows southward from near the center of the valley and enters Gold Creek which crosses the south end of the valley. Relatively flat areas of up to 500 acres are found in the southern one-half of the valley, and it is in this vicinity that the hypothetical site is located. Gold Creek flows eastward across the southern end of the valley, then cuts through a small rise and enters the mountain valley to the east. Gold Creek is joined by several other streams to become the Pioneer River which generally flows east, eventually entering the Americana River and the Columbus Ocean. 


\section{Climatology}

The site location has a continental climate. Cold winter temperatures are seasonally followed by substantially warmer summer temperatures. For example, in Centertown, the mean normal temperature for January is near $15^{\circ} \mathrm{F}$, while in July this temperature increases to about $62^{\circ} \mathrm{F}$. Wintertime low temperatures often fall to $-20^{\circ} \mathrm{F}$ to $-40^{\circ} \mathrm{F}$, while summertime highs often reach 80 to $90^{\circ} \mathrm{F}$. Total precipitation is low, averaging about 20 inches per year. June is nomally the wettest month, receiving 2.5 inches of precipitation. Water evaporation from Class $A$ pans is estimated to be 35 inches per year with 80 percent of this evaporation occurring between May and October. Average relative humidity varies from summer daytime lows of 25-50 pere cent to year around nightime heights of 60-70 percent.

Severe weather in the region includes summer thunderstorms (sometimes with damaging hail), strong winds, rare tornadoes and sub-zero temperatures. Thunderstorms occur ir. the Centertown area approximately 35 times per year. Hailstorms are far less common, but do cecur in most years.

Demography

Centertown is the largest population center in the vicinity of the hypothetical site with approximately 50,000 people.

During the 1960-1970 decade, the population of the general area declined. However, in recent years there has been a slight to moderate increase in population. Approximately 75 percent of the area population resides in Centertown with the balance in small towns and rural areas within 25 to 35 miles of Centertown.

Land Use

Land use within 50 miles of Centertown is strongly influenced by topography. The major population centers are all located in the valleys where year around access is possible. Thu major land use in the valleys of the region is agriculture, while in the mountains, conservation, 
recreation, and forestry are the major uses. Lesser uses in the valleys, including that of the hypothetical site, include industrialization and recreation, as well as livestock grazing. Irrigation is limited to relatively small acreages.

Current land values in agricultural areas is approximately $\$ 500$ per acre for large tracts with $200+$ acres of land.

Transportation Facilities

The hypothetical site location contains a well developed system composed of two railroads, airport, and federal and state highways. Daily jet flights are scheduled from the Centertown airport to majo: cities. The site is located adjacent to a major federal highway, and a major railroad line crosses the western edge of the site valley within five miles of the hypotherical site location.

Construction Work Force

The current labor situation in the Centertown area closely parallels other industrial regions of the country. Similarities include: 1) a low employment rate in the local construction industry, 2) ample skilled and experienced craftsmen available and qualified for all phases of industrial construction, 3) competitive contractors available who are highly comperitive, and 4) an organizational structure of labor for training, testing, and certification apprentices to the trades.

Utilities, Fuel, and Communications

Utility services for electric power fuel and communications are available at the hypothetical site. Natural gas supplies are questionable, however. Cave River is fifteen miles north of the hypothetical site location. Water for construction activities would be obtained by drilling 100 foot deep wells into the groundwater at the site. 
Armospheric Diffusion Properties

The meteorological investigations of the Centertown area have been at the regional levels and predominantly theoretical. In the general area of the hypothetical site, the effects of local topography may contribute to air pollution problems. The mountainous terrain surrounding the site and its valley is known to cause air flow channelization and inversion effects. Early morning inversions commonly occur in the valleys of western Montana during all months. However, they are more pronounced in fall and winter and have a longer duration.

In the vicinity of the hypotherical site, it has been found that calm wind periods account for nearly one third of the observation during the morning and early afternoon and for one fourth of all observations. The remainder of the time the wind blows from all sectors with a similar frequency of occurrence. Average wind speeds are approximately twenty miles per hour during unstable conditions and four miles per hour during stable conditions.

Geology and Seismology

The valley of the hypothetical site contains alluvial fill to depths of 500 feet or more. This alluvia is poorly sorted mixture, ranging from fine silty clay to boulders and conglomerates. The fill rests on an irregular bedrock surface of moderate relief.

The alluvial fill at the site presents no serious problems either for site preparation by grading or for construction of facilities.

The high permeability of the fill material will require lining or sealing of the liquid retaining and evaportiting ponds.

The area is classified as a Class 3 in seismic risk. 


\section{Sewage Disposal}

Disposal of sewage and waste water from the site, with the exception of streams with a high concentration of soluble potassium salts, will present no problem if they are treated to meet the Montana quality discharge standards. 